Estabelecimento de uma arquitetura de referência para aplicações em televisão digital 

SERVIÇO DE PÓS-GRADUAÇÃO DO ICMC-USP

Data de Depósito: 31 de Agosto de 2012

Assinatura:

\section{Estabelecimento de uma arquitetura de referência para aplicações de televisão digital}

\section{Leonardo Simas Duarte}

Orientadora: Profa. Dra. Elisa Yumi Nakagawa

Dissertação apresentada ao Instituto de Ciências Matemáticas e de Computação - ICMC-USP, como parte dos requisitos para obtenção do título de Mestre em Ciências - Ciências de Computação e Matemática Computacional. EXEMPLAR DE DEFESA 
Ficha catalográfica elaborada pela Biblioteca Prof. Achille Bassi e Seção Técnica de Informática, ICMC/USP, com os dados fornecidos pelo(a) autor(a)

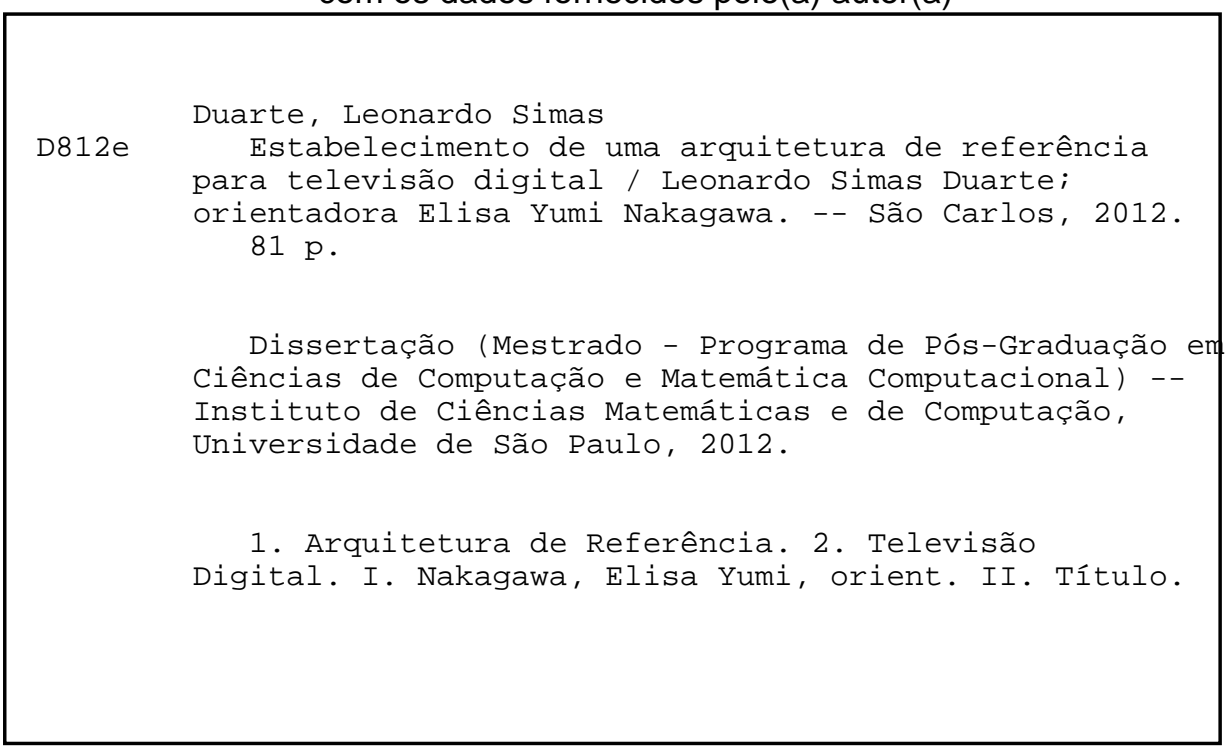


Dedido essa obra ao grande Yeshua, Jesus Cristo, o Senhor absoluto da minha vida. E à adjuntora da minha vida, minha esposa Tayna Duarte. 



\section{Agradecimentos}

Agradeço primeiramente a Deus pela possibilidade de concluir essa pesquisa, porque mesmo para as coisas pequenas como "cair a folha"de uma árvore Deus tem ciência e tem sua aprovação, então eu só tenho a agradecer a ele por ter a ciência de todo o esforço desse trabalho e ter principalmente a sua aprovação.

Quero agradecer a todas as pessoas que se fizeram presentes, que se preocuparam, que foram solidárias, que torceram por mim. Em especial à minha esposa Tayna Duarte, que foi meu grande esteio particular, que mostrou ser a verdadeira tradução da frase que os casados dizem no altar, "Na alegria e na tristeza, na saúde e na doença", e complementando a frase "no mestrado".

Em especial gostaria de agradecer aos meus pais Maria Rita Duarte e Raimundo Nonato Duarte, e ao meu irmão Frederico Duarte, por me ensinarem seus valores e apresentarem sempre grandes oportunidades de crescimento para a minha vida, por serem exemplos de perseverança, honestidade e idoneidade para a minha vida.

Agradeço a minha família da fé, meus irmãos em Cristo que foram meus intercessores, sendo participes de todo êxito que venha a conquistar. Em especial o Pr. André Tomazini, Pr. Lael Almeida, Pr. Régis Thadeu e Pra. Suellen Silva.

À professora Elisa Yumi Nakagawa, por ser esse exemplo de amizade, orientação, dedicação. Seus ensinamentos preciosos jamais serão esquecidos, e não possuo palavras para descrever a minha gratidão por todo seu companheirismo, que Deus lhe recompense abundantemente.

Agradeço aos professores da FUCAPI, que me concederam cartas de recomendação para o mestrado Prof. Dr. Niomar Lins Pimenta, Prof. Dr. 
Marco Antonio Pinheiro de Cristo e Prof. MSc. Antonio Luiz Maúes, obrigado pela confiança que foi depositada.

O meu muito obrigado tambem aos colegas do Labes, Lucas Bueno, Milena Guessi e Maria Adelina. 
Bem sei eu Senhor, que tudo podes, e que nenhum dos teus propósitos pode ser impedido.

Jó $42: 2$ 

Sistemas embarcados, inclusive para eletrônica de consumo, vêm se tornando cada vez mais complexos, requerendo a utilização de novas tecnologias, bem como novas abordagens para o seu desenvolvimento. Em particular, o desenvolvimento de aplicações para TV Digital interativa têm requerido crescente aplicação de novas técnicas de programação e engenharia de software, visando facilitar o desenvolvimento e manutenção desses sistemas. Em paralelo, arquiteturas de referência, um tipo especial de arquitetura de software, têm sido proposta para diversos domínios de aplicação e têm contribuído efetivamente para o desenvolvimento, padronização e evolução de sistemas de software de tais domínios. Contudo, o uso de arquiteturas de referência ainda não foi explorado em profundidade no desenvolvimento de aplicações para o domínio de TV Digital. Nesse contexto, o principal objetivo desse trabalho é propor uma arquitetura de referência para o domínio de TV Digital interativa, que facilite o desenvolvimento de aplicações para o ambiente procedural do middleware para o receptor digital. Como principais resultados alcançados neste trabalho, têm-se a contribuição para a área de TV Digital, buscando promover essa área que têm se destacado consideravelmente nos últimos anos. 

Embedded systems, especially in consumer electronics, are becoming increasingly complex, requiring the use of new technologies and approaches for their development. In particular, the development of interactive applications for digital TV requires new programming techniques and software engineering practices in order to facilitate the reliability and maintenance of these systems. In a parallel perspective, reference architectures, an special type of software architecture, have been proposed for several applications domain and have effectively contributed to the development, standardization, and evolution of software systems on such domains. However, the use of reference architectures has not been in depth explored in the digital TV domain. In this context, this work proposes a reference architecture for this domain. This architecture enables the development of applications for the procedural middleware environment for the digital TV receiver. The main result achieved in this work is the contribution to the development of interactive TV middleware-based applications, aiming at promoting this area that has been substantially explored in recent years. 

1 Introdução 1

1.1 Contextualização . . . . . . . . . . . . . . . . . . . . . . 1

1.2 Motivação . . . . . . . . . . . . . . . . . . . . . . 3

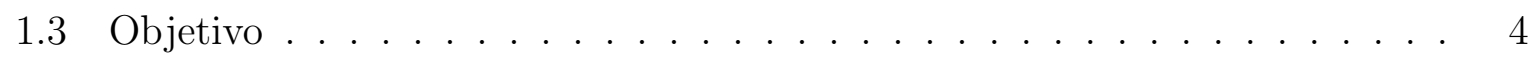

1.4 Organização . . . . . . . . . . . . . . . . . . . . . 4

2 Sistemas Embarcados e TV Digital: Uma Visão Geral 5

2.1 Considerações Iniciais . . . . . . . . . . . . . . . . . . . . . . . . . . . . . . .

2.2 Arquitetura de Sistemas Embarcados . . . . . . . . . . . . . . 5

2.3 Eletrônica de Consumo . . . . . . . . . . . . . . . . . . 7

2.4 TV Digital . . . . . . . . . . . . . . . . . . . . . . . . 9

2.4.1 TV Digital: Aplicações Interativas . . . . . . . . . . . . . . . . . . 11

2.4 .2 Infraestrutura da TV Digital Interativa . . . . . . . . . . . . . . 12

2.5 Orientação a Aspectos e Sistemas Embarcados . . . . . . . . . . . . . . . . 13

2.5.1 Terminologia em Orientação a Aspectos . . . . . . . . . . . . . . . 14

2.5.2 Modelagem de Sistemas Orientados a Aspectos . . . . . . . . . . 15

2.5.3 Tecnologias para a Implementação de Sistemas Orientados a Aspectos 15

2.5.4 Orientação a Aspectos no Desenvolvimento de Sistemas Embarcados 16

2.6 Considerações Finais . . . . . . . . . . . . . . . . . . . . . 24

3 Arquitetura de Software e Arquitetura de Referência 25

3.1 Considerações Iniciais . . . . . . . . . . . . . . . . . . . . . . . . . . . . . . . 25

3.2 Arquitetura de Software e Arquitetura de Referência . . . . . . . . . . . 26

3.2.1 Terminologias e Conceitos . . . . . . . . . . . . . . 26

3.2 .2 Arquitetura de Referência . . . . . . . . . . . . . . . . 27

3.2.3 Processo para Construção de Arquiteturas de Referência . . . . . . 28

3.3 Arquitetura de Software para TV Digital Interativa . . . . . . . . . . . . . . 29

3.3.1 Middleware MHP e Convergência para o GEM . . . . . . . . . . . . 33

3.3.2 Arquitetura e Componentes do GINGA . . . . . . . . . . . . . . 35

3.4 Considerações Finais . . . . . . . . . . . . . . . . . . 37 
4 ArciTV: Arquitetura de referência para iTV 39

4.1 Considerações Iniciais . . . . . . . . . . . . . . . . . . . . . . . . . . . . 39

4.2 Contexto de Atuação da ArciTV . . . . . . . . . . . . . . . . . . . 40

4.3 Passo RA-1: Investigação das Fontes de Informações . . . . . . . . . . . . . 41

4.3.1 Arquiteturas e Ferramentas para iTV . . . . . . . . . . . . . . . 41

4.4 Passo RA-2: Estabelecimento de Requisitos arquiteturais para TV Digital Interativa . . . . . . . . . . . . . . . . . . 46

4.5 Passo RA-3: Projeto Arquitetural . . . . . . . . . . . . . . . . . . 48

4.5.1 Visão Geral . . . . . . . . . . . . . . . . . . . . . . . . . 48

4.5.2 Visão em Módulo . . . . . . . . . . . . . . . . . . . . . . . . 49

4.5.3 Visão de Implantação . . . . . . . . . . . . . . . . . . . . . . . . 53

4.6 Passo RA-4: Avaliação da Arquitetura de Referência . . . . . . . . . . . 53

4.7 Considerações Finais . . . . . . . . . . . . . . . . . . . . . 54

5 Estudo de Caso: Utilização da ArciTV 55

5.1 Considerações Iniciais . . . . . . . . . . . . . . . . . . . . . 55

5.2 Motivação para o Estudo de Caso . . . . . . . . . . . . . . . . . 55

5.3 Sistemas de Armazenamento de Dados para iDTV . . . . . . . . . . . 57

5.4 Requisitos Arquiteturais Instanciados da ArciTV . . . . . . . . . . . . . . 58

5.5 Considerações Finais . . . . . . . . . . . . . . . . . . . . 64

6 Conclusão $\quad \mathbf{6 5}$

6.1 Caracterização da Pesquisa Realizada . . . . . . . . . . . . . . . . . . . 65

6.2 Contribuições . . . . . . . . . . . . . . . . . . 66

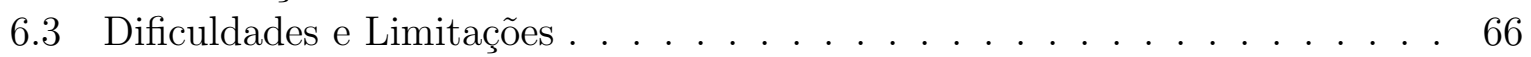

6.4 Trabalhos Futuros . . . . . . . . . . . . . . . . 66

$\begin{array}{ll}\text { Referências } & 81\end{array}$ 
1.1 Arquitetura de Software do Receptor Digital com MHP . . . . . . . . . . . 2

2.1 Exemplo de Arquitetura em Camadas para Sistemas Embarcados (Adaptado de Noergaard (2005)) . . . . . . . . . . . . . . 6

2.2 Sistemas Embarcados para Eletrônica de Consumo (Adaptado de Electronics AND You (2009)) . . . . . . . . . . . . . . . . 7

2.3 Modelos de Smartphones (Mobile Network, 2009) . . . . . . . . . . . . 8

2.4 A Evolução da Camada de Software em Sistemas Embarcados para Eletrônica de Consumo (Genuchten, 2007a) . . . . . . . . . . . 8

2.5 A Eletrônica de Consumo para Jogos Pervasivos (Adaptado de Mottola et

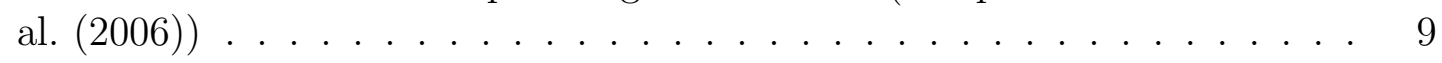

2.6 Exemplo de Conversão do Sinal Analógico vs. Digital em TV. (Fagerqvist e Marcussen, 2000) . . . . . . . . . . . . . . . . . . 9 9

2.7 Modelo de Negócios para Aplicações Interativas em TV Digital (Fagerqvist e Marcussen, 2000) . . . . . . . . . . . . . . . . . . . . 10

2.8 Infraestrutura para TV Digital Interativa . . . . . . . . . . . . . . . 11

2.9 Exemplos de Aplicações Interativas . . . . . . . . . . . . . . . . . . . . 11

2.10 Infraestrutura da TV Digital Interativa . . . . . . . . . . . . . . . . . 12

2.11 Formato de Envio de Dados DSMCC (Tan et al., 2003) . . . . . . . . . . 13

2.12 Sistema com Execução no Modelo Orientado a Aspectos . . . . . . . . . . 14

2.13 Subáreas de Pesquisas em Orientação a Aspectos e Sistemas Embarcados. . 17

2.14 Arquitetura do Sistema PURE. . . . . . . . . . . . . . . . 17

2.15 Framework DERAF . . . . . . . . . . . . . . . . 18

2.16 Métricas de Qualidade de Software (Kartal e Schmidt, 2007) . . . . . . . . 19

2.17 Arquitetura Software do Sistema de Aúdio, do Dispositivo Móvel da marca Motorola MVME5100 (Adaptado de Kartal e Schmidt (2007)) . . . . . . . 20

2.18 Resultado dos Comparativos de Performance Presentes em Kartal e Sch$\operatorname{midt}(2007) \ldots \ldots \ldots \ldots \ldots \ldots \ldots$

2.19 Exemplo de Estrutura de Times de Objetos com Consulta para um Pacote (Adaptado de Herrmann et al. (2009)) . . . . . . . . . . . . . . . . . . . 21

2.20 Resultados do Modelo Implementado na Pesquisa de Hundt (2009). . . . . 22

2.21 Framework do Metamodelo Estrutural presente em Fanjiang et al. (2010) 22 
2.22 Arquitetura do middleware para TV Digital Brasileira (International Telecommunications Union, 2001) . . . . . . . . . . . . 23

2.23 Diagrama de Classes do Ginga-CC com Modelagem Orientada a Aspectos (Saraiva et al., 2010) . . . . . . . . . . . . . . . . 24

3.1 Relações entre Terminologias (adaptado de Bass e Clements (2003) . . . . 27

3.2 Estrutura Geral do ProSA-RA (Nakagawa et al., 2009b) . . . . . . . . . . 28

3.3 Arquitetura STB . . . . . . . . . . . . . . . . . . . . . . . . 29

3.4 Padronizações de Middleware para TVD . . . . . . . . . . . . . . . . . . . 30

3.5 Norma ITU J.202 para Middleware Procedural (Adaptado de (ITU, 2011)) 31

3.6 Norma ITU J.202 para Middleware Declarativo (Adaptado de (ITU, 2011) 33

3.7 MHP Profiles . . . . . . . . . . . . . . . . . . . 34

3.8 Modelo de Ciclo de Vida JavaTV . . . . . . . . . . . . . . . . . . . . . . 34

3.9 Estrutura do Ambiente do Middleware Ginga. . . . . . . . . . . . . . . . 36

4.1 Cenário de Aplicações Desenvolvidas para o Ambiente Declarativo. . . . . 40

4.2 Cenário de Aplicações Desenvolvidas para o Ambiente Procedural. . . . . . 41

4.3 Arquitetura de Referência (Finke e Balfanz, 2004) . . . . . . . . . . . . . . 42

4.4 Arquitetura de Referência extraída de Vrba et al. (2006) . . . . . . . . . . 43

4.5 Arquitetura de Referência extraída de Wang et al. (2009) . . . . . . . . . . 44

4.6 Arquitetura de Referência extraída de Pequeno et al. (2010) . . . . . . . . 44

4.7 Infraestrutura P2P para a Arquitetura em TV Digital (Ló andrez Nores et al., 2010). . . . . . . . . . . . . . . . . . . . 45

4.8 Exemplo de uso da iTV como Veículo de Automação Residencial. (Figura extraída de Montgomery, L. (2012). . . . . . . . . . . . . . . . . . . . 46

4.9 Arquitetura com Interação entre Automação Residencial e TV Digital. (Figura extraída de Viana et al. (2009)) . . . . . . . . . . . . . . . . . 47

4.10 Visão Geral do ArciTV . . . . . . . . . . . . . . . . . . . . . . . . . . . . . 49

4.11 Visão em Módulo da ArciTV. . . . . . . . . . . . . . . . . . . . . 50

4.12 Funcionalidades Espalhadas em Ambiente de iTV. . . . . . . . . . . . . 51

4.13 Interações Multimodais, extraído de Universidade Vrije em Bruxelas (2012) 51

4.14 Integração entre Protocolos Xlet e Bundle. . . . . . . . . . . . . . . . . . 52

4.15 Visão de Implantação da ArciTV . . . . . . . . . . . . . . . . . . . . 53

5.1 Cenário de Armazenamento para Sistemas TV. . . . . . . . . . . . . 56

5.2 Evolução dos Sistemas de Armazenamento para TV Digital. . . . . . . . . 57

5.3 Instanciação da Arquitetura de Referência . . . . . . . . . . . . . . . . . . 60

5.4 Aplicação Executada no Emulador Xletview. . . . . . . . . . . . . . . . . 61

5.5 Casos de Uso para Aplicação de Armazenamento USB na iTV . . . . . . . 62

5.6 Arquitetura MVC . . . . . . . . . . . . . . . . . . . 62

5.7 Diagrama de Estados . . . . . . . . . . . . . . . . . . . . . 63

5.8 Diagrama de Atividades . . . . . . . . . . . . . . . . . . 64 


\section{Lista de Tabelas}

3.1 Plataformas de Software . . . . . . . . . . . . . . . . . . . . . 33

3.2 Etapas de interação entre Xlet e Application Manager . . . . . . . . . . 35

4.1 Plataformas de Software . . . . . . . . . . . . . . . . . . . 42

5.1 Comparação entre pesquisas existentes para armazenamento televisivo. . 59 



\section{Lista de Abreviaturas e Siglas}

$\begin{array}{ll}\text { AAC } & \text { Advanced Audio Coding } \\ \text { ACAP } & \text { Advanced Common Application Plataform } \\ \text { ACM } & \text { Association of Computer Machinery } \\ \text { ATSC } & \text { Advanced Television Systems Committee } \\ \text { CDC } & \text { Connected Device Configuration } \\ \text { DASE } & \text { DTV Application Software Environment } \\ \text { DMB } & \text { Digital Multimedia Broadcasting } \\ \text { DSMCC } & \text { Digital Storage Media Command Control } \\ \text { DTV } & \text { Digital Television } \\ \text { DVB } & \text { Digital Video Broadcasting } \\ \text { DVR } & \text { Digital Video Recorder } \\ \text { EDTV } & \text { Enhanced Definition TV } \\ \text { EPG } & \text { Electronic Program Guide } \\ \text { ETSI } & \text { European Telecommunications Standards Institute } \\ \text { GEM } & \text { Globally Executable MHP } \\ \text { HAVi } & \text { Home Audio and Video Interoperability } \\ \text { HDMI } & \text { High Definition Multimedia Interface } \\ \text { HDTV } & \text { High Definition TV } \\ \text { IPTV } & \text { Internet Protocol Television } \\ \text { ISDB } & \text { Integrated Services Digital Broadcasting } \\ \text { ISO } & \text { International Organization for Standardization } \\ \text { ITU } & \text { International Telecommunication Union } \\ \text { JMF } & \text { Java Media Framework } \\ \text { JVM } & \text { Java Virtual Machine } \\ \text { MHP } & \text { Multimedia Home Plataform } \\ \text { MHEG } & \text { Multimedia and Hypermedia Experts Group } \\ \text { MPEG } & \text { Moving Picture Experts Group } \\ \text { NCL } & \text { Nested Context Language } \\ \text { OCAP } & \text { OpenCable Application Plataform } \\ \text { OSI } & \text { Open Systems Interconnection } \\ \text { QoS } & \text { Quality of Service } \\ \text { RTOS } & \text { Real-Time Operating System } \\ \text { SBTVD } & \text { Sistema Brasileiro de Televisão Digital } \\ \text { SDTV } & \text { Standard Definition Television } \\ \text { STB } & \text { Set-Top Box } \\ \text { TVD } & \text { TV Digital } \\ \text { USB } & \text { Universal Serial Bus } \\ \text { XML } & \text { Extensible Markup Language } \\ & \end{array}$




\subsection{Contextualização}

Sistemas embarcados vêm se tornando parte integrante e essencial das atividades diárias das pessoas e, em virtude disso, a indústria de sistemas embarcados tem crescido nos últimos anos e concebido sistemas para uma diversidade de plataformas, tais como, automobilística, eletrodomésticos e eletrônica de consumo. Em paralelo, uma crescente demanda de novas funcionalidades para essas plataformas tem gerado novos desafios tecnológicos, tais como um melhor gerenciamento de recursos e otimização de processamento (Oliver, 2009a). Esse crescimento em associação com a convergência digital entre as plataformas tem feito com que o desenvolvimento de sistemas embarcados necessitasse utilizar de fato de técnicas, métodos, processos, entre outros, que vêm sendo propostos pela Engenharia de Software (Genuchten, 2007b).

O crescimento da sinergia entre as áreas de Engenharia de Software e Sistemas Embarcados tem resultado em pesquisas que buscaram melhor estruturar os sistemas embarcados por meio de uma arquitetura em camadas (Jerraya e Wolf, 1998; Karlof et al., 2002; Koong et al., 2009; Miljkovic et al., 2010). Existem contribuições de pesquisas em todas as camadas de sistemas embarcados: (i) camada de hardware, com aplicações que utilizem a tecnologia de FPGA (Field Programmable Gateway Array) (Engel e Spinczyk, 2009a); (ii) camada de sistema operacional, com aplicações para o kernel ${ }^{1}$ e device drivers (Park e Hong, 2009), (iii) camada de software, com aplicações a nível de usuário (Hundt e Glesner, 2009). Em particular, a plataforma de TV Digital, que se destaca como um sistema embarcado para eletrônica de consumo, tem apresentado também uma arquitetura em camada (Saraiva et al., 2010), tendo, por exemplo, a camada de hardware, de sistema operacional e de aplicação.

A TV Digital refere-se a uma plataforma que vem cada vez mais se disseminando, sendo capaz de transmitir e receber sinais de áudio e vídeo de alta definição, bem como dados por meio, por exemplo, de difusão via broadcasting na frequência de VHF/UHF ( Very High Frequency/Ultra High Frequency)(Union,

\footnotetext{
${ }^{1}$ Componente central de um sistema operacional.
} 
1996). Nesse contexto, a ITU2 (Internacional Telecommunication Union) definiu um modelo de referência para ser um padrão aberto de TV Digital(Union, 2006). De um modo geral, a comunicação entre as duas partes (produtor de conteúdo e usuário) é possível por meio do uso de um emissor de conteúdo e de um receptor digital de conteúdo.

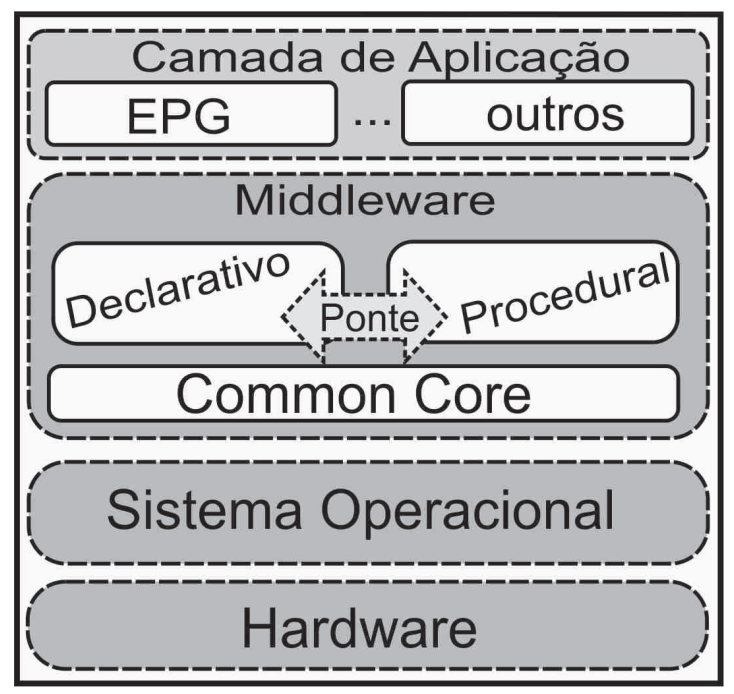

Figura 1.1: Arquitetura de Software do Receptor Digital com MHP (Adaptado de (Union, 2006))

Observa-se que muitos desafios têm surgido para a concepção de um sistema de TV Digital, como, por exemplo, a definição de métodos de compressão, multiplexação, modulação e especificação do hardware. Há também desafios no estabelecimento das especificações de software do receptor digital que se refere ao dispositivo que recebe e decodifica os sinais recebidos e a serem exibidos. Aos usuários em particular, uma dessas especificações refere-se ao do middleware que se refere a uma camada de software responsável por intercomunicar o sistema operacional em execução no receptor e as aplicações interativas disponíveis para o usuário, abstraindo assim implementações complexas e o funcionamento do hardware (Morris e Smith-Chaigneau, 2005). Por exemplo, o sistema europeu de TV Digital - DVB ${ }^{3}$ (Digital Video Broadcasting) - utiliza o middleware MHP (Multimedia Home Platform) (Union, 2006), ilustrado na Figura 1.1. Ele é responsável pela execução dos $X_{\text {Xets }}^{4}$ e das aplicações em linguagem de script. O componente $A p$ plication Manager é responsável por gerenciar o ciclo de vida dos Xlets. A JVM ${ }^{5}$ (Java Virtual Machine) tem papel importante na execução e gerenciamento dos aplicativos escritos na linguagem Java ${ }^{6}$.

Ainda nesse cenário, uma diversidade de aplicações interativas para a plataforma de TV Digital tem sido propostas, como por exemplo aplicações para comércio eletrônico televisivo, para transações bancárias, entre outras. A arquitetura de software do MHP engloba os ambientes procedural e declarativo (Union, 2006), responsáveis respectivamente pela execução dos Xlets (interface Java) e aplicações em linguagem de script. A arquitetura do MHP na Figura 1.1, o componente Application Manager é res-

\footnotetext{
${ }^{2}$ http://www.itu.int/

${ }^{3}$ http://www.dvb.org/

${ }^{4}$ http://java.sun.com/developer/technicalArticles/javatv/apiintro/. Xlets são aplicações similares aos applets e midlets e possuem uma interface do usuário que permite com que uma fonte externa possam controlá-los.

${ }^{5}$ http://java.sun.com/docs/books/jvms/

${ }^{6} \mathrm{http}: / /$ www.java.com
} 
ponsável em gerenciar o ciclo de vida dos Xlets, com essa funcionalidade contida no ambiente procedural denominado DVB-J7 (Union, 2003).

Em uma perspectiva paralela, a Engenharia de Software têm penetrado no desenvolvimento para TV Digital em todas as camadas do middleware. Para as camadas de Common Core e Procedural existem em especial iniciativas na área de padrões arquiteturais. Em particular, com o objetivo de facilitar e sistematizar o desenvolvimento de sistemas de software, a Engenharia de Software tem também proposto uma diversidade de arquiteturas de referência. Uma arquitetura de referência pode ser entendida como uma arquitetura de software genérica que representa uma família de sistemas, sendo utilizada como base para o projeto de arquiteturas concretas dessa família (Angelov et al., 2009). Ela promove o reúso do projeto arquitetural e o entendimento sobre um domínio específico. Sendo assim, arquiteturas de referência podem ser encontradas para os mais diversos domínios como, por exemplo, para o de teste de software (Nakagawa et al., 2007), robôs (National Instruments, 2010), indústria automotiva (AUTOSAR, 2012), navegadores da Internet (Grosskurth e Godfrey, 2005) e computação na nuvem (Liu et al., 2011), entre outros. É importante destacar, no entanto, que a proposição de uma arquitetura de referência não é uma tarefa trivial, pois requer um vasto conhecimento sobre o domínio para o qual a arquitetura está sendo criada (Nakagawa et al., 2009b).

Em uma perspectiva paralela, o conceito de separação de interesses (Dijkstra, 1976) tem sido foco de atenção, em virtude do surgimento de uma nova abordagem de desenvolvimento de software, a POA (Kiczales et al., 1997). A POA (Programação Orientada a Aspectos) possibilita melhorar ainda mais a separação de interesses se comparada com a orientação a objetos, um paradigma de programação que já tem se evidenciado nos últimos anos e melhorado significativamente a capacidade de alcançar uma boa separação de interesses. De modo geral, o principal objetivo da POA é possibilitar a manipulação dos interesses transversais (do inglês, crosscutting concerns) - interesses que estão espalhados ou entrelaçados com outros interesses do sistema - tão separados quanto possível, encapsulando-os em unidades chamadas de aspectos e, em seguida, combinando-os para construir uma aplicação completa. Como exemplos bastante conhecidos tem-se a persistência e o tracing.

A POA tem sido tambem investigada mais recentemente para o desenvolvimento de sistemas embarcados. Suas vantagens têm sido exploradas em pesquisas, inclusive multidisciplinares, que envolvem diferentes tipos de sistemas embarcados, tais como sistemas de tempo real (Wehrmeister et al., 2008), sistemas embarcados de processamento distribuído (Zhang e Liu, 2005) e sistemas embarcados para eletrônica de consumo (Hundt e Glesner, 2009), e em diferentes camadas da arquitetura desses sistemas (Saraiva et al., 2010).

\subsection{Motivação}

Apesar da relevância de arquiteturas de referência no desenvolvimento de sistemas de software, observa-se que há uma carência de arquiteturas de referência para o domínio de TV Digital. Além disso, existe também uma carência de estudos mais aprofundados sobre uma padronização das aplicaçãoes para TV Digital interativa, no ambiente procedural do middleware, gerando isso granularidade no desenvolvimento, ausência de reúso e dificuldades de integração e manutenabilidade de sistemas. Um ferramenta de organização para o desenvolvimento de sistemas nesse domínio, com diretrizes formatadas segundo as necessidades de recursos como uma arquitetura de referência, seria de importânica singular para a maturidade do desenvolvimento de aplicações na plataforma de TV Digital interativa.

\footnotetext{
${ }^{7}$ Modelo procedural baseado em Java para o middleware MHP.
} 
Observa-se ainda que, para o desenvolvimento dessas aplicações, um melhor separação de interesses não tem sido foco de atenção. Em suma, a falta de sistematização no desenvolvimento de aplicações para a plataforma de TV Digital pode ser caracterizado como o principal problema a ser tratado no contexto deste trabalho.

\subsection{Objetivo}

A principal contribuição deste trabalho é o estabelecimento da ArciTV uma arquitetura de referência que dá suporte ao desenvolvimento de aplicações para TV Digital e que possa explorar o uso de orientação a aspecto no desenvolvimento dessas aplicações. Inclusive vale destacar que essa arquitetura deverá estar de acordo com requisitos estabelecidos pelo middleware da plataforma de TV Digital alvo. Baseada em aspectos, essa arquitetura visa melhorar a separação de interesses e, como consequência, contribuindo para a modularidade, o reúso e a produtividade.

Como resultados, espera-se ter uma arquitetura de referência para o domínio de TV Digital interativa, que agregue conhecimentos de como desenvolver para esse domínio. Para observar a viabilidade da arquitetura de referência proposta, uma aplicação foi projetada e implementada a partir da instanciação da arquitetura. Além disso, objetiva-se contribuir para a área de TV Digital com uma forma (ou seja, uma arquitetura de referência) que facilite o desenvolvimento de aplicações para o domínio de TV Digital.

\subsection{Organização}

Neste capítulo foi apresentado o contexto no qual este projeto de mestrado de insere e a motivação que levou à sua condução, bem como os principais objetivos. O restante deste trabalho está organizado da seguinte forma.

No Capítulo 2 são apresentados conceitos relacionados à Sistemas Embarcados.

No Capítulo 3 são discutidos conceitos e terminologias relacionadas à arquitetura de software.

No Capítulo 4 é apresentado em detalhes acerca do desenvolvimento da ArciTV.

No Capítulo 5 é apresentado um estudo de caso que ilustra em detalhes o desenvolvimento de uma aplicação baseada na arquitetura proposta no contexto desse trabalho.

Por fim, no Capítulo 6 são discutidos os principais resultados deste trabalho, as contribuições e perspectivas de trabalhos futuros. 


\section{Sistemas Embarcados e TV Digital: Uma Visão Geral}

\subsection{Considerações Iniciais}

Sistemas embarcados vêm se tornando cada vez mais parte integrante das atividades diárias. Em virtude disso, em particular, a indústria de eletroeletrônicos tem crescido nos últimos anos e trazido sistemas embarcados a diversos tipos de plataformas, tais como, automobilística, eletrodomésticos, equipamentos hospitalares e eletrônica de consumo. Devido ao forte aumento no uso de sistemas embarcados nas últimas décadas, as indústrias tem especilizado seus nichos de mercado de acordo com os diferentes aplicações empregadas (Vardaman, 1997). Esse cenário fez com que surgissem diferentes áreas de pesquisa envolvendo o desenvolvimento de sistemas embarcados, tais como, sistemas embarcados e distribuídos, sistemas de tempo real, eletrônica de consumo.

Dessa forma, na Seção 2.2 são apresentados conceitos básicos relacionados a sistemas embarcados. Na Seção 2.3 são apresentados os sitemas embarcados para eletrônica de consumo. As arquiteturas utilizadas em sistemas embarcados para eletrônica de consumo são discutidas na Seção 2.4. Por fim, na Seção 2.5, são discutidas as considerações finais deste capítulo.

\subsection{Arquitetura de Sistemas Embarcados}

A arquitetura em um sistema embarcado é a abstração do dispositivo embarcado (Noergaard, 2005), com representação generalizada do sistema, sem apresentação de informações tecnológicas detalhadas como código fonte e conFigurações de circuitos elétricos. No nível arquitetural, os componentes de hardware e software em um sistema embarcado são representados como diferentes "elementos"que possuem 
"interações"em suas tarefas. Os elementos são representações do hardware e software com abstração de detalhes de implementação, com descrição de detalhes comportamentais e inter-relacionais (Marwedel, 2011).

Elementos arquiteturais podem ser internamente integrados com o dispositivo embarcado (Chen e Törngren, 2004), (Yennun e Kintala, 1993), (Jacobson e Pan-Wei, 2004), ou funcionar externamente com o sistemas embarcados e interagir com elementos internos. Com isso, uma arquitetura de sistema embarcado pode incluir elementos do sistema embarcado, elementos de interação com o sistema embarcado, propriedades de cada elemento individual e interação de relacionamentos entre elementos (Wagelaar, 2004).

De acordo com Noergaard (2005), existem diversas estruturas arquiteturais para sistemas embarcados; porém, em uma abstração de mais alto nível, existe o modelo representado na Figura 2.1, no qual os sistemas embarcados são constituídos no mínimo por uma camada de hardware e, opcionalmente, pelas camadas de sistema operacional e aplicação.

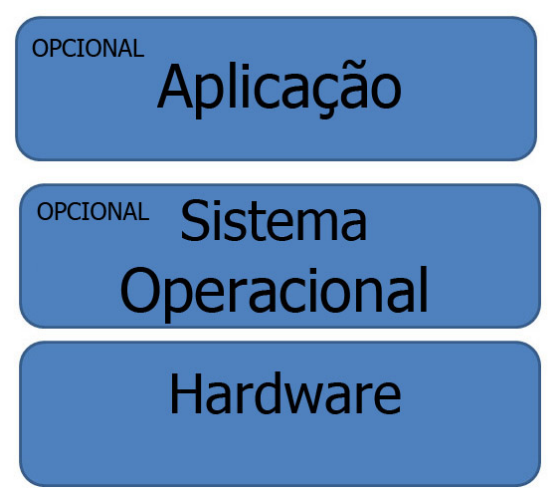

Figura 2.1: Exemplo de Arquitetura em Camadas para Sistemas Embarcados (Adaptado de Noergaard (2005))

A representação arquitetural da Figura 2.1 é estritamente modular, cujo modelo pode derivar diferenciadas arquiteturas, conforme as áreas de atuação dos sistemas embarcados. Apesar do conceito de arquitetura em camadas não ser usado unicamente para representação de sistemas embarcados, sua estrutura é útil para discernimento de diversas estruturas de elementos inter-relacionais de hardware e software presentes em sistemas embarcados. As principais vantagens dessa abordagem no tocante ao estudo de arquiteturas para sistemas embarcados são as seguintes (Barr, 1999):

- A representação visual de elementos e as funções de relacionamento associadas com esses elementos;

- A representação modular das estruturas permite nivelamento de todo um projeto de sistemas embarcados. Isso é especialmente útil, devido aos módulos de um sistema embarcado possuírem funcionamento interdependente; e

- A separação de elementos em camadas permite que a organização estrutural de elementos seja otimizada, minimizando o risco de simplicação de interações complexas, ou maximização de interações simples. 


\subsection{Eletrônica de Consumo}

Devido à forte penetração no mercado norte americano de produtos comerciais dirigidos as características dos consumidores, Miller (1999) forneceu uma das primeiras perspectivas sobre sistemas embarcados para eletrônica de consumo. Nesse período, a $\mathrm{FCC}^{1}$ (Federal Communication Comission) normatizou a eletrônica de consumo distribuida nas seguintes plataformas (Miller, 1999): (a)TV Digital Terrestre, (b) Dispositivos de exibição de DVD (Digital Video Decoder), (c) Câmeras Digitais e (d) Sistemas embarcados utilizados em entretenimento. Na Figura 2.2 são ilustrados alguns dos produtos comerciais da eletrônica de consumo.

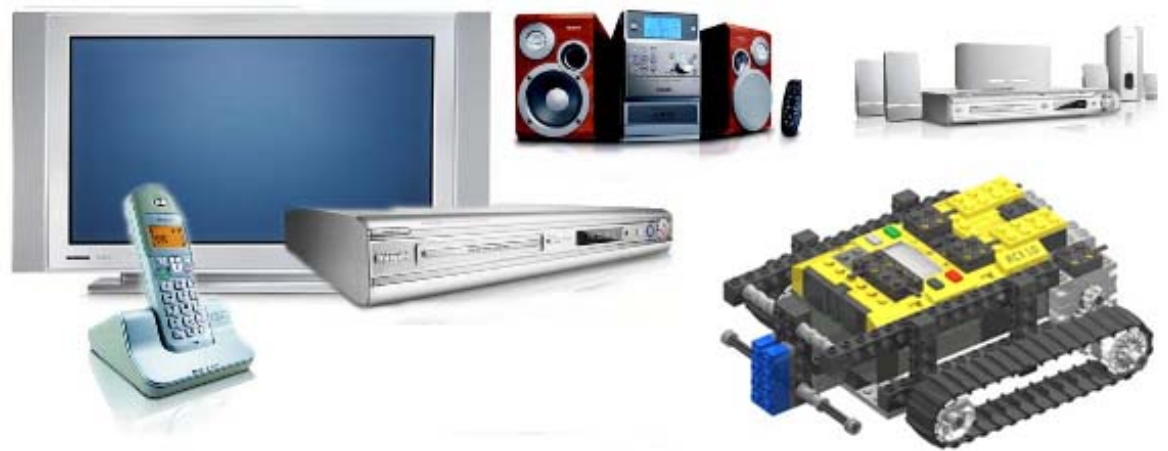

Figura 2.2: Sistemas Embarcados para Eletrônica de Consumo (Adaptado de Electronics AND You (2009))

Em uma perspectiva posterior, o telefone celular tornou-se uma nova plataforma para sistemas embarcados para eletrônica de consumo (Ling et al., 2007). Isso se deu pelo fato da elevada aceitação pelo consumidor e elevada granularidade desses sistemas, provendo inclusive acesso instântaneo a chamadas de voz e serviços de dados.

Devido ao surgimento de novas funcionalidades, poder de processamento e convergência digital, uma nova classe de dispositivos móveis emergiu, os Smartphones (Oliver, 2009b), ilustrados na Figura 2.3. Dentre às múltiplas funcionalidades oferecidas por esses dispositivos está a interação com múltiplos protocolos WiFi (Wireless Fidelity), (Bluetooth) e EDGE (Enhanced Data Rates for GSM Evolution), e interações em redes sociais. De acordo com Kairer (2008), no ano de 2007 o número de smartphones vendidos tiveram um aumento de $60 \%$ em relação ao ano anterior, ou seja, cerca de 115 milhões de dispositivos nesse ano. Esses dados provam a forte penetração desses dispositivos no mercado de embarcados para eletrônica de consumo. No primeiro quadrimestre do ano de 2010 (Kairer, 2010), as vendas quase duplicaram, com um número estimado de 315 milhões de smartphones vendidos, trazendo, com isso, um acréscimo de $17 \%$ de vendas em relação ao mesmo período do ano anterior.

Com a crescente demanda de novas funcionalidades para as plataformas de dispositivos móveis, novos desafios tecnológicos emergiram. Segundo Oliver (2009b), fazem-se necessários o gerenciamento de recursos, otimização de processamento, armazenamento persistente, estruturação de novos protocolos e dispositivos de entrada e saída. Esse crescimento em associação com a convergência digital que ocorre entre plataformas fez com que os dispositivos tivessem a evolução diferenciada na camada de software. A Figura 2.4 ilustra um comparativo entre três áreas tecnológicas, "indústria de computadores", "indústria de telefones móveis"e "indústria de eletrônica de consumo", e seus respectivos nichos de desenvolvimento

\footnotetext{
${ }^{1}$ http://www.fcc.gov - Acessado em 12 de janeiro de 2011.
} 


\section{CAPÍTULO 2. SISTEMAS EMBARCADOS E TV DIGITAL: UMA VISÃO GERAL}

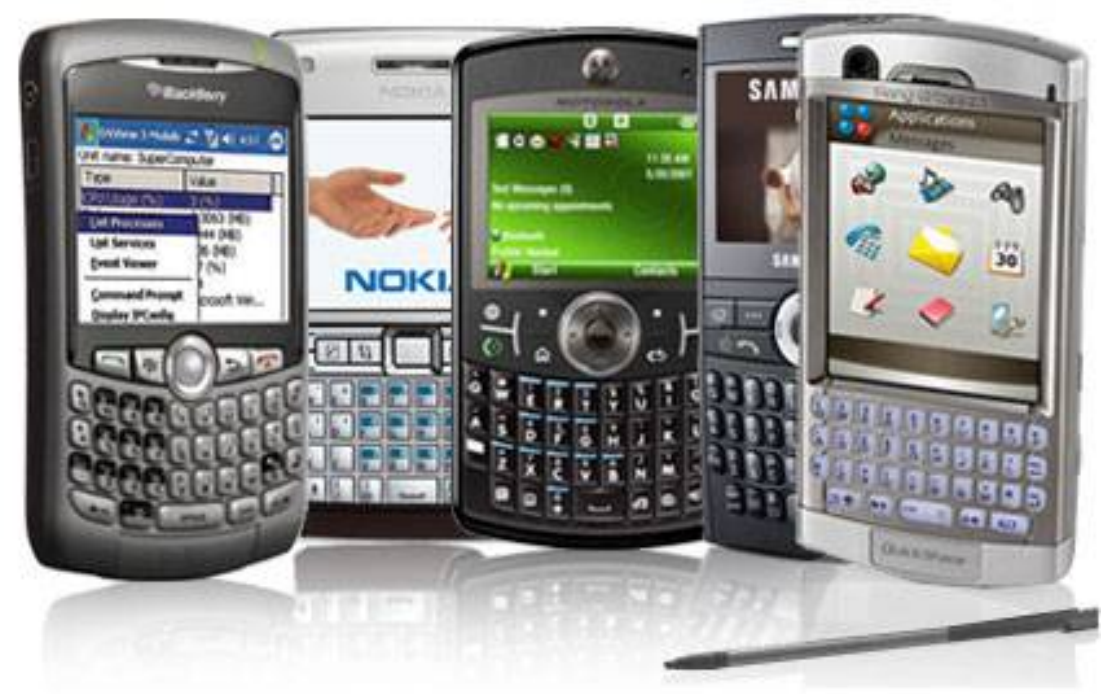

Figura 2.3: Modelos de Smartphones (Mobile Network, 2009)

(Genuchten, 2007a). Conforme pode-se notar, a indústria de computadores no decorrer dos anos migrou esforços da área de softwares proprietários para software livres e abertos. Ainda na mesma perspectiva, é possível destacar a extensão de áreas de atuação para a indústria de eletrônica de consumo e o mercado de smartphones.

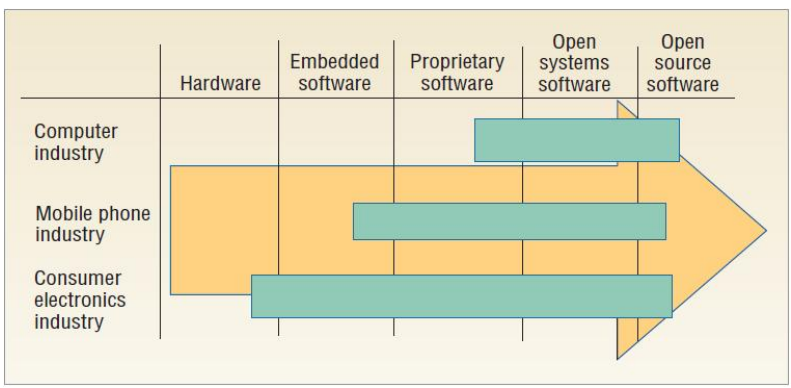

Figura 2.4: A Evolução da Camada de Software em Sistemas Embarcados para Eletrônica de Consumo (Genuchten, 2007a)

A eletrônica de consumo tem se destacado na área de jogos eletrônicos pervasivos ${ }^{2}$ (Mottola et al., 2006), conforme demonstrado na Figura 2.5, no qual o jogo requer interações cooperativas entre múltpilos usuários móveis para alcançar um objetivo comum, sendo que a dinâmica do jogo é determinada por interações físicas e virtuais. Nessa área de jogos pervasivos, diversos modelos foram desenvolvidos (Cheok et al., 2003; Flintham et al., 2003; Steffen P. et al., 2006; Thomas et al., 2002), com objetivos diferentes de interação entre o ambiente físico e virtual. Devido a essas características, os aspectos tecnológicos devem diretamente ser considerados, tais como as plataformas de hardware que irão executar jogos por meio de ambientes pervasivo, interação homem-máquina e usabilidade.

\footnotetext{
${ }^{2}$ Sistemas computacionais com interação direta com o usuário, porem, adaptados ao ambiente.
} 


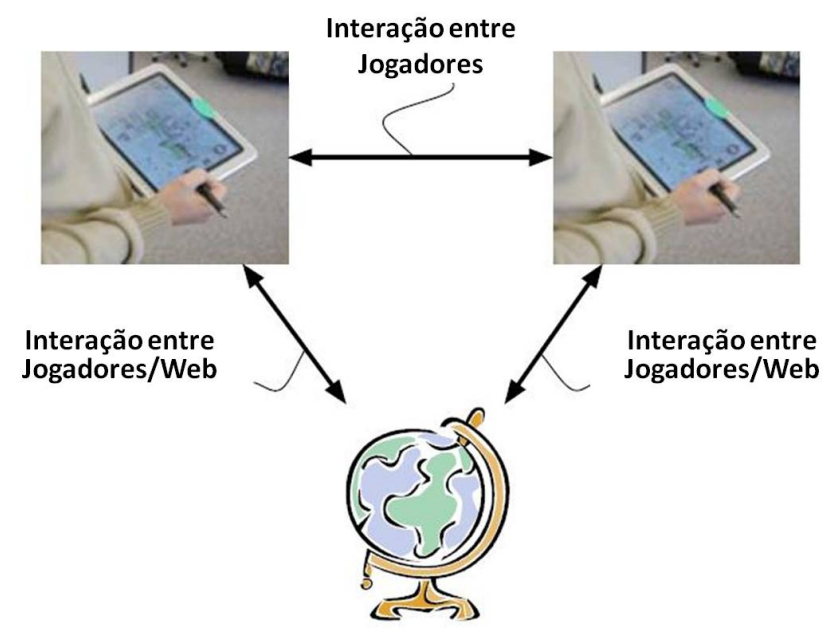

Figura 2.5: A Eletrônica de Consumo para Jogos Pervasivos (Adaptado de Mottola et al. $(2006))$

\subsection{TV Digital}

A difusão digital de televisão, de maneira geral, implica transformar o sinal analógico da TV em informação digital, conforme a Figura 2.6. Um sinal analógico transmitido pode ser descrito como uma curva contínua transmitida. Essa curva pode, durante a transmissão, ser distorcida e, assim, entregar um resultado ruim para o receptor. Se o sinal é transmitido com técnicas digitais, o sinal pode ser visto como uma série de uns e zeros discretizada. Sinais contendo informações digitais (referido como sinais digitais) também podem sofrer distorções, mas a diferença é que esses sinais podem ser corrigidos e, portanto, fornecer um melhor resultado. Para tanto, são aplicados algoritmos de compressão de vídeo como o MPEG- $2^{3}$, o sinal original de vídeo é comprimido a frações entre 1/4 e 1/10 do seu tamanho, o que permite que uma banda de $6 \mathrm{MHz}$ (largura de banda utilizada para a transmissão de canais de TV no Brasil por exemplo), que era usada para transportar apenas um canal de vídeo analógico, possa ser usada para transmitir de quatro a dez canais digitais.

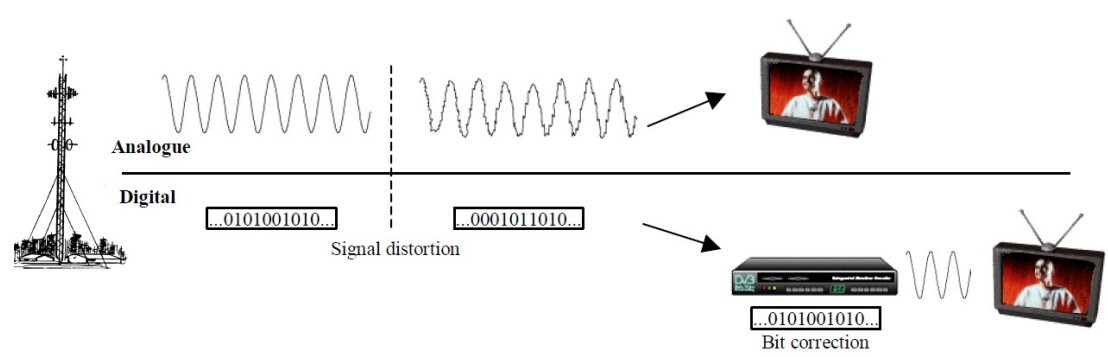

Figura 2.6: Exemplo de Conversão do Sinal Analógico vs. Digital em TV. (Fagerqvist e Marcussen, 2000)

Entretanto, o grande diferencial da transmissão digital não está apenas na quantidade de canais que ela permite transmitir, mas está na possibilidade de transmitir dados juntamente ao sinal de vídeo. Mesmo existindo algumas técnicas para transmissão de dados junto ao vídeo para transmissão analógica, a

\footnotetext{
${ }^{3}$ Modelo de compressão de dados para aúdio e vídeo digitais.
} 


\section{CAPÍTULO 2. SISTEMAS EMBARCADOS E TV DIGITAL: UMA VISÃO GERAL}

quantidade de dados transmitida é muito inferior ao suportado pela transmissão digital. Essa facilidade é que torna viável boa parte dos serviços interativos, que eram impossibilitados pelo alto custo da tecnologia.

O modelo de negócios básico utilizado na televisão digital é apresentado na Figura 2.7, no qual um prestador de serviço de transmissão envia serviços por meio de um operador de rede. A transmissão de televisão digital é realizada por meio de um $\mathrm{TS}^{4}$ (Transport Stream), e um terminal receptor de fluxo de transporte MPEG-2 decodifica e apresenta o conteúdo na tela da televisão. O terminal receptor inclui um decodificador que interpreta o fluxo de transporte MPEG-2, e também pode ser visto como uma plataforma operacional para serviços interativos.

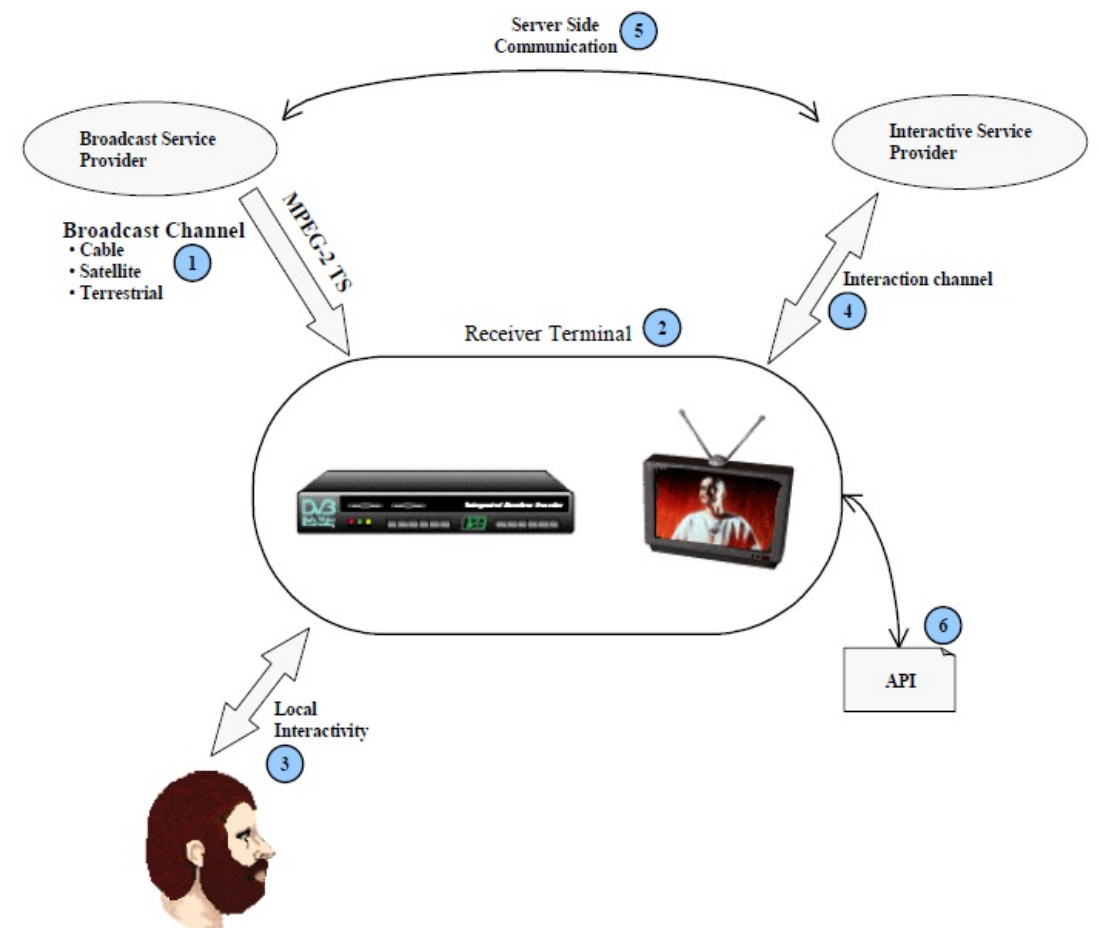

Figura 2.7: Modelo de Negócios para Aplicações Interativas em TV Digital (Fagerqvist e Marcussen, 2000)

Ainda nessa mesma perspectiva, outra vantagem com a televisão digital é a possibilidade de incluir serviços avançados interativos com o programa de televisão. Essa interatividade irá introduzir vários tipos de serviços pay-per-view ${ }^{5}$, bem como novas possibilidades para fazer compras para casa e shows de televisão interativa, e o espectador pode interagir localmente com os aplicativos incluídos nos serviços disponíveis.

Os aplicativos também podem comunicar-se com um provedor de serviços interativos por meio da utilização de um canal de interação. Esse canal de interação pode ser estabelecido, por exemplo, por meio de um modem no receptor. Os telespectadores podem por esse meio fazer solicitações de aplicações e receber respostas de interação. Os prestadores de serviços interativos podem comunicar-se com os prestadores de serviços de transmissão para permitir uma resposta de um pedido comum no canal de transmissão. O terminal receptor interpreta os aplicativos que estão incluídos nos serviços, esses aplicativos são desenvolvidos usando uma API, que fazem parte da plataforma de televisão digital.

\footnotetext{
${ }^{4}$ Sigla do inglês, fluxo de transporte MPEG-2

${ }^{5}$ Termo do inglês, para serviço de habilitação de programas para TV
} 


\subsubsection{TV Digital: Aplicações Interativas}

A interatividade para TV Digital trata da interconectividade de usuários de TV com as provedoras de conteúdo, conforme Figura 2.8, agregando, com isso mais valor ao sistema, e obedecendo características do sistema como interruptabilidade, granularidade, degradação suave, previsão limitada, dentre outras, conforme Fernandes (2006), que define interatividade como: "A interatividade de um processo ou ação pode ser descrita como uma atividade mútua e simultânea da parte dos dois participantes, normalmente trabalhando em direção de um mesmo objetivo".

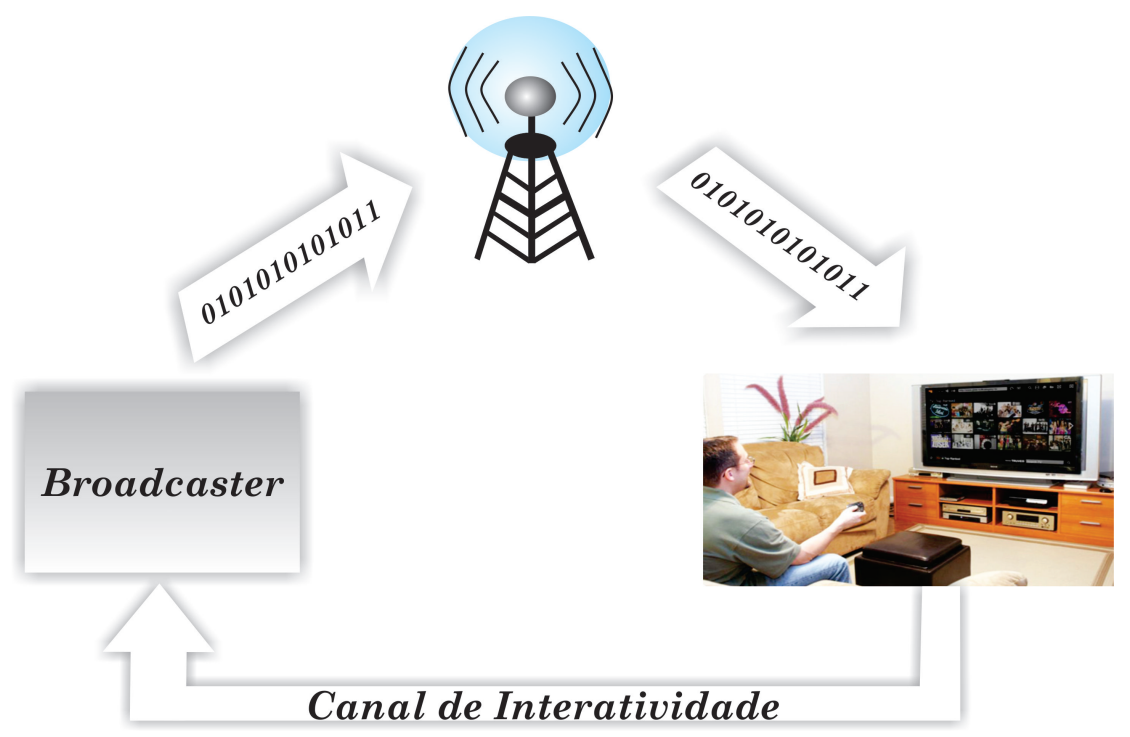

Figura 2.8: Infraestrutura para TV Digital interativa

De acordo com Morris e Smith-Chaigneau (2005), a plataforma de TV Digital interativa abrange diversificados serviços, devido à alta granularidade das aplicações e extensão de utilização pelo consumidor. As principais aplicações interativas são EPGs (Eletronic Program Guide), Walled Gardens ${ }^{6}$, T-Commerce ${ }^{7}$, T-mail, T-Banking ${ }^{8}$, T-Learning ${ }^{9}$, T-Social ${ }^{10}$ e T-Health $^{11}$. Na Figura 2.9 são ilustradas algumas dessas aplicações.
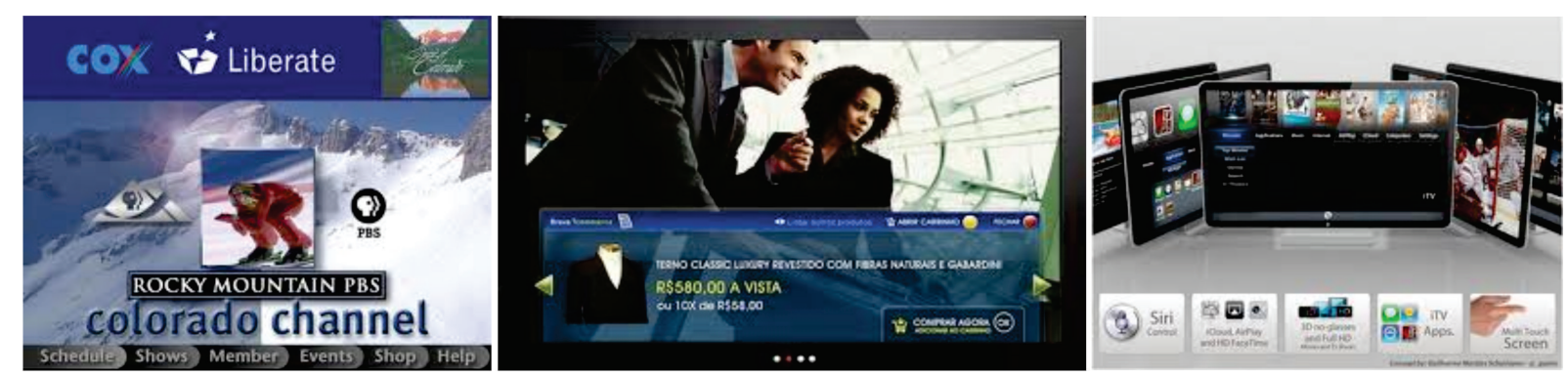

Figura 2.9: Exemplos de Aplicações Interativas

\footnotetext{
${ }^{6}$ portal interativo para TV.

${ }^{7}$ Comércio eletrônico televisivo

${ }^{8}$ Aplicações bancárias para TV Digital.

${ }^{9}$ Aplicações de aprendizado para TV Digital.

${ }^{10}$ Aplicações sociais para TV Digital. Ex: Votação.

${ }^{11}$ Aplicações para área de saúde em TV Digital
} 
Na TVDi ${ }^{12}$ um fator impactante no desenvolvimento de aplicações é a utilização do canal de retorno (Montez e Becker, 2005). Esse componente da infraestrutura do sistema permite interações em tempo real entre o consumidor e o provedor de conteúdo, oferecendo com isso feedbacks dinâmicos e produção de conteúdos sob medida.

\subsubsection{Infraestrutura da TV Digital Interativa}

De acordo com Morris e Smith-Chaigneau (2005) e Montez e Becker (2005), a infraestrutura televisiva para a plataforma de TV Digital possui quatro componentes em sua arquitetura, conforme a Figura 2.10. Cada um desses componentes executa um tratamento para os dados interativos no formato de serviços, distribuídos fisicamente entre fluxos de aúdio, vídeo e dados. Posteriomente, esses serviços são organizados como Transport Streams, para a realização de codificação e compressão. A conceituação de cada um desses componentes está expressa abaixo:

1. Provedor de Conteúdo: Responsável pelo Backend ${ }^{13}$.

2. Receptor: Item de interação direta com o consumidor.

3. Meio de difusão: Tecnologia física responsável pelo comunicação entre consumidor e provedor.

4. Canal de Retorno: Componente de interação direta entre consumidor e provedor.
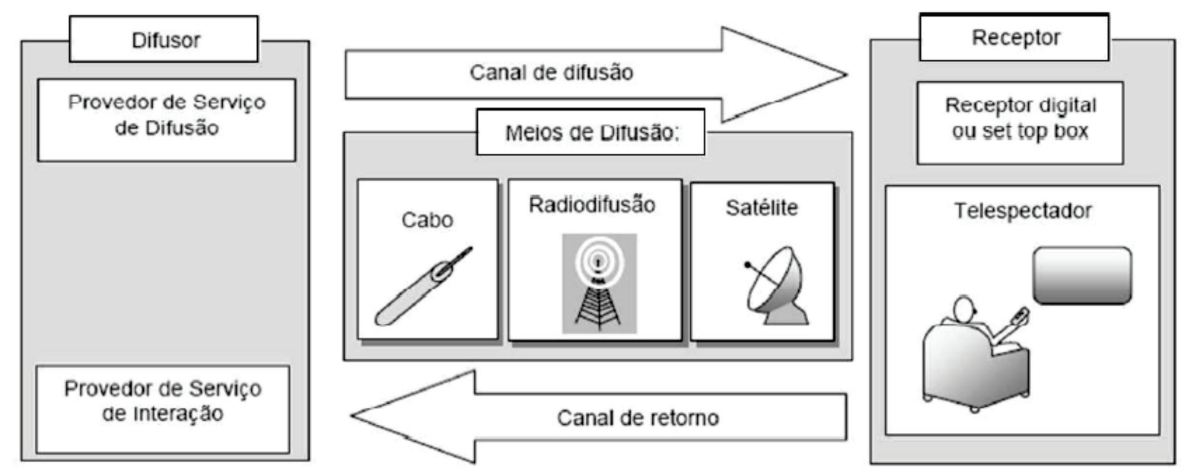

Figura 2.10: Infraestrutura da TV Digital Interativa(Montez e Becker, 2005)

Conforme a Figura 2.10, o difusor é representado pela emissora de TV, que é o componente responsável pela edição e posterior envio de conteúdo pelo meio físico de difusão. Nesse estágio são utilizadas técnicas de codificação multimídia para aúdio e vídeo (ISO (International Organization for Standardization), 2000), e inserção de dados e aplicativos interativos pelo padrão DSMCC ( Digital Storage Media Command Control)(ISO (International Organization for Standardization), 1998), que fazem a difusão pelo padrão de empacotamento Transport Stream na codificação MPEG2, conforme a Figura 2.11 .

O estágio de recepção é realizado por meio do $\mathrm{STB}^{14}$, o qual, realiza o processo inverso ao gerador de conteúdo, desmembrando pacotes e decodificando os sinais digitais em aúdio, vídeo e dados para o consumidor. Para tanto, esse componente possui em sua arquitetura o ambiente de hardware e software

\footnotetext{
${ }^{12}$ Sigla para TV Digital interativa

${ }^{13}$ Componente da infraestrutura de TV responsável pela administração de dados e acessos

${ }^{14}$ Abreviação para o termo em inglês, Set Top Box
} 


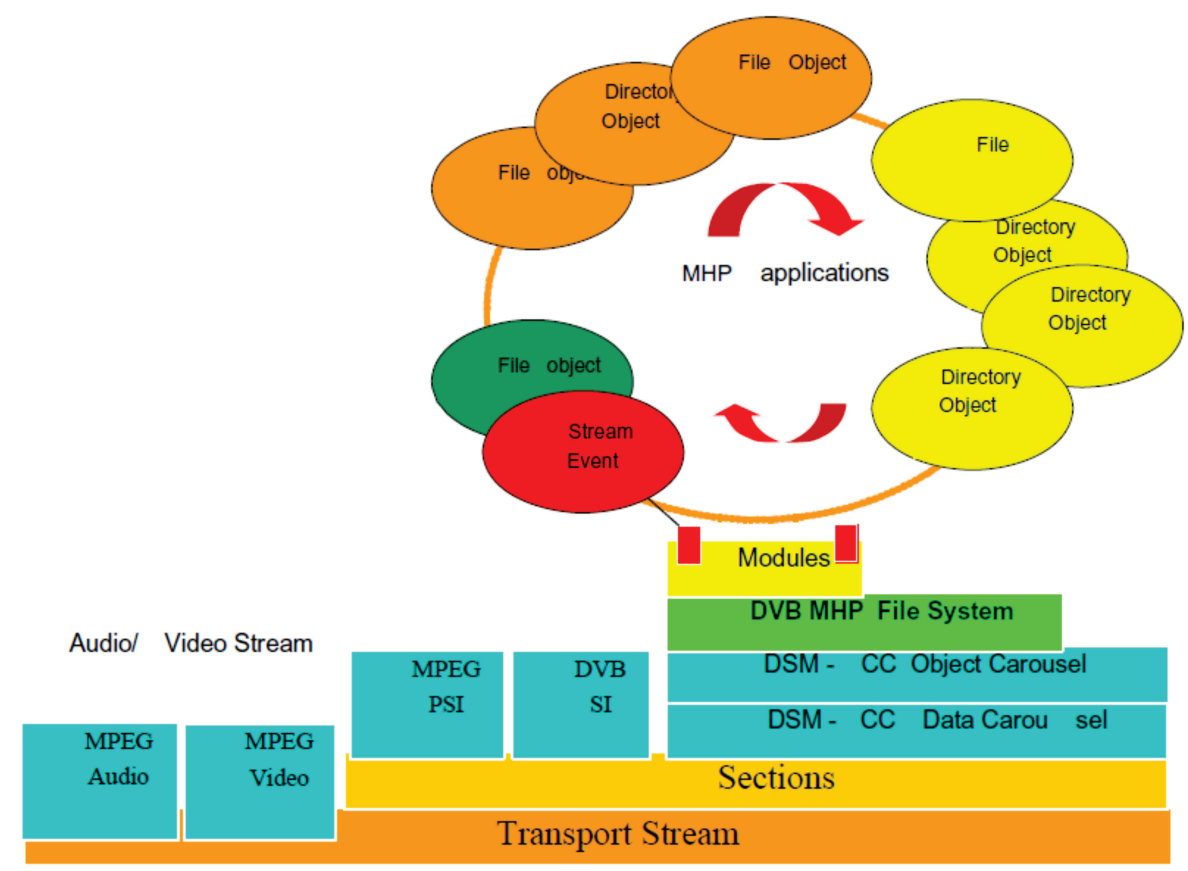

Figura 2.11: Formato de Envio de Dados DSMCC (Tan et al., 2003)

adequados para decodificação, demultiplexação e demodulação. A nível mundial, existem acordos e parcerias entre indústria e centro acadêmicos de pesquisa na área, que normatizaram padrões e especificações para a tecnologia de TV Digital, e os modelos de negócios, ordens políticas e sociais influenciaram a existência de diferentes padrões, conforme a região geográfica (Morris e Smith-Chaigneau, 2005), (Fernandes, 2006);

\subsection{Orientação a Aspectos e Sistemas Embarcados}

A separação de interesses tem sido um princípio que tem direcionado o desenvolvimento de sistemas de software por décadas. Esse princípio foi inicialmente proposto por Dijkstra (1976) e refere-se à habilidade de identificar, encapsular e manipular aquelas partes de software que são relevantes para um particular conceito, objetivo, propósito, propriedade, ou área de interesse. Segundo Kiczales et al. (2001a), entende-se por separação de interesses a ideia de projetar e implementar sistemas de software como unidades naturais de interesses, refletindo, com isso, a "abstração humana", ao contrário de usar abordagens impostas, com unidades específicas para uma técnica, linguagem ou ferramenta sendo adotada. Assim, um sistema pode ser decomposto em problemas menores, de modo que diferentes interesses possam ser abordados, e cada um dos problemas pode ser resolvido separadamente com uma abstração natural e, posteriormente, ser combinado para a produção de uma solução completa, conforme Figura 2.12.

A orientação a aspectos pode ser aplicada em sistemas de software de diferentes domínios e de diferentes níveis, desde aplicações de baixo nível (Engel e Spinczyk, 2009b), até aplicações de alto nível como no gerenciamento de transações web (Akkawi et al., 2001). Em paralelo, as pesquisas de Kiczales et al. (1997) têm mostrado que em sistemas com elevados níveis de complexidade, abstrações como a orientação a objetos tornaram-se inadequadas, com inserção de módulos, procedimentos, classes e objetos, que representam requisitos funcionais da aplicação. Nesse contexto, a orientação a aspectos torna-se interessante. A seguir, é apresentada a terminologia referente à orientação a aspectos. 


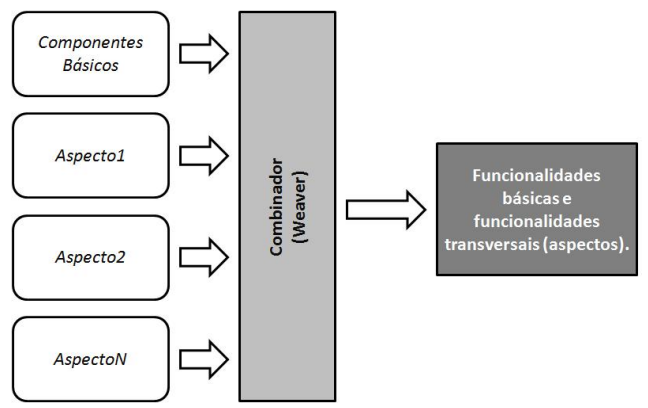

Figura 2.12: Sistema com Execução no Modelo Orientado a Aspectos (Adaptada de Kiczales et al. (1997)).

\subsubsection{Terminologia em Orientação a Aspectos}

Buscando estabelecer um consenso quanto à terminologia relacionado à POA na comunidade científicas e na indústria de software que utilizavam a POA, buscou-se uma padronização no $1^{o}$ Workshop Brasileiro de Desenvolvimento de Software Orientado a Aspectos. Dessa forma, esses termos, também destacados em Filman et al. (2004), Elrad et al. (2001b) e em The AspectJ Team (2006), com as respectivas traduções são:

Interesse (Concern): Diferentes tópicos e questões em uma abordagem de software, podendo se referir tanto a requisitos funcionais (por exemplo, elementos de escalabilidade) quanto a questões de implementação (por exemplo, estruturas usuais que devem ser armazenadas em buffer);

Interesse Entrelaçado (Crosscutting concern): Interesse cuja implementação tende a estar estrelaçada na execução de outros interesses;

Entrelaçamento de código (Code tangling): Execução de aplicação com códigos entrelaçados, por exemplo, implementação da separação de interesse entre uma funcionalidade entrelaçada e as demais funcionalidades;

Espalhamento de código (Code scaterring): Distribuição de trechos de código similares por vários módulos do programa, sendo necessário várias alterações de código em momentos de modificações;

Pontos de Junção (Join points): Locais de inserção de comportamentos adicionais no fluxo de programa, por exemplo, interesses adicionais em um código;

Adendo (Advice): Comportamento de interesse utilizado na execução de ponto de junção;

Designador de Junção (Pointcut designator): Construtor que descreve um grupo de junções, fornecendo o mecanismo que permite quantificações (Filman e Friedman, 2000);

Combinação (Weaving): Processo de combinação de módulo e comportamentos de interesses transversais em um programa executável;

Empacotador (Wrapper): Mecanismo de coordenação da execução de adendos nos pontos de junção, sendo que a execução pode ser realizada, antes, durante ou depois dos pontos de junção; e

Aspecto (Aspect): São elementos que encapsulam interesses que entrecortam as funcionalidades de um sistema. Um aspecto possui a especificação dos pontos de junção, e adendos para o comportamento de um sistema quando um ponto de junção for alcançado. 


\subsubsection{Modelagem de Sistemas Orientados a Aspectos}

O desenvolvimento orientado a aspectos apresenta um conjunto de técnicas, bem como métodos adotados para à análise e projeto de sistemas orientados a aspectos (Chavez, 2004), (Clarke e Baniassad, 2005). Nas pesquisas de Camargo et al. (2003), Clarke e Walker (2001), Clarke e Walker (2002), Rashid et al. (2003), Rocha (2005), Stein et al. (2002) e Suzuki e Yamamoto (1999) são apresentadas propostas do uso de UML, por meio de extensões dessa linguagem para a construção de modelos orientados a aspectos. Tem se usado em particular o mecanismo de estereótipos, tais como « aspect $\gg, \ll$ introduction $\gg$, $\ll$ introduces $\gg$, « advice $\gg$ e $\ll$ pointcut $\gg$, para representar estruturas específicas da POA.

Segundo Clarke e Walker (2001), o esteriótipo « aspect 》 representa os aspectos específicos de cada classe de aplicação, que entrecortam chamadas aos seus construtores por meio de pontos de junção, possuem interfaces bem definidas e podem ou não ser instanciados no momento da compilação. $\mathrm{O}$ esteriótipo « introduction 》 é um atributo ou elemento de programação, construtor ou método, que é adicionado a um tipo que pode estender a estrutura de tipos. O esteriótipo « advice $\gg$ representa o adendo, ou seja, um código que executa no ponto de junção, utilizado o escopo de execução. O esteriótipo « pointcut $\gg$ representa o escopo de execução, com representações do comportamento de entrelaçamento.

Os trabalhos de Chavez (2004) e Clarke e Baniassad (2005) utilizam a separação de interesses em um modelo de desenvolvimento orientado a aspectos. Esse método é denominado Theme e utiliza a orientação a aspectos em todas as fases de um projeto de software, com o encapsulamento dos temas em entidades transversais e básicas. Os temas transversais possuem em seus encapsulamentos comportamentos que se encontram dispersos por várias partes do sistema, e os temas básicos encapsulam funcionalidades básicas do âmbito do software construído. Os temas possuem correlacionamento duplo: (i) divisão de conceitos básicos e (ii) entrelaçamento de conceitos. A divisão de conceitos ocorre quando uma mesma entidade ou componente de projeto apresenta-se em vários temas. Esse cenário faz com que os temas possuam relacionamentos de sobreposição (do inglês, override) e intercalação (do inglês, merge). Quando um tema encapsula interesses transversais, sua composição acontece por meio de ligação de relacionamento (do inglês, bind).

\subsubsection{Tecnologias para a Implementação de Sistemas Orientados a Aspectos}

Para a implementação de sistemas orientados a aspecto, surgiu a necessidade de desenvolvimento de linguagens e ferramentas de implementação (Alwis (2002), Coady et al. (2001), Gal et al. (2001), Kiczales et al. (2001a), Kiczales et al. (2001b) e Kim (2002)). A pesquisa apresentada em Elrad et al. (2001a) apresenta as quatro estruturas básicas que as tecnologias de POA devem apresentar: (i) modelo de pontos de junção; (ii) um componente de identificação de pontos de junção; (iii) unidades de encapsulamento para as particularidades dos pontos de junção e relacionamentos; e (iv) procedimento de combinação dos componentes com o domínio base do sistema.

Uma diversidade de ambientes, ferramentas e linguagens têm sido desenvolvidos para apoiar o desenvolvimento de sistemas orientados a aspecto. Essas iniciativas foram direcionadas para diversas linguagens de programação, tais como, Java, C, C++, C\#, Smalltalk e PHP. 
Os principais frameworks ${ }^{15}$ para o desenvolvimento de programas em Java utilizando POA são: AspectWerkz (Bonér e Vasseur, 2004) que permite no momento da compilação a combinação de aspectos, com codificação realizada em linguagem XML e Java; JBoss AOP (Burke e Brock, 2003) que utiliza a linguagem Java na definição de adendos da implementação de uma interface Java padrão, enquanto que a linguagem XML é utilizada como Pointcut designator, e Spring AOP (Johnson et al., 2004) que é parte do Framework Spring ${ }^{16}$, e que viabiliza a execução de adendos e conjuntos de junções em classes da linguagem Java, sem necessidade de compilações especiais. Já o AspectJ (Kiczales et al., 2001a) é uma extensão da linguagem Java para dar apoio ao desenvolvimento de sistemas orientados a aspecto em Java. Em uma abordagem equiparada ao AspectJ, pode-se citar o AspectC++ (Gal et al., 2001), AspectC e AspectC\# (Kim, 2002), para C++, C e C\#, respectivamente.

Para o desenvolvimento de sistemas utilizando a POA para Smalltalk tem-se o AspectS (Hirschfeld, 2003). A implementação do AspectS foi desenvolvida para Squeak ${ }^{17}$, e sua abordagem para utilização é semelhante ao Aspect J. Também pode-se encontrar o AOPHP, desenvolvido por Stamey (2007) em Java 1.5 e implementada com o servidor Apache ${ }^{18}$, possibilitando a implementação de adendos, pontos de junção e empacotamento de adendos, dando suporte ao desenvolvimento de sistemas orientados a aspecto em PHP.

\subsubsection{Orientação a Aspectos no Desenvolvimento de Sistemas Em- barcados}

Considerando as vantagens da orientação a aspectos no desenvolvimento de sistemas de software, a POA tem sido também explorada no desenvolvimento de sistemas embarcados. Para o levantamento das pesquisas que envolvessem a POA na área de Sistemas Embarcados, foi conduzida uma Revisão Sistemática (Duarte e Nakagawa, 2012), sendo que essa técnica surgiu na área de Medicina e foi trazida para a Engenharia de Software com o objetivo de aperfeiçoar a tomada de decisão relacionada ao desenvolvimento de software por meio do conhecimento das melhores evidências resultantes de experiências (Kitchenham, 2004).

Como resultados da revisão sistemática, foram encontrados 25 trabalhos científicos que discutem a aplicação da orientação a aspectos no desenvolvimento de sistemas embarcados. Com base nesses trabalhos, foram identicadas particularidades e possibilidades de novas pesquisas nessa área. Além disso, esses trabalhos podem ser classificados em seis divisões principais de pesquisas correlatas e subáreas de atuação, conforme a Figura 2.13, na qual estão quantificados trabalhos identificados na revisão sistemática.

Dentre as divisões que possuem a maior quantidade de pesquisas está o uso da POA para sistemas embarcados em processamento distribuído (Beuche et al., 1999), (Haupt, 2006), (Silva et al., 2005), em particular na otimização de recursos por meio do uso de tecnologias de hardware (FPGA). As pesquisa na área de sistemas embarcados para processamento distribuído ocorreram devido à necessidade de sistemas embarcados desse tipo possuírem a necessidade de operação diante de cenários extremos de escassez de memória, processamento, sincronização e consumo de energia. Os exemplos desse cenário são os sistemas automotivos, no quais limosines podem ser consideradas sistemas distribuídos sobre rodas com cerca de

\footnotetext{
${ }^{15}$ É uma abstração que une códigos comuns entre vários projetos de software, provendo uma funcionalidade genérica.

${ }^{16}$ Spring Framework, um framework para apoio ao desenvolvimento de aplicações baseadas na plataforma J2EE.

${ }^{17}$ Disponível em http://www.squeak.org/ - Acessado em 12 de janeiro de 2011.

${ }^{18}$ Disponível em http://www.apache.org/ - Acessado em 12 de janeiro de 2011.
} 


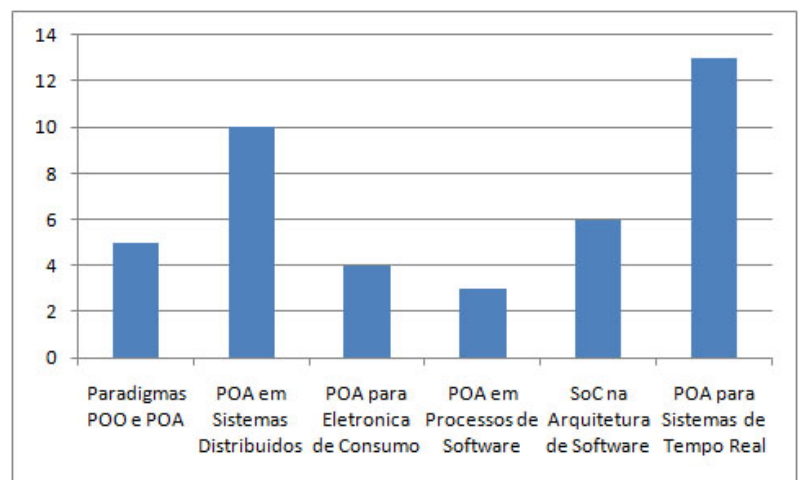

Figura 2.13: Subáreas de Pesquisas em Orientação a Aspectos e Sistemas Embarcados.

60 processadores em rede. Sistemas operacionais embarcados dedicados são necessários para manter o gerenciamento, adaptabilidade, portabilidade e eficiência de software nesses sistemas embarcados. Devido a esse cenário, inicialmente foi desenvolvido o PURE (Portable, universal runtime executive), um ambiente de execução orientado a aspectos desenvolvido para sistemas operacionais embarcados para aplicações distribuídas, conforme a Figura 2.14. De acordo com essa Figura, o sistema PURE possui um núcleo de execução nomeado de CORE, que implementa aspectos para utilizar objetos ativos e passivos da arquitetura. Como uma extensão do CORE, consta o NEXT abrigando pontos de junção de aplicações, endereçamentos, paralelismo por meio de threads e sincronização.

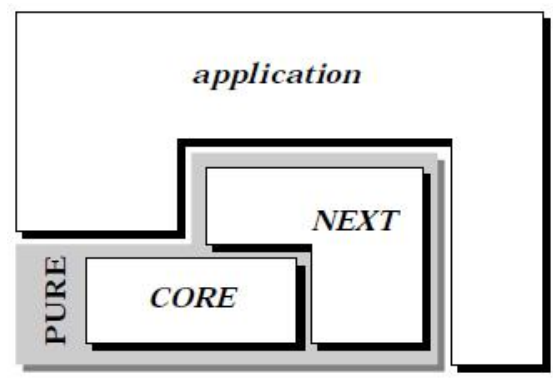

Figura 2.14: Arquitetura do Sistema PURE. (Beuche et al., 1999)

Na subárea de sistemas embarcados de tempo real, as pesquisas de Gustafsson et al. (2007) estrutura um modelo de orientação a aspectos que busca otimizar performance de software embarcados por meio da combinação de comportamento de elementos ativos de atualizações sob demanda, e esse modelo é nomeado de ECA (Event-conditionaction). Existe nesse modelo a exploração das vantagens da POA para gerenciamento da natureza de entrecortes das atualizações, e os experimentos dessa pesquisa foram realizados no sistema COMET (A component-based real-time database for automotive systems.), uma base de dados para software de sistemas embarcados automotivos.

Nas pesquisas de Wehrmeister et al. (2007) e Freitas et al. (2007), a orientação a aspectos foi utilizada em sistemas embarcardos de tempo real com processamento distribuído, mostrando, com isso, a multidisciplinaridade dessa linha de pesquisa. Isso aconteceu devido a esses sistemas possuírem requisitos não funcionais, com propriedades transversais, condicionais, e que possuem restrições espalhadas por todo o sistema. Devido a essa característica, abordagens puramente orientadas a objetos tornam-se limitadas para alguns desses cenários. Na Figura 2.15 é apresentado um framework proposto em Wehrmeister et al. (2007).

Esse framework, nomeado de DERAF (Distributed Embedded Real-time Aspects Framework), combina a utilização de aspectos com a RT-UML (Real Time UML), sendo que cada requisito não funcional é 
gerenciado por um ou mais aspectos. Como exemplos de aspectos, tem-se o TimmingAttributes e PeriodicTiming que adicionam atributos de tempo para objetos ativos (deadline, priority, start/end time $e$ etc). Existem outros aspectos nesse framework, tais como o DataFreshness e ConcurrentAccessControl que adaptam o modelo de execução de atividades.

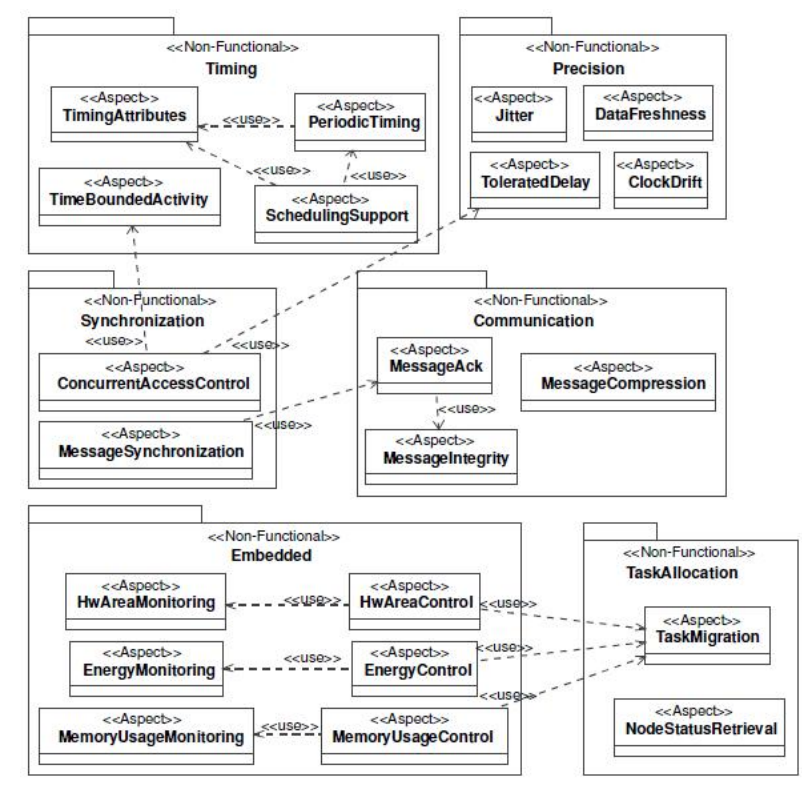

Figura 2.15: Framework DERAF (Wehrmeister et al., 2007)

Em uma outra perspectiva, há também trabalhos que buscam comparar a orientação a aspectos com outros paradigmas quanto a utilização no desenvolvimento de sistemas embarcados: Kartal e Schmidt (2007), Mikkonen (2007), e Freitas et al. (2007). Esses trabalhos mostram principalmente comparativos entre a utilização da orientação a objetos e a orientação a aspectos.

A pesquisa de Kartal e Schmidt (2007) apresenta uma avaliação experimental do uso de POA na utilização de interesses transversais em sistemas embarcados de tempo real. A separação de interesses é implementada em um mesmo tipo de projeto com o comparativo entre dois paradigmas: orientação a objetos e orientação a aspectos.

No experimento realizado por Kartal e Schmidt (2007) foram utilizadas ferramentas de tracing $^{19}$, para parâmetros de valor nulo (overflow), mudanças de range e recursos de sincronismo como interesses transversais. Os interesses transversais são primeiramente implementados utilizando técnicas de POO (Programação Orientada a Objetos) e posteriormente a POA.

As métricas de qualidade de software e os resultados alcançados com esse experimento são apresentados na Figura 2.16. As métricas foram extraídas de Chidamber e Kemerer (1994) e suas nomenclaturas são as seguintes: (a) WMC (Weighted Methods Per Class), (b) CBO (Coupling Between Objects), (c) RFC (do inglês, Response for a Class) e (d) LCM (Lack of Cohesion in Methods). Em consideração às características do experimento, com os interesses transversais ocupando cerca de $20 \%$ das linhas de código e implementação das métricas de Chidamber e Kemerer (1994), a POA melhorou os atributos de qualidade de software de forma expressiva para sistemas embarcados.

Em uma perspectiva paralela, Wehrmeister et al. (2007) comparou o uso da POA com a abordagem orientada de modelos. Posteriormente, Wehrmeister et al. (2008) realizou um comparativo entre os paradigmas orientado a objetos e orientado a aspectos para o desenvolvimento de DERTS (Distributed

\footnotetext{
${ }^{19}$ Termo do inglês, que é sinônimo de registro temporal de atividades.
} 


\section{CAPÍTULO 2. SISTEMAS EMBARCADOS E TV DIGITAL: UMA VISÃO GERAL}

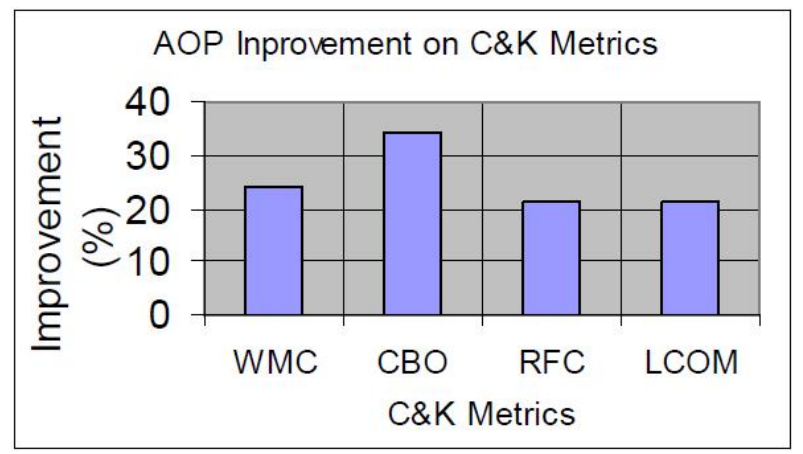

Figura 2.16: Métricas de Qualidade de Software (Kartal e Schmidt, 2007)

Embedded Real-Time System); para isso, foram utilizadas métricas de engenharia de software voltadas ao reúso e à qualidade. Dentre as métricas abordadas, foram consideradas: (a) separação de interesses, (b) acoplamento, (c) coesão, (d) quantidade de código e (e) número de atributos. As pesquisas desenvolvidas nesse âmbito são voltadas para a utilização dos interesses transversais na otimização de requisitos funcionais e não funcionais, visando, com isso, aplicações modulares.

Em um outro contexto, Fanjiang et al. (2010), Hundt (2009), Kartal e Schmidt (2007) e Saraiva et al. (2010) exploraram plataformas novas, as quais, eram sistemas embarcados para eletrônica de consumo, ou seja, retinham características direcionadas ao consumidor como, desempenho de recursos, usabilidade, linha de produto de desenvolvimento, dentre outras.

A pesquisa em Kartal e Schmidt (2007) possui múltiplas áreas de pesquisas, a qual, previamente apresentada com um comparativo entre paradigmas de programação, sendo aplicado em sistemas embarcados de tempo real para eletrônica de consumo. As métricas de qualidade de software apresentadas anteriormente não foram os únicos resultados alcançados, a pesquisa em questão também possui análise de resultados na área de desempenho computacional, por meio do uso de POA na camada de aplicação. A Figura 2.17 apresenta o experimento realizado, o qual, utilizou um dos modelos de telefone da marca Motorola, o software embarcado com POA está representado pelo diagrama, sendo o mesmo embarcado em um processador MVME5100, para posterior execução no dispositivo móvel.

Os testes de performace realizados nessa plataforma tiveram três métricas principais, desempenho da CPU, desempenho de memória e tempo de execução, conforme mostrado na Figura 2.18. A implementação dos interesses transversais com técnicas de POA removem as instâncias de classes para as funcionalidades similares em POO, as quais são usadas para execução de funcionalidades transversais.

As otimizações de desempenho são baseadas na evasão de criação de instâncias de classes e mensagens de comunicação ${ }^{20}$, ou seja, quando os interesses transversais são implementados utilizando técnicas de POA, as mensagens de comunicação que implementam funcionalidades transversais são substituídas por códigos de adendos, que são inseridos em componentes de códigos automaticamente, pelo combinador de aspectos. Isso ocorre afim de demonstrar que os recursos de comunicação entre duas tarefas em execução requerem um tempo de execução maior, devido a maior exigência de recursos de processamento. Como POA nesse cenários reduz essa comunicação, o sistema possui um tempo de execução e recursos de processamento otimizados.

Em um cenário parecido, o contexto abordado na pesquisa de Hundt (2009) possui uma análise da utilização de POA na camada de aplicação, visando otimizações de desempenho. Nessa pesquisa, são identificados os mecanismos de execução de aspectos em diferentes níveis de interação com $\mathrm{JVM}^{21}$ (do

\footnotetext{
${ }^{20}$ Comunicação entre classes e objetos no caso de utilização de POO.

${ }^{21}$ Camada de software intermediária utilizadas nas tecnologias em Java.
} 


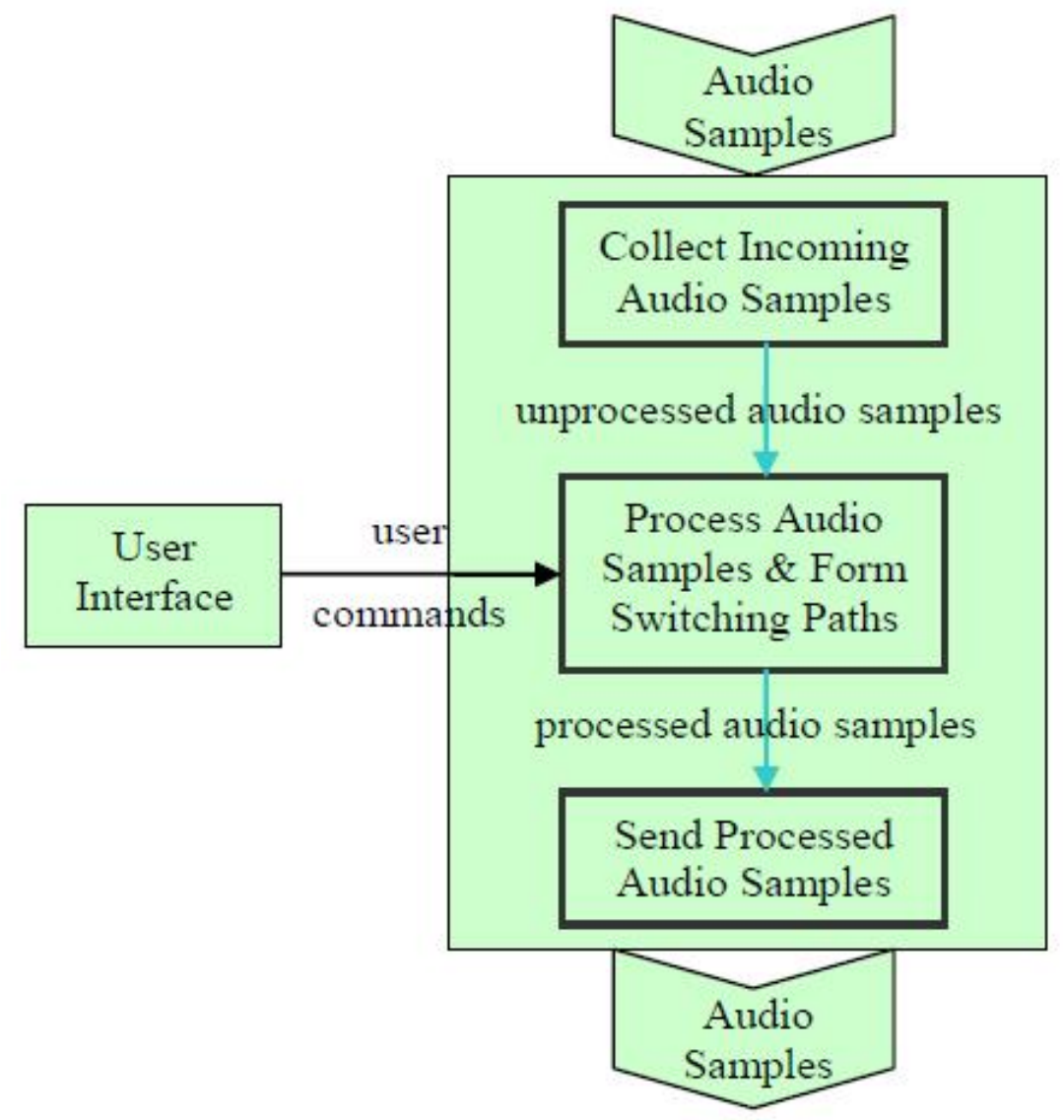

Figura 2.17: Arquitetura Software do Sistema de Aúdio, do Dispositivo Móvel da marca Motorola MVME5100 (Adaptado de Kartal e Schmidt (2007))

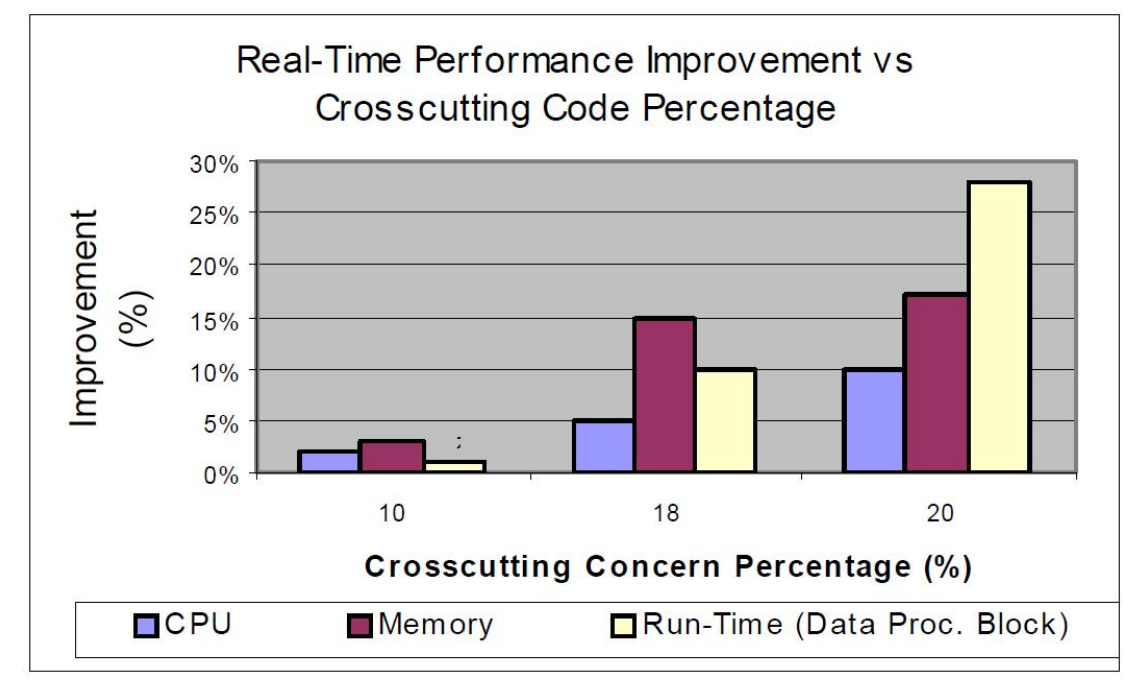

Figura 2.18: Resultado dos Comparativos de Performance Presentes em Kartal e Schmidt (2007)

inglês, Java Virtual Machine). Os experimentos iniciais dessa pesquisa foram realizados em dispositivos móveis, assim como apresentado em (Kartal e Schmidt, 2007), e os resultados alcançados demonstraram 
ganhos no tempo de execução, o que geraram posteriores otimizações avançadas, com uso de técnicas de modularização para dispositivos com aplicações baseadas em Java.

No trabalho de Hundt (2009), o modelo de otimizações com uso de POA na camada de aplicação, as características exploradas para uso de recursos, foram as fontes de overhead $;^{22}$ encontradas, na execução de aplicações na linguagem OT/ $\mathrm{J}^{23}$ (Herrmann et al., 2007), a qual é utilizada em sistemas embarcados para eletrônica de consumo baseados em Java.

Dentre as características da linguagem OT/J, suas políticas específicas para utilização do aspecto podem ser para uso explícito, implícito, globalmente ou por meio de threads ${ }^{24}$. Foram identificadas como as três principais fontes de overhead;(a) o processo de registro de aspectos, (b)ativação do aspecto, com a consulta de métodos de uma classe em OT/J para uma biblioteca, e (c) o processo de dispatch do aspecto, na existência de chamadas adicionais a instância após a compilação, como nos casos de herança e polimorfismo do método. Esse processo é demonstrado na Figura 2.19.

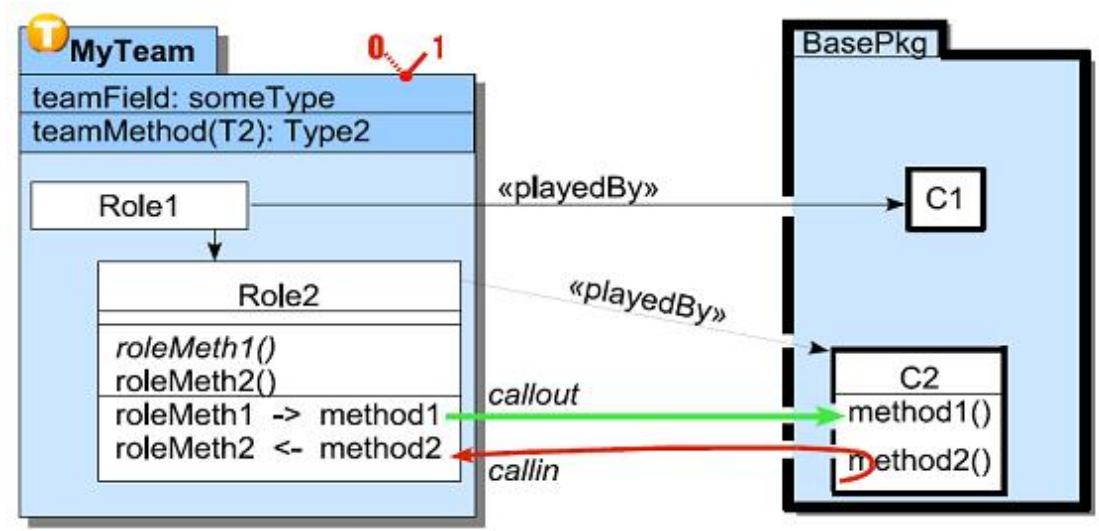

Figura 2.19: Exemplo de Estrutura de Times de Objetos com Consulta para um Pacote (Adaptado de Herrmann et al. (2009))

Na extensão da arquitetura proposta em Hundt (2009), foram propostas estruturas de dados adicionais, utilizadas para armazenar informações de dados importantes para execução de código orientado a aspectos, como códigos de registro, informações implícitas de heranças e instruções adicionais em bytecodes usadas para suportar a execução do aspecto. Por fim, para a execução do processo de combinação de aspectos, foi desenvolvida uma API (abreviação do inglês, Application Program Interface) de interface, para acesso as informações armazenadas nas estruturas de dados na JVM, e a infra-estrutura de execução final desse projeto foi inserida na documentação da OT/J.

Os resultados foram alcançados nessa pesquisa, com a execução de um método team-level ${ }^{25} 3000$ vezes, causando 3000 subseqüentes ativações e desativações. As instâncias team foram utilizadas em ordem linear de crescimento. O gráfico da Figura 2.20 realiza um comparativo de desempenho da aplicação, executada com a estrutura original (JamVM orig) e com a estrutura nova (JamVM ait).

Em outra perspectiva, ainda na área de sistemas embarcados para eletrônica de consumo, na pesquisa de Fanjiang et al. (2010) foram exploradas caracterítiscas presentes em dispositivos móveis, os quais se

\footnotetext{
${ }^{22}$ Overhead é geralmente considerado qualquer processamento ou armazenamento em excesso, seja de tempo de computação, de memória, de largura de banda ou qualquer outro recurso que seja requerido para ser utilizado ou gasto para executar uma determinada tarefa.

${ }^{23}$ Abreviação do termo Object Teams Java

${ }^{24}$ Forma de um processo computacional dividir a si mesmo em duas ou mais tarefas que podem ser executadas concorrentemente.

${ }^{25}$ Nomenclatura de método dentro da linguagem $\mathrm{OT} / \mathrm{J}$.
} 


\section{CAPÍTULO 2. SISTEMAS EMBARCADOS E TV DIGITAL: UMA VISÃO GERAL}

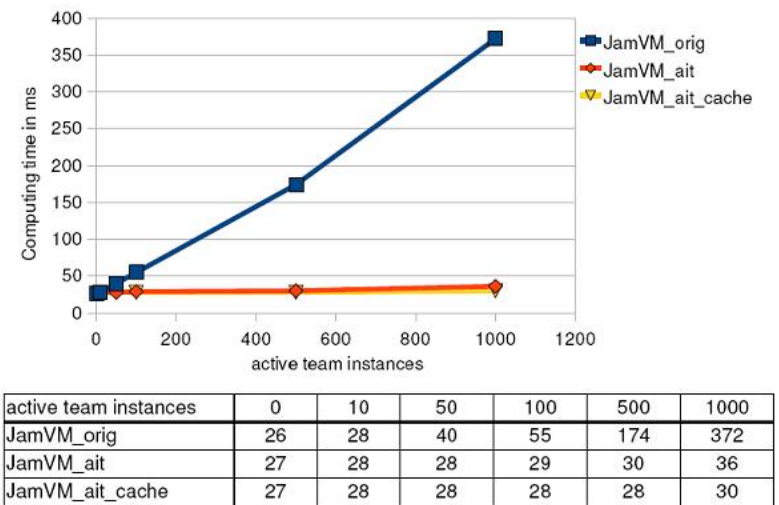

Figura 2.20: Resultados do Modelo Implementado na Pesquisa de Hundt (2009).

enquadram na área de sistemas embarcados para eletrônica (Jonker e Linnartz, 2004). Uma das características principais de software de dispositivos móveis é a dependência de contexto ${ }^{26}$, essa característica traz nesse cenário o uso de interesses transversais.

A modelagem de sistemas embarcados para eletrônica de consumo que possuam características de separação de interesses é crescente. Os sensores e atuadores sensíveis a contexto são tecnologias presentes nesse cerne, e a contribuição de Fanjiang et al. (2010) é a modelagem de um processo de desenvolvimento orientado a aspectos, com notações extendidas de UML voltadas para software embarcado de dispositivos móveis, com uso dos interesses transversais para tratamento das funcionalidades reativas desse contexto.

O metamodelo estrutural dessa pesquisa foi apresentado na Figura 2.21, e os esteriótipos adotados são respectivamente; (a) 《SensorAspect 》, o qual, é o aspecto que indica os sensores recebendo dados do ambiente em um determinado contexto.; (b) « ContextAspect $\gg$, que é o aspecto indicador de condições do ambiente de transição e standalone, identificando o contexto específico de cada situação.; (c) « ReactionAspect 》, o qual, é aspecto responsável pela definição do comportamento reativo do sistema.

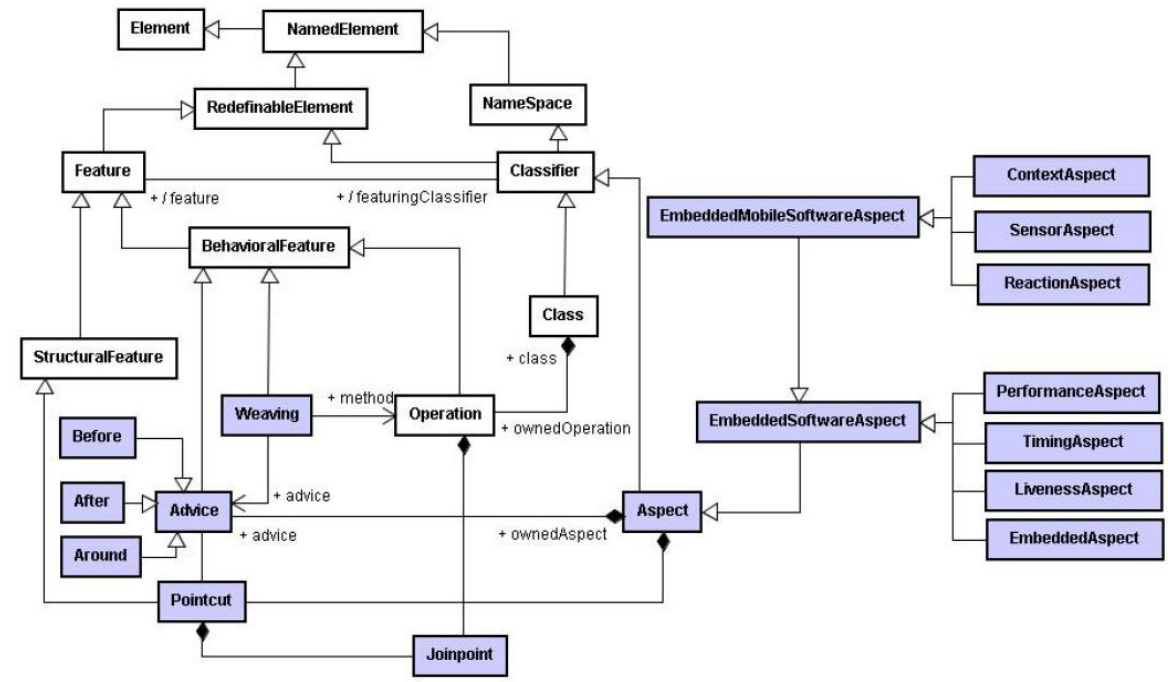

Figura 2.21: Framework do Metamodelo Estrutural presente em Fanjiang et al. (2010)

\footnotetext{
${ }^{26}$ Percepção do contexto atual do usuário, de acordo com sua mobilidade.
} 
No cenário de sistemas embarcados para eletrônica de consumo, foram constatados iniciativas na área de TV Digital Saraiva et al. (2010) utilizou POA no desenvolvimento na camada de middleware para a plataforma de TV Digital brasileira (SBTVD - Sistema Brasileiro de Televisão Digital Interativa), com o objetivo de realizar refatoração no Ginga ${ }^{27}$, visando, com isso, auto-gerenciamento. O middleware resultante da pesquisa de Saraiva et al. (2010) foi nomeado de GingaForAll. Baseado em linha de produto de software (software product line), a estrutura de seus componentes visa principalmente a modularização de funcionalidades dispersas, como por exemplo em tunning (sintonização). O processo de desenvolvimento baseado em modelos foi utilizado em alto nível de abstração para permitir o auto-gerenciamento de funcionalidades comuns e variáveis, objetivando com isso gerenciamento de assets de código e modelos reconfiguráveis. Essa modificações realizadas no middleware Ginga promoveu facilidades de customização de aplicações e recursos da plataforma.

O Ginga teve desenvolvimento em virtude da junção de dois middlewares anteriores, FlexTV (Leite et al., 2006) e MAESTRO (Soares, 2006). O FlexTV é responsável pelo ambiente procedural do middleware, incluía um conjunto de APIs já consolidadas em outros middlewares e funcionalidades inovadoras, como a possibilidade de comunicação com múltiplos dispositivos. O MAESTRO é responsável pelo ambiente declarativo do middleware, com foco em oferecer facilidade do sincronismo espaço-temporal em ambiente multimídia, por meio da linguagem declarativa $\mathrm{NCL}^{28}$ (abreviação do inglês, Nested Context Language) e a linguagem de script Lua ${ }^{29}$. Assim, o Ginga tem nativo em sua arquitetura o ambiente procedural (Ginga-J) e declarativo (Ginga-NCL), com um estrutura de núcleo para suporte e orquestração desses ambientes (Ginga COMMON CORE), com a sua respectiva normatização em International Telecommunications Union (2001). A arquitetura do middleware Ginga é apresentada na Figura 2.22.

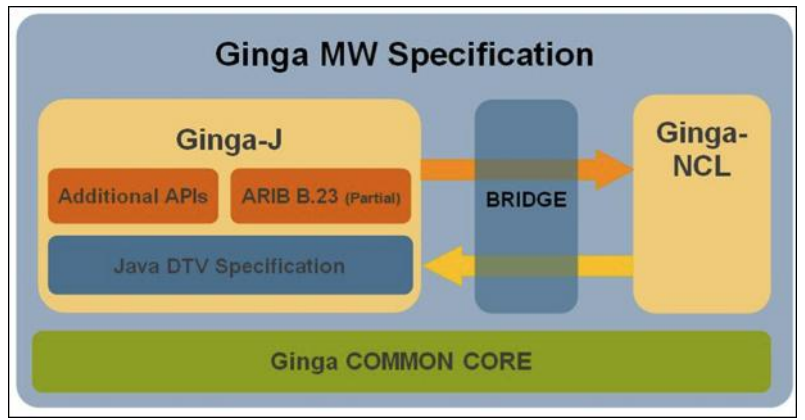

Figura 2.22: Arquitetura do middleware para TV Digital Brasileira (International Telecommunications Union, 2001)

Na pesquisa de Saraiva et al. (2010), as contribuições foram geradas no Ginga-CC ${ }^{30}$ e, inicialmente, a abordagem utilizada para identificação dos interesses transversais foi a análise baseada em funcionalidades (do inglês, Feature-Oriented Analysis), proposta por Conejero et al. (2009) para descoberta de famílias de produtos.

Sob uma perspectiva similar, foram utilizadas nesse cenário métricas de qualidade. As métricas de avaliação utilizadas foram CBO, MPC (do inglês, Messaging Passing Coupling) e DAC (do inglês, Data Abstraction Coupling), as quais apresentaram que os interesses transversais a serem implementados seriam $\ll$ ResourceManagement $\gg, \ll$ Synchronization $\gg, \ll$ Transmission/Distribution $\gg$, conforme apresentado na Figura 2.23.

\footnotetext{
${ }^{27}$ middleware para TV Digital Brasileira.

${ }^{28}$ www.ncl.org.br - Acessado em 12 de janeiro de 2011.

${ }^{29}$ www.lua.org - Acessado em 12 de janeiro de 2011.

${ }^{30}$ Abreviação para Ginga COMMON CORE
} 


\section{CAPÍTULO 2. SISTEMAS EMBARCADOS E TV DIGITAL: UMA VISÃO GERAL}

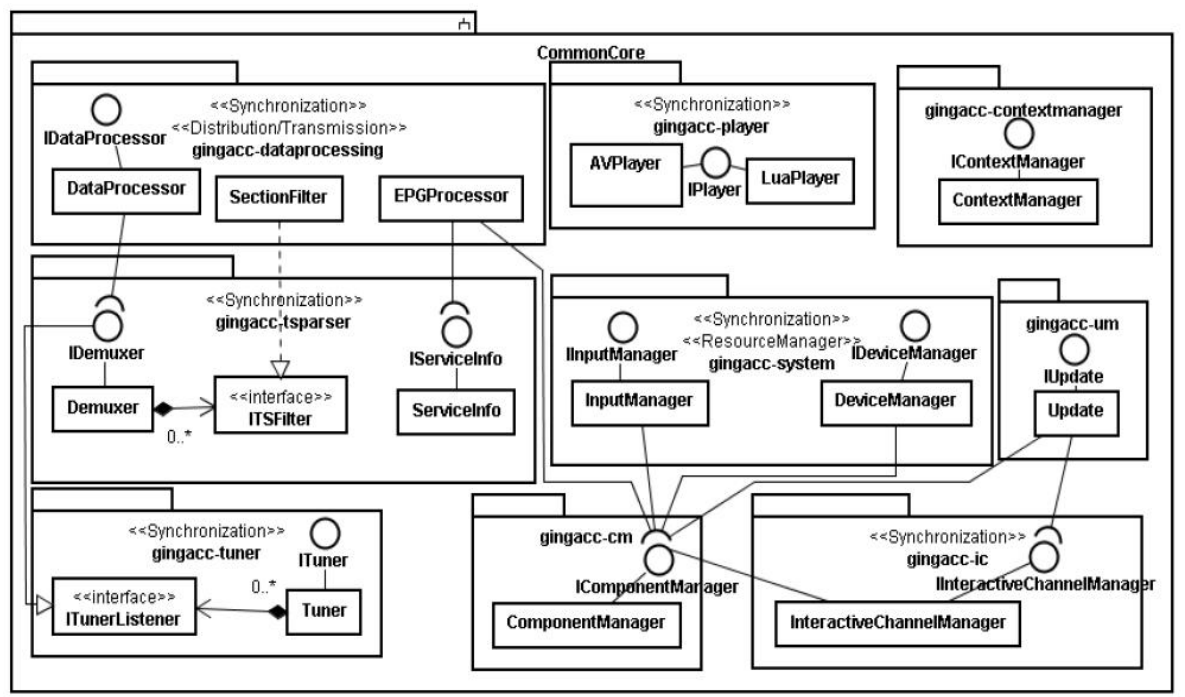

Figura 2.23: Diagrama de Classes do Ginga-CC com Modelagem Orientada a Aspectos (Saraiva et al., 2010)

\subsection{Considerações Finais}

No desenvolvimento de sistemas embarcados, pode-se observar pesquisas em diversas subáreas, envolvendo profissionais com diferentes especialidades, bem como diversas plataformas de atuação. Dentre essas subáreas, existe o desenvolvimento de sistemas embarcados para eletrônica de consumo, relacionado aos produtos e pesquisas que tenham interação mais direta com o consumidor, com contribuições para a plataforma televisiva, dispositivos móveis, indústria de entretenimento e ambientes inteligentes. Em virtude disso, diversas pesquisa foram desenvolvidas no tocante às arquiteturas desses sistemas, considerando os elementos interrelacionados, comportamentos dos elementos e estruturas de comunicação entre hardware e software.

Em especial foi apresentado um panorama geral da área de pesquisa para TV Digital, apresentado sua infraestrutura física e alguns modelos de negócios. O próximo capítulo apresenta de uma maneira mais detalhada os conceitos relacionados à arquitetura de software para a plataforma de TV Digital, o ambiente de desenvolvimento de software, camada de middleware e pesquisas relacionadas. 


\section{Arquitetura de Software e Arquitetura de Referência}

\subsection{Considerações Iniciais}

Em decorrência da crescente demanda de novos sistemas de software de maior complexidade tem se feito necessários modelos de representação e desenvolvimento novos. Estruturas e processos, nomenclaturas, gerência de configuração e arquiteturas exercem funções prioritárias no desenvolvimento de sistemas. Com um enfoque especial para as Arquiteturas de Software, as quais, são estruturas essenciais na organização, estruturação, qualidade de sistemas, tendo em vista suas metodologias de desenvolvimento, padrões de projeto e arquiteturas de referência (Bass e Clements, 2003).

Ainda nesse contexto, arquiteturas de referência tem-se apresentado como um tipo especial de arquiteturas, provendo direcionamentos para sistemas dos mais diversificados domínio de atuação. Bass e Clements (2003) descreve arquitetura de referência como um conjunto de abstrações de funcionalidades de um domínio, estruturadas de forma a auxiliar no desenvolvimento de um conjunto de sistemas.

Paralelo a isso, a arquitetura de software têm sido explorada para o desenvolvimento de pesquisa na área de TV Digital interativa(Morris e Smith-Chaigneau, 2005), visando com isso otimizações em processos de desenvolvimento, robustez de aplicações, controle de processos de negócios, estruturação de linhas de produtos, dentre outras vantagens.

Na Seção 3.2 são apresentados conceitos e terminologias relacionados à arquitetura de software e arquitetura de referência. Na Seção 3.3, os conceitos relacionados a plataforma de TV Digital interativa são apresentados. Por fim, na Seção 3.4 são apresentadas as considerações finais deste capítulo. 


\subsection{Arquitetura de Software e Arquitetura de Referência}

Devido a crescente demanda de organização de sistemas de software uma nova área de pesquisa surgiu no contexto de Arquitetura de Software. A primeira pesquisa pautada nessa área foi no final da década de 60 (Kruchten et al., 2006), porém, no decorrer dos próximos 20 anos seu uso passou a ser associado com a arquitetura de sistemas, com estruturas de hardware, ou com um grupo pontual de computadores. Entretanto, o reconhecimento, penetração acadêmica e industrial ocorreu no início da década de 90 (Boehm, 2006).

As arquiteturas de software são consideradas as estruturas centrais de um sistema (Clements et al., 2002). De acordo com Bass e Clements (2003), a arquitetura compreende as propriedades perceptíveis de elementos de software e o relacionamento entre as partes componentes. As arquiteturas abstraem o comportamento desses sistemas, sem a apresentação de detalhes de implementações, com descrição dos relacionamentos e conexões entre componentes.

De acordo com Wasserman (1996), a área de Arquitetura de Software é considerada o componente discriminante para manutenibilidade de sistemas e inserção de aspectos de qualidade. Em comum acordo com essa visão, a $S E I^{1}$ determina a forte relação entre requisitos de qualidade e suas arquiteturas, sendo interpretadas como os divisores fundamentais para qualidade de sistemas. Conforme Nakagawa et al. (2009b), os requisitos funcionais e não-funcionais são diretamente influenciados pelas metas empreendidas pela arquitetura de software. Posteriormente, serão apresentadas as terminologias referentes à arquitetura de software, primordiais ao entendimento dessa pesquisa.

\subsubsection{Terminologias e Conceitos}

Em pesquisas na área de Arquitetura de Software, existem inúmeros conceitos empregados para cada segmento, porém, um vocabulário tem sido estabelecido. Os termos mais comumente utilizados nesse vocabulário são (SEI, 2011); instância arquitetural, estilo arquitetural, padrão arquitetural, arquitetura concreta, modelo de referência e arquitetura de referência.

A arquitetura concentra consiste em um grupo de especificações, que direcionam o desenvolvimento individual dos módulos de software pertencentes a um sistema (SEI, 2011). Esse conceito, esta ligado diretamente à instância arquitetural, o qual é uma arquitetura concreta específica aplicada em um determinado domínio.

Ainda nesse contexto, o estilo arquitetural trata-se das delimitações ou restrições de uma instância arquitetural ou de uma arquitetura concreta (Bass e Clements, 2003). Esse mesmo conceito de estilo arquitetural permite que os desenvolvedores e engenheiros de software determinem o domínio específico do sistema de software em questão. Tem-se como exemplo o estilo Cliente-Servidor, o qual define a existência de duas entidades distintas e dependentes: o cliente e o servidor. O conceito de estilo arquitetural também define protocolos de comunicação entre cada entidade envolvida.

Uma das peculiaridades dos estilos arquiteturais são as referências a atributos de qualidade, dando aos engenheiros de software a possibilidade de escolha entre estilos, com o foco no cenário do projeto. Tendo como exemplo, alguns estilos são orientados segundo a segurança das aplicações, outros ao desempenho, outros ao modelo de negócios, e a decisão de estilos arquiteturais implica em uma série de fatores no início de um projeto.

\footnotetext{
${ }^{1}$ Termo do inglês, Software Engineering Institute - http://www.sei.cmu.edu/
} 


\section{CAPÍTULO 3. ARQUITETURA DE SOFTWARE E ARQUITETURA DE} REFERÊNCIA

O conceito modelo de referência, segundo Bass e Clements (2003), consiste na divisão de funcionalidades de um módulo conjunto e os relacionamentos dessas divisões. Essas divisões implicam em partes conjuntas para o fiel funcionamento dos sistemas de um domínio, ou na resolução de um problema. Um exemplo desse cenário é apresentado em OASIS (2006), que define a partir de um modelo abstrato o conceito de $S O A$ ( Service Oriented Architecture).

Em um cenário paralelo, enquando que um modelo de referência consiste na unificação de conceitos mínimos, relacionamentos independentes de padrões e axiomas (OASIS, 2006), as arquiteturas de referência são conceituadas como algutinações de modelos de referência em elementos de software, que implementam funcionalidades em um domínio de maneira cooperativa segundo Angelov et al. (2009), Bass e Clements (2003) e Mendes (2002). Ou seja, arquiteturas de referências são implementações de modelos de refência de maneira organizada e sistemática, agrupando funcionalidades e permitindo reúso e qualidade de sistemas. A Figura 3.1 expressa o relacionamento entre as terminologias.

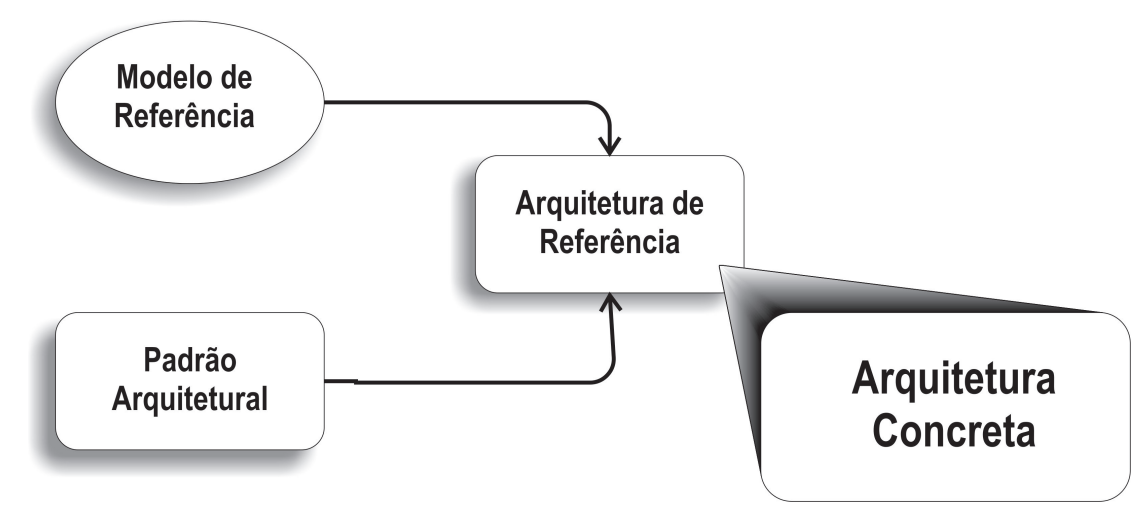

Figura 3.1: Relações entre Terminologias (adaptado de Bass e Clements (2003)

Frente à importância empregada a arquitetura de software no desenvolvimento de sistemas, existem iniciativas em relação à sua representação. Face a essa necessidade e até mesmo a adequação da arquitetura de software para fins industriais, sua caracterização precisava ter ausência de ambiguidade, como por exemplo com o uso de ADLs (Architectural Description Languages) (Medvidovic e Taylor, 2000), a qual, fornecem abstrações eficientes para modelagem de grandes sistemas.

Ainda nesse contexto, a UML ( Unified Modeling Language) tem emergido como uma das formas mais utilizadas para a representação de arquiteturas de software, com sua adoção acadêmica e no ambiente industrial (Medvidovic et al., 2002). Essa linguagem possui um extenso número de ferramentas e construções pré-definidas, além disso, possui representações de fácil manipulação pelos desenvolvedores.

\subsubsection{Arquitetura de Referência}

Arquiteturas de referência tem apresentado destaque na área de arquiteturas de software, evidenciando e norteando especificações em diferentes domínios de aplicação (Angelov et al., 2008). Esse cenário ocorre devido à influência direta da arquitetura de referência na qualidade das arquiteturas concretas.

De acordo com Muller (2008a), as arquiteturas de referência orientam o desenvolvimento da arquitetua concreta, promovendo com isso integração entre sistemas e componentes. Portanto, uma arquitetura de referência pode ser utilzada em vários contextos, resultando no desenvolvimento de instâncias arquiteturais distintas, facilintado as metas e prazos estipulados pelos stakeholders ${ }^{2}$.

\footnotetext{
${ }^{2}$ Termo utilizado em arquitetura de software referente às partes interessadas que devem estar de acordo com as práticas de governança corporativa executadas pela empresa.
} 
$\mathrm{Na}$ área de arquiteturas de referências existem diversas arquiteturas sendo propostas, tendo como exemplo aquelas apresentadas por Arsanjani et al. (2007), Choi et al. (2009), Eickelmann e Richardson (1996), Nakagawa (2006), Nakagawa et al. (2007). Mesmo com essa diversidade de iniciativas, poucas arquiteturas de referência são encontradas para o domínio de eletrônica de consumo.

\subsubsection{Processo para Construção de Arquiteturas de Referência}

Considerando-se a relevância de arquiteturas de referência, investigar os meios pelos quais elas são construídas é interessante. Pode-se então encontrar trabalhos relacionados ao projeto de arquiteturas de referência (Bayer et al., 2004; Eklund et al., 2005; Muller, 2008b). Nesse contexto, o grupo de trabalho ao qual faz parte este projeto de mestrado propôs o ProSA-RA (Nakagawa et al., 2011, 2009a,b), um processo que visa a construção, representação e avaliação de arquiteturas de referência orientadas a aspectos. Para a aplicação do ProSA-RA, conforme ilustrado na Figura 3.2, são conduzidos os seguintes passos:

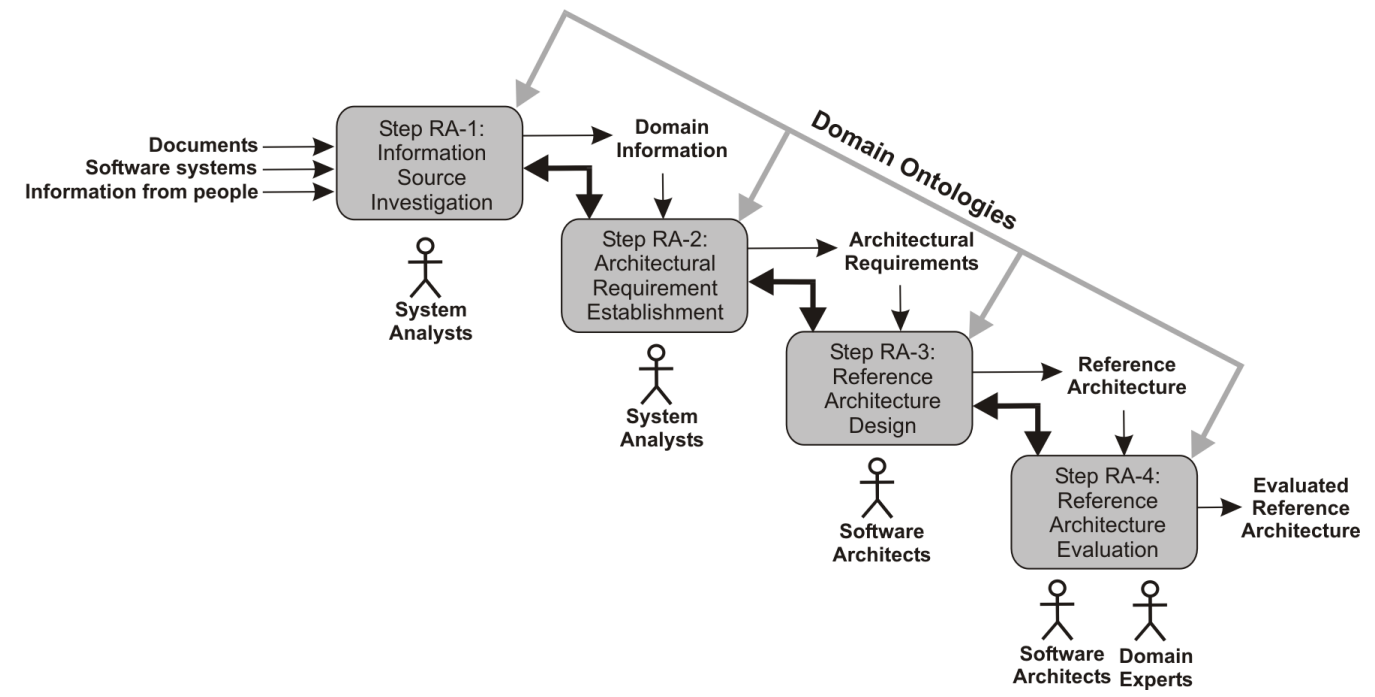

Figura 3.2: Estrutura Geral do ProSA-RA (Nakagawa et al., 2009b)

- Passo RA-1 - Identificação das Fontes de Informação: refere-se à investigação e seleção de fontes de informação, objetivando o levantamento de informações sobre o domínio para o qual está sendo criada a arquitetura de referência;

- Passo RA-2 - Estabelecimento dos Requisitos Arquiteturais: refere-se a identificação dos requisitos da arquitetura de referência com base nas fontes de informações. Em síntese, primeiramente identificam-se os requisitos de sistemas do domínio e, em seguida, estabelecem-se quais são os requisitos específicos da arquitetura de referência, isto é, os requisitos arquiteturais. A seguir, os requisitos arquiteturais são mapeados para os conceitos do domínio alvo. Nesse ponto, identificam-se aqueles conceitos que possuem característica transversal, por exemplo, a persistência que é um interesse transversal. Dessa forma, identificam-se os aspectos arquiteturais, ou seja, módulos em nível de arquitetura que agregam interesses transversais;

- Passo RA-3 - Projeto da Arquitetura de Referência: a partir dos requisitos arquiteturais e dos conceitos identificados no passo anterior, é estabelecida uma descrição arquitetural da arquitetura de referência, considerando-se também padrões e estilos arquiteturais. A seguir, constrói-se a descrição arquitetural utilizando-se visões arquiteturais. Particularmente, as visões de módulos, de 
tempo de execução, de implantação e conceitual têm sido propostos para descrever essas arquiteturas (Nakagawa e Maldonado, 2008); contudo, outras visões podem ser relevantes considerando-se diferentes stakeholders ou o uso e a natureza da arquitetura de referência; e

- Passo RA-4 - Avaliação da Arquitetura de Referência: Nesse ponto pode-se utilizar uma checklist para a avaliação dessas arquiteturas ou então conduzir estudos de caso ou experimentos para observar a viabilidade da arquitetura proposta.

Destaca-se que o ProSA-RA tem sido utilizado para guiar a construção de arquiteturas de referência de diferentes domínios, tais como para ferramentas de visualização (Nakagawa et al., 2009b) e ambientes educacionais (Fioravanti et al., 2010). Vale ainda destacar que tem sido também utilizado para a construção de uma arquitetura de referência para sistemas marítimos (Borg, 2011).

\subsection{Arquitetura de Software para TV Digital Interativa}

Na plataforma de TV Digital, a principal estrutura responsável por prover um ambiente para a execução de aplicações interativas e entrega de serviços aos terminais de TVDI é o middleware. De acordo com Issarny et al. (2007), o middleware é uma camada de software entre o sistema operacional de rede e aplicações, que abstrai do desenvolvedor de software especificidades da plataforma e oferece soluções de reúso de software, principalmente para problemas de heterogeneidade, interoperabilidade e segurança.

De uma maneira geral, a definição de middleware está associada a sistemas distribuídos, trata-se de uma estrutura que permite aplicações distribuídas comunicarem-se de maneira transparente e usarem funções da plataforma de maneira independente do hardware, sistema operacional, interfaces de rede e armazenamento. Um middleware fornece entidades ou componentes de software reusáveis que permitem a construção de aplicações interoperáveis entre plataformas heterogêneas (Issarny et al., 2007).

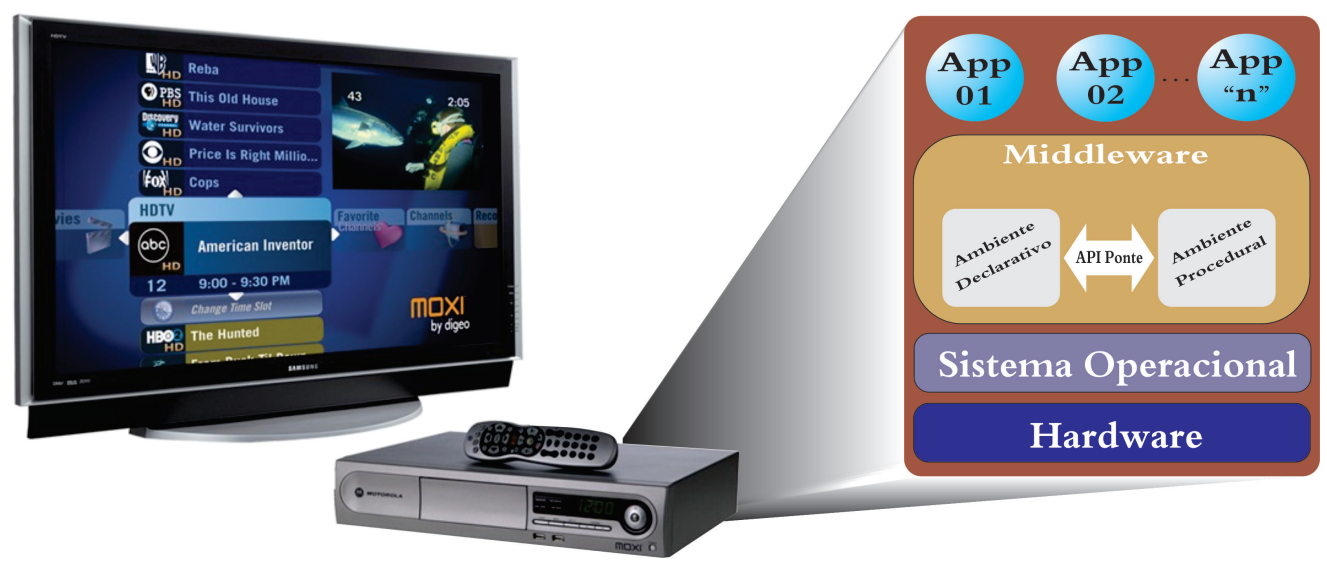

Figura 3.3: Arquitetura STB

A evolução das tecnologias em middleware para TV Digital foi ditada pela crescente necessidade de harmonização entre os padrões e tecnologias existentes. O cenário antigo do mercado em middleware é caracterizado por um conjunto de tecnologias fechadas, num mercado vertical dominado por poucas empresas. A não existência de padrões abertos dificultava o crescimento dos serviços para a TV Digital e o avanço da tecnologia em geral. Entre os principais middlewares proprietários podem ser citados; Microsoft TV (www.microsoft.com/mediaroom/), Galio (www.antlimited.com/galio bbtv.asp), MYRIO (http : 
//www.myriosolution.com), MediaHighWay (http : //www.mediahighway.com.au), NDS, Imagenio (www.imageniotelevision.com), OpenTV (www.opentvdigital.com) e PowerTV (www.powertvmedia.com) (Morris e Smith-Chaigneau, 2005).

Com o surgimento de padrões abertos, MHP(Multimedia Home Plataform), OCAP(OpenCable Application Platform), ACAP(Advanced Common Application Platform for Interactive Television), DASE (DTV Application Software Enviroment), ARIB(Association of Radio Industries and Businesses), GINGA ${ }^{3}$, muitas tecnologias já existentes puderam ser incorporadas às especificações de middleware, por meio de um conjunto de API's que tratam de funções específicas do $\operatorname{STB}($ Set Top Box). Como exemplos podem ser citados os consórcios HAVi (Home Audio Video Interoperability), DAVIC (Digital Audio Video Council) e JavaTV, tecnologias XML, HTML, ECMAScript, JavaScript, NCL, SMIL, LUA, etc. A Figura 3.4 ilustra a convergência dos middlewares de um mercado fechado e vertical para um aberto, harmonizado e horizontal. Conforme a Figura a tendência de harmonização é crescente; os esforços das principais entidades que definem padrões de middleware dos sistemas de TV Digital culminaram com a especificação de um conjunto de componentes comum a todos os padrões, definido como GEM (Globally Executable $M H P)$.

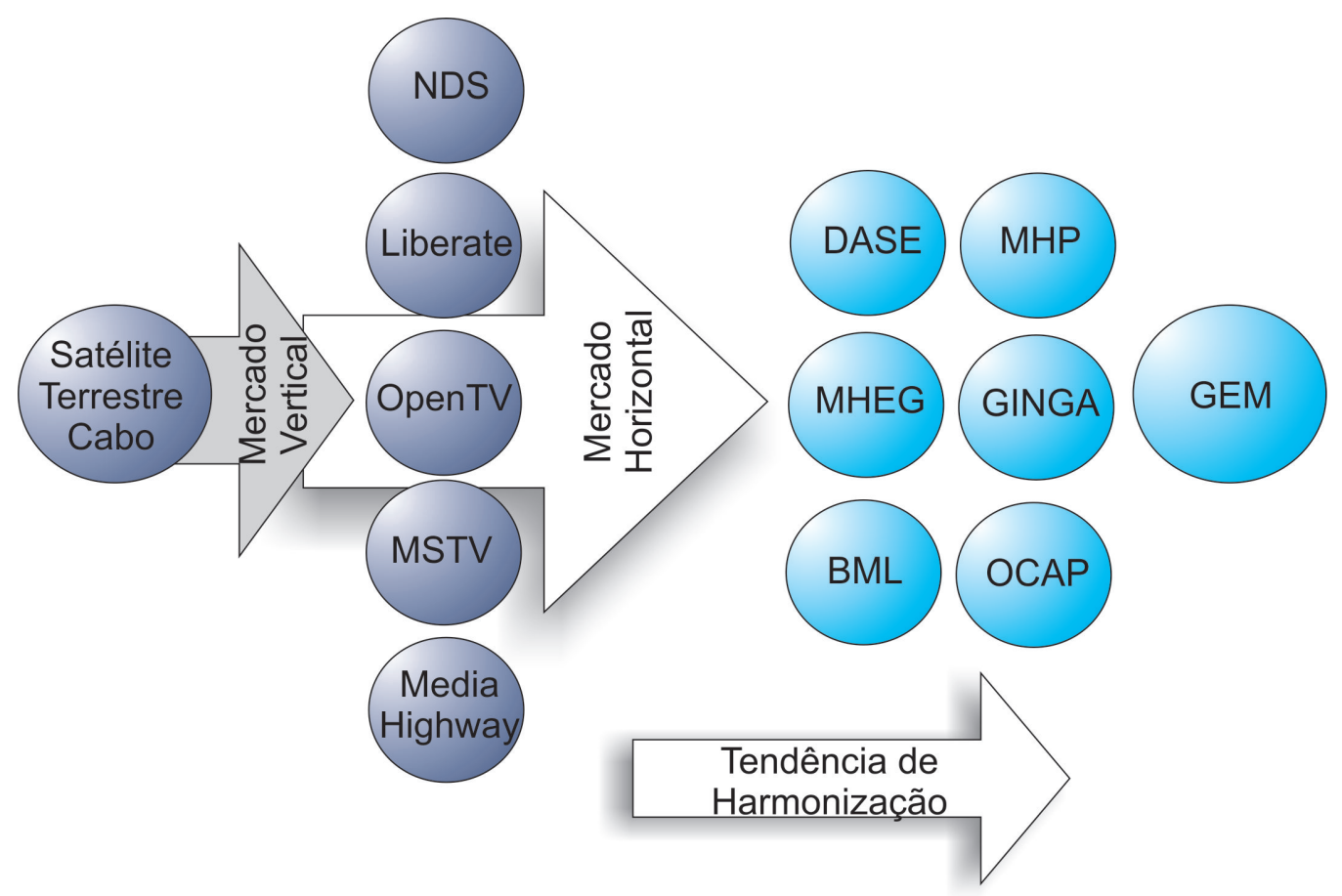

Figura 3.4: Padronizações de Middleware para TVD (Adaptado de (Morris e Smith-Chaigneau, 2005)

As tecnologias que agregam middlewares em TV Digital podem ser agrupadas em dois grandes grupos, diferenciados principalmente pelo tipo de suporte dado ao desenvolvimento de aplicações para a plataforma. Dessa forma, os middlewares para TV Digital dos padrões existentes apresentam ambientes para programação procedural e declarativa de aplicativos. Na primeira, os middlewares oferecem máquinas de execução que interpretam código escrito em alguma linguagem de programação (por exemplo, Java). Nesses ambientes, geralmente um miniaplicativo controlado por uma máquina de estados executa sobre o middleware, comunicando-se com um gerenciador de aplicações, utilizando e liberando recursos

\footnotetext{
${ }^{3}$ Abreviação do middleware brasileiro.
} 


\section{CAPÍTULO 3. ARQUITETURA DE SOFTWARE E ARQUITETURA DE}

REFERÊNCIA

do sistema. Na segunda forma, uma máquina de apresentação trata de interpretar um documento escrito em algum padrão de gramática, criando uma estrutura em árvore correspondente, a partir da qual realiza o controle sobre o aplicativo (Soares et al., 2006).

Aplicações que executam sobre middleware procedural utilizam linguagem de programação cujo estilo decompõe o problema numa implementação algorítmica. Embora possuam um nível de abstração menor que aplicações declarativas, apresentam vantagens como o reúso de componentes ou a possibilidade de criação dos próprios componentes para execução de tarefas específicas. Como exemplos de middleware procedural podem ser citados: B.23, (OCAP-J), (ACAP-J), DASE, (DVB-J), GEM e GINGA-J.

As normas ITU (International Telecommunication Union) J.200 (Worldwide Common Core - Application Environment for Digital Interactive Television Services) e J.202 (Harmonization of Procedural Content Format for Interactive TV Applications) (ITU, 2011) definem algumas das funções para ambientes procedurais que devem ser implementados nos middlewares de TV Digital. Basicamente, há um conjunto de componentes derivados da tecnologia Java que oferecem funcionalidades básicas. Além desses, há o suporte para apresentação de mídia com o JMF (Java Media Framework); controle de áudio/vídeo com API's HAVi, DAViC; acesso a informações de serviços e canal de transmissão com JavaTV. A Figura 3.5 ilustra a arquitetura definida para ambientes procedurais pela ITU J.200 e J.202.

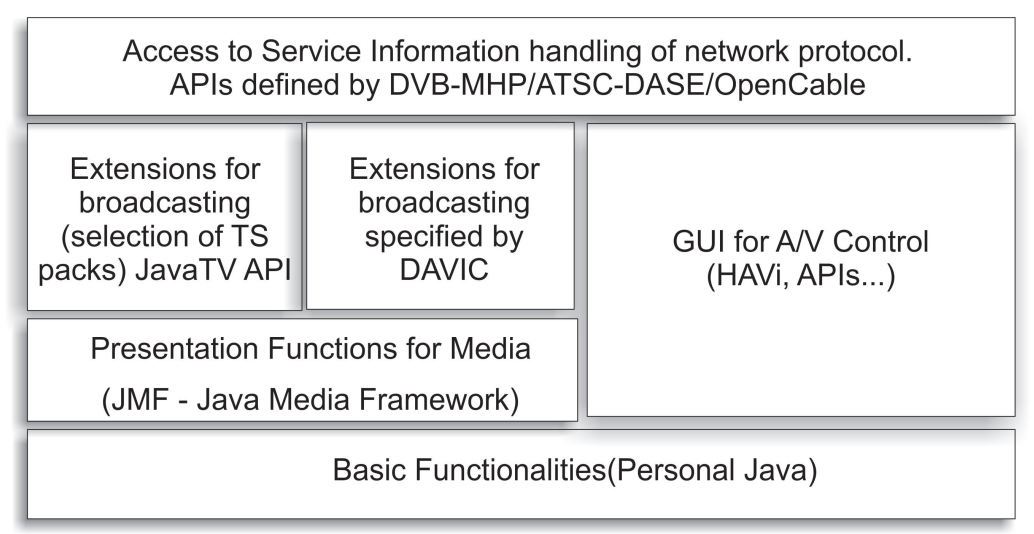

Figura 3.5: Norma ITU J.202 para Middleware Procedural (Adaptado de (ITU, 2011)

As três últimas tecnologias citadas HAVi, DAViC e JavaTV, compõem a maioria dos middlewares procedurais existentes. Foram desenvolvidas independentes dos padrões de middleware, mas acabaram sendo posteriormente incorporadas a eles. Essas APIs são apresentadas a seguir:

Home Audio Vídeo Interoperability(HAVi): Padrão definido por um consórcio formado por companhias de produtos de consumo audiovisuais que especifica uma forma comum para conexão e interoperação de dispositivos de áudio e vídeo digital. A especificação permite que dispositivos de áudio e vídeo interajam entre si, definindo mecanismos que permitem que as funcionalidades de um dispositivo possam ser remotamente usadas e controladas por outro dispositivo (HAVi, 2011). Para a TV, esse padrão foi adotado por prover um conjunto de APIs com suporte específicos para TV, tais como funções para lidar com gráficos e construção de interface com o usuário. O HAVi Level 2UI (HAVi nível 2, Interface do Usuário), por exemplo, é um subconjimto do HAVi que possui funcionalidades extras que tornam possível o desenvolvimento de interfaces com o usuário com componentes específicos para o ambiente de TV Digital. Além dos recursos citados, o HAVi define ainda uma arquitetura de software distribuída cujos elementos asseguram interoperabilidade e implementam serviços de gerenciamento de rede e comunicação entre dispositivos. 
Digital Audio Visual Council (DAViC) O DAViC é uma associação de diversos setores da indústria audiovisual, agregando companhias entre fabricantes de produtos eletrônicos e de telecomunicações, emissoras, agências de governo e organizações de pesquisa em mais de 25 países (DAVIC, 2011). A ideia por trás do consórcio é de fornecer interoperabilidade, com ênfase nas informações audiovisuais digitais interativas. Para obter essa interoperabilidade, as especificações DAViC definem interfaces em diversos pontos de referência onde cada uma é caracterizada como um conjunto de fluxos de informações e protocolos, que tratam de padrões específicos sobre disposição de informações. Assim, as especificações DAViC dispõem sobre formatos de conteúdo para diversos tipos de objetos (fonte, texto, hipertexto, áudio e vídeo), incluindo também facilidades para o controle de áudio e legenda.

JavaTV E uma extensão da plataforma Java que fornece funcionalidades aos desenvolvedores para a produção de conteúdo para TV Digital (Sun, 2009a). O principal objetivo da tecnologia é viabilizar o desenvolvimento de aplicações interativas portáveis, que são independentes da tecnologia da rede de difusão. A API provê uma abstração que permite aos aplicativos escritos em Java denominados Xlets $^{4}$ e interpretados na máquina virtual dentro da arquitetura de um receptor de TV Digital, obter informações sobre determinado serviço de uma forma independente do protocolo utilizado. Dessa forma, uma aplicação pode ser reusada em uma variedade de ambientes. Embora desenvolvida para ser utilizada em arquiteturas específicas para STBs, a API pode ser utilizada em ambiente computacional convencional (Calder et al., 2004), tanto que a maioria dos emuladores atuais de TV Digital dispõem de recursos do JavaTV. A implementação de referência JavaTV consiste, em essência, de um conjunto de grupos funcionais ou pacotes Java, a maioria sub-pacotes de javax.tv.

No que se refere à middleware declarativo, aplicações para esses ambientes utilizam linguagens e estruturas (geralmente baseadas em XML) que enfatizam uma descrição declarativa do problema. Embora apresentem um maior nível de abstração, são projetadas para um domínio específico. Em TV Digital, linguagens declarativas são utilizadas principalmente para criar apresentações multimídia com separação entre conteúdo e estrutura da apresentação e sincronização temporal de mídias (vídeo, áudio, imagens, texto, etc.) (Barbosa e Soares, 2008). Como exemplos de middleware declarativos podem ser citados DVB-HTML(Union, 2003), Ginga-NCL(Moreno et al., 2011), ISDB-BML(Soares et al., 2010), OCAP-X(Morris e Smith-Chaigneau, 2005), DASE-HTML(Oliveira et al., 2008).

As normas ITU J.200 e J.20I (Harmonization of Declarative Content Format for Interactive TV Applications) definem algumas das funções para ambientes declarativos que devem ser implementados nos middleware de TV Digital. Conforme a Figura 3.6 o middleware declarativo possui suporte á conteúdo ECMAScript e XHTML (Extensible HiperText Markup Language), por meio de máquinas apropriadas, além dc suporte à formatação com CSS (Cascading Style Sheets), extensão para XML (XML Parser) e um browser sobre o qual o conteúdo é executado. O browser permite ainda acesso às funcionalidades do receptor (mídias, interfaces de rede, canal de retorno, etc.).

Todos os padrões abertos de TV Digital oferecem suporte à middleware procedural e declarativo compatíveis com as normas ITU. Entretanto, para cada um dos ambientes, os middlewares utilizam além das tecnologias padrão (HAVi, DAVIC, JavaTV, XHTML, XML), tecnologias específicas criadas para atender às necessidades de cada middleware. Assim, o DVB-MHP definiu o DVB-HTML declarativo, o ARIB definiu o ARIB-BML (Broadcast Markup Language) e o ISDTV definiu o Ginga-NCL, com base no modelo NCM (Nested Context Model) discutido adiante. É interessante ressaltar que as normas ITU ainda

\footnotetext{
${ }^{4}$ Interface em Java para execução de aplicações na plataforma de TV Digital.
} 
CAPÍTULO 3. ARQUITETURA DE SOFTWARE E ARQUITETURA DE REFERÊNCIA

\begin{tabular}{|c|c|c|c|}
\hline CSS & \multicolumn{2}{|c|}{$\begin{array}{l}\text { ECMAScript Engine } \\
\text { and DOM }\end{array}$} & $\begin{array}{c}\text { HTML/XHTML } \\
\text { DTD }\end{array}$ \\
\hline \multicolumn{3}{|c|}{ TV Extensions } & XML Parser \\
\hline \multicolumn{4}{|c|}{ User Agent (Browser) } \\
\hline $\begin{array}{c}\text { Receiver } \\
\text { Functionalities }\end{array}$ & $\begin{array}{c}\text { Digital } \\
\text { Video (MPEG) }\end{array}$ & Monor & Network \\
\hline
\end{tabular}

Figura 3.6: Norma ITU J.202 para Middleware Declarativo (Adaptado de (ITU, 2011)

especificam um mecanismo de interação entre os dois ambientes, por meio de um componentes-ponte que permite a troca de recursos entre a parte procedural e a parte declarativa dos middlewares. A Tabela 3.1 resume os ambientes de aplicações para receptores fixos e móveis dos padrões de TV Digital.

Tabela 3.1: Plataformas de Software

\begin{tabular}{|c|c|c|c|}
\hline middleware & Sistema TVDi & Ambiente Declarativo & Ambiente Procedural \\
\hline$\overline{\mathrm{ACAP}}$ & ATSC & $\begin{array}{l}\text { ACAP-X: XHTML } \\
\text { ECMAScript }\end{array}$ & ACAP-J: Java \\
\hline MHP & $\mathrm{DVB} / \mathrm{T}$ & $\begin{array}{l}\text { DVB-HTML: XHTML } \\
\text { e ECMAScript }\end{array}$ & DVB-J: Java \\
\hline ARIB-BML & ISDB/T & $\begin{array}{l}\text { ARIB-BML: XHTML e } \\
\text { ECMAScript }\end{array}$ & GEM: Java \\
\hline GINGA & SBTVD & $\begin{array}{l}\text { GINGA-NCL: NCL e } \\
\text { Lua }\end{array}$ & Ginga-J: Java \\
\hline
\end{tabular}

\subsubsection{Middleware MHP e Convergência para o GEM}

O MHP é um padrão aberto adotado para a entrega de aplicações e serviços aos terminais (STBs) da rede de difusão do sistema DVB. O middleware é composto por API's e tecnologias associadas dentre as citadas anteriormente, além de um conjunto de testes de conformidade definidos pelas normas do DVB e do European Telecommunications Standards Institute - ETSI (ETSI, 2011). O MHP é um padrão consolidado, e é derivado interação entre serviços de Internet e difusão. Exemplos de aplicações desse ambiente incluem Browser para E-mail e API Java para acesso a Internet, conforme a Figura 3.7.

Além do MHP 1.0.x e 1.1.x, um outro componente especificado é o GEM, o qual, foi definido pela norma ETSI TS 102819 (ETSI, 2011) como subconjunto do MHP 1.0.2, e apresenta uma API estável e genérica como base de referência para interoperabilidade entre padrões. Aplicações GEM-compatíveis podem executar em qualquer middleware que agregue o subconjunto GEM. O GEM define um conjunto de funcionalidades MHP que são tecnologicamente neutras, ou seja, remove qualquer API que seja específica do MHP, adicionando mecanismos de substituição para adequar-se às outras tecnologias.

Uma das funções mais importantes em um middleware de TV Digital é o gerenciamento de aplicativos e recursos da plataforma, além da possibilidade de intercomunicação entre aplicativos em plataformas distribuídas (por exemplo, em serviços interativos de chat pela TV). Os aplicativos MHP e de outros middleware em geral têm um rigoroso mecanismo para gerenciar o ciclo de vida das aplicações e a liberação 


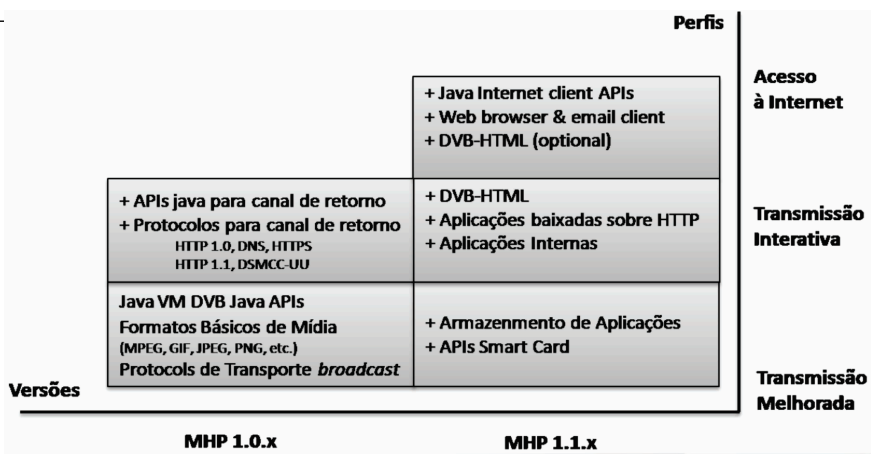

Figura 3.7: MHP Profiles (Adaptado de (Morris e Smith-Chaigneau, 2005)

para uso de recursos da plataforma. O principal modelo adotado para gerenciamento de aplicações é o definido pelo JavaTV, denominado Xlet Lifecycle Model (Calder et al., 2004), no qual figuram três elementos:

Xlet Miniaplicativo Java que tem o ciclo de vida caracterizado como máquina de estados. Um Xlet possui os estados de Carregado (pronto para ser ativado), Ativo(em execução), Pausado (em espera) ou Destruído (eliminado da plataforma).

Application Manager Gerenciador de Xlets, ou seja, entidade que controla os recursos do ambiente de software do receptor, bem como aplicações que nele executam.

XletContext Componente pelo qual Xlet e Application Manager interagem.

Para cada miniaplicativo Xlet no receptor, o ciclo de vida é definido desde o momento em que ele é criado até quando for destruído. O Xlet atua no ambiente executando sucessivas mudanças de estado, controladas pelo Application Manager por meio do XletContext. Sobre o middleware, uma típica seqüência de execução de um Xlet, em interação com o gerenciador, é caracterizada pelos seguintes passos descritos na Tabela 3.2 e ilustrados na Figura 3.8;

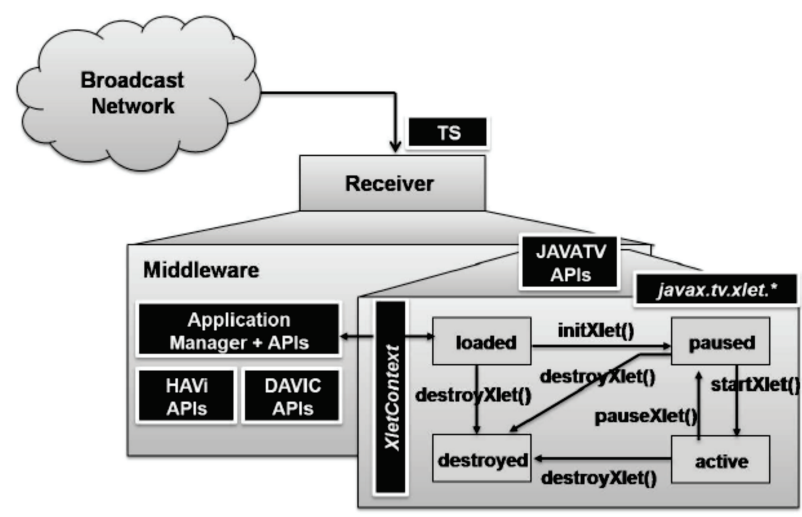

Figura 3.8: Modelo de Ciclo de Vida JavaTV (Adaptado de (Morris e Smith-Chaigneau, 2005)

Outra característica importante do ambiente de aplicações para TV Digital é o suporte para a comunicação entre aplicativos. O IXC (Abreviação do inglês, Inter-Xlet Communication) é um mecanismo de interação entre aplicações de TV Digital que tem como base o compartilhamento de objetos relacionados a funcionalidades providas por Xlets, registrados numa entidade pública, visíveis e acessíveis por outros 
Tabela 3.2: Etapas de interação entre Xlet e Application Manager

\begin{tabular}{|c|c|}
\hline Application Manager & Xlet \\
\hline $\begin{array}{l}\text { O Application Manager, ao receber um fluxo de } \\
\text { dados e decodificá-lo, identifica um possível apli- } \\
\text { cativo que irá executar e criar uma instância de } \\
\text { um xlet. }\end{array}$ & $\begin{array}{l}\text { Um construtor default é chamado par ao } \\
\text { xlet que em estado de loaded. }\end{array}$ \\
\hline $\begin{array}{l}\text { O Application Manager obtém o contexto ne- } \\
\text { cessário para a inicialização do xlet por meio da } \\
\text { criação de um objeto XletContext. }\end{array}$ & $\begin{array}{l}\text { O xlet usa o objeto XletContext para ini- } \\
\text { cializar a si próprio, entrando no estado } \\
\text { de paused. }\end{array}$ \\
\hline $\begin{array}{l}\text { O Application Manager decide se é o momento } \\
\text { oportuno para o xlet realizar seu serviço, po- } \\
\text { dendo notificá-lo a entrado no estado de active. }\end{array}$ & $\begin{array}{l}\text { O xlet adquire os recursos necessários a } \\
\text { sua execução e começa a realizar seu ser- } \\
\text { viço. }\end{array}$ \\
\hline $\begin{array}{l}\text { O Application Manager não necessita mais da } \\
\text { realização do serviço pelo xlet sinalizando-o a } \\
\text { interromper sua execução. }\end{array}$ & $\begin{array}{l}\text { O xlet interrompe a execução de seu ser- } \\
\text { viço liberando os recursos utilizados até o } \\
\text { momento entrando em estado de paused e } \\
\text { aguardando o próximo comando do geren- } \\
\text { ciador. }\end{array}$ \\
\hline $\begin{array}{l}\text { O Application Manager decide que não é mais } \\
\text { necessário a execução do xlet. Então o gerencia- } \\
\text { dor sinaliza ao xlet que este deve ser destruído. }\end{array}$ & $\begin{array}{l}\text { O xlet prepara-se para ser finalizado, sal- } \\
\text { vando as conFigurações atuais como prefe- } \\
\text { rências do usuário. O xlet entra no estado } \\
\text { de destroyed e deixa de existir no ambiente } \\
\text { de execução. }\end{array}$ \\
\hline
\end{tabular}

Xlets. O modelo do IXC baseia-se no RMI (Abreviação do inglês, Remote Method Invocation), sistema de comunicação distribuída baseado em Java que permite a aplicativos acessarem funcionalidades presentes em JVMs remotas.

O IXC existe principalmente para garantir segurança no acesso aos dados compartilhados por Xlets diferentes (Morris e Smith-Chaigneau, 2005). MHP e OCAP permitem a Xlets registrar funcionalidades (por meio de uma operação BIND) em uma entidade padrão, o IXC Registry, que por sua vez publica um objeto que protege o acesso direto ao objeto registrado pelo Xlet. Quando um outro Xlet necessita usar uma função registrada no IXC ele realiza uma consulta (por meio da operação LOOKUP), obtendo uma cópia do objeto (conhecida como classe Stub) que previamente registrou a função. Isso garante a proteção ao objeto original, assim como ocorre no Java RMI. No MHP, o IXC é implementado nos grupos funcionais de org.dvb.ixc.*.

\subsubsection{Arquitetura e Componentes do GINGA}

A arquitetura do middleware para TV Digital definido pelo SBTVD(Sistema Brasileiro de Televisão Digital) para compor o sistema ISDTV é compatível com as especificações ITU J.200, J.201 e J.202, ao apresentar tecnologias que suportam a programação de aplicações interativas sob os dois paradigmas de programação: o procedural, com suporte dado pela máquina de execução Ginga-J e o declarativo, representado pela máquina de apresentação Ginga-NCL. Conforme ilustra a Figura 3.9, a especificação do Ginga determina um ambiente de aplicações composto pelos seguintes elementos estruturais.

- Máquina de apresentação e Máquina de execução, de acordo com a ABNT NBR 15606-2; 
CAPÍTULO 3. ARQUITETURA DE SOFTWARE E ARQUITETURA DE REFERÊNCIA

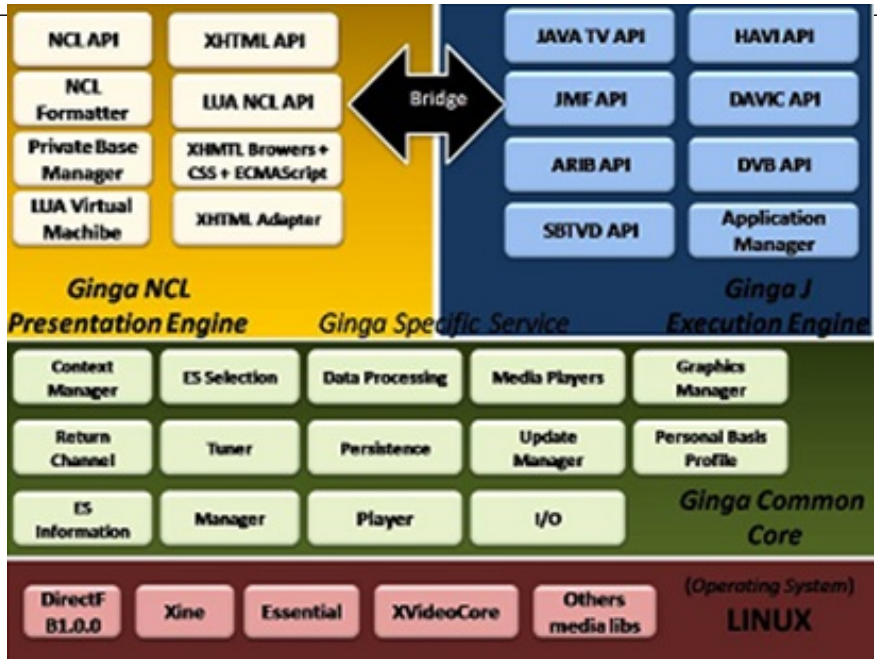

Figura 3.9: Estrutura do Ambiente do Middleware Ginga.

- Ponte entre as duas máquinas - Mecanismo para aplicações que permite o mapeamento bidirecional entre as APIs Java e os objetos e métodos do DOM (Document Object Model), ECMAScript, LUAScript que compõem o domínio declarativo;

- Monitor do ciclo de vida da aplicação: Aplicação ou recurso do sistema operacional para controle do estado do software. Sua função inclui a gerência de todo o ciclo de vida da aplicação, incluindo inicialização, término e controle. O monitor do ciclo de vida de aplicações é definido no ambiente procedural;

- Aplicações Programadas para a máquina de apresentação, execução ou para ambas;

- Outras Mídias incluem stream de mídia como áudio/dados ou monomídias como imagens/textos;

- Software Nativo inclui software legado ou escrito usando APIs com novas funcionalidades;

O cenário de definição do middleware procedural brasileiro está, até o período em que foi escrita esta Dissertação, com alguns pontos em aberto. Apesar da especificação apontar o GEM como API integrável às demais do ISDTV, o fórum do SBTVD, por razões de ordem econômica e/ou política, levantou a discussão sobre a possibilidade de incorporar, em detrimento do GEM, APIs fabricadas pela Sun Microsystems, sob a tecnologia JavaDTV. O JavaDTV é derivado da especificação JavaME para dispositivos de consumo portáteis, composto pelo CDC (Connected Device Configuration), PBP (Personal Basis Profile), FP (Foundation Profile) e JavaTV, apresentado algumas particularidades como a API de widgets LWUIT (Lightweight User Interface Toolkit), derivado dos pacotes gráficos do (Abstract Window Toolkit) e Swing Java.

Sob o ponto de vista declarativo, o middleware Ginga-NCL, especificado pela ABNT NBR 15606-2, fornece uma máquina de apresentação para conteúdo multimídia baseado em scripts. O subsistema lógico do Ginga-NCL processa documentos no padrão da linguagem NCL, própria para a apresentação e sincronização de conteúdo multimídia, baseada no modelo NCM . Além de NCL, há suporte também para conteúdo ECMAScript, CSS e XHTML. O Ginga-NCL permite também a inserção de programação dinâmica às aplicações, por meio do suporte dado a execução de código escrito na linguagem LUA. Para cada tipo de mídia que executa sobre o Ginga-NCL (JPEG, PNG, MPEG, scripts, ou LUA), existem componentes correspondentes, numa camada abaixo do middleware, no Ginga Common Core, os chamados Adapters. 


\subsection{Considerações Finais}

Neste capítulo foram apresentados tópicos relacionados à arquitetura de software e arquitetura de referência, sendo esses imprescindíveis no contexto dessa pesquisa. Foram também apresentados conceitos, tecnologias e características de arquiteturas de software para aplicações em TV Digital interativa. É válido comentar que não foram encontrados no levantamento bibliográfico, trabalhos que tratem especificamente de arquiteturas de referência para o domínio de TV Digital interativa. Nesse contexto, o próximo capítulo apresenta uma arquitetura de referência para aplicações desse domínio que foi estabelecida por meio da condução deste trabalho. 



\section{ArciTV: Arquitetura de referência para}

\subsection{Considerações Iniciais}

Neste capítulo, é apresentada a arquitetura de referência para a plataforma de TV Digital interativa, denominada ArciTV (Reference Architecture for Interactive Digital Television). A arquitetura de referência apresentada tem como escopo apoiar a fase de projeto arquitetural para construção de aplicações interativas, no contexto do ambiente procedural para TV Digital.

Para a construção da ArciTV foi utilizado o ProSA-RA (Nakagawa et al., 2009b), um processo de desenvolvimento de arquiteturas de referência. Esse processo provê os passos de desenvolvimento arquitetural, desde o levantamento de fontes de informações do domínio, até a fase de avaliação da arquitetura constituída. Visando uma descrição mais detalhada da arquitetura proposta, foram utilizadas três visões arquiteturais: (a) visão em módulos, (b) visão em tempo de execução, e (c) visão de implantação. Além disso, foi constituída a visão geral da arquitetura, com estruturas de alto nível com o objetivo de facilitar o entendimento de seus componentes.

Este capítulo está organizado de acordo com os passo de desenvolvimento do ProSA-RA. Dessa forma, a Seção 4.2 contem a contextualização do cenário de atuação da ArciTV, ou seja, o ambiente de execução da arquitetura. a Seção 4.3 contêm as fontes de informações para a geração da ArciTV, ou seja, os artigos, pesquisas, teses e dissertações da área de TV Digital, fontes de uma revisão de sistemática. Em sequência, a Seção 4.4 apresenta o levantamento de requisitos arquiteturais para a geração da ArciTV. $\mathrm{Na}$ Seção 4.5, são organizadas as visões arquiteturas, com a visão geral da arquitetura, visão em módulo e visão de implantação. A Seção 4.6, apresenta a validação da arquitetura de referência. 


\subsection{Contexto de Atuação da ArciTV}

As aplicações na área de TV Digital interativa são divididas em dois ambientes de execução, o ambiente declarativo e o ambiente procedural, conforme a Figura 4.1. De acordo com esse contexto, as aplicações em TV Digital podem ser desenvolvidas por meio de linguagens de marcação ${ }^{1}$ onde basicamente o conteúdo seria renderizado ${ }^{2}$ na tela do receptor digital, conforme o ambiente web (DAVIC, 2011). Para esse contexto do ambiente declarativo, as aplicações que tivessem uma simples execução por meio da exibição de telas e conteúdo estático como textos e imagens seriam exibidas sem soluções algoritmas avançadas.

Ainda nesse contexto, para aplicações que necessitem de implementações algoritmas mais apuradas, como apresentado por de Ávila e Zorzo (2009) com a construção de Engine de Recomendação de Conteúdo ${ }^{3}$ e Saraiva et al. (2010) com o uso de técnicas de POA para a construção de componentes de software para a camada de middleware, faz-se necessárias implementaçãos na camada Common Core do middleware.

Aplicações desenvolvidas nesse âmbito ocasionam o uso de recursos do Common Core do middleware e posterior desenvolvimento da interface no ambiente declarativo, conforme apresentado na Figura 4.1. O processo de desenvolvimento para TV Digital interativa para esse cenário requer automatização e ferramentas, no entanto o desenvolvimento em Common Core oferece melhores resultados de desempenho para os recursos computacionais.

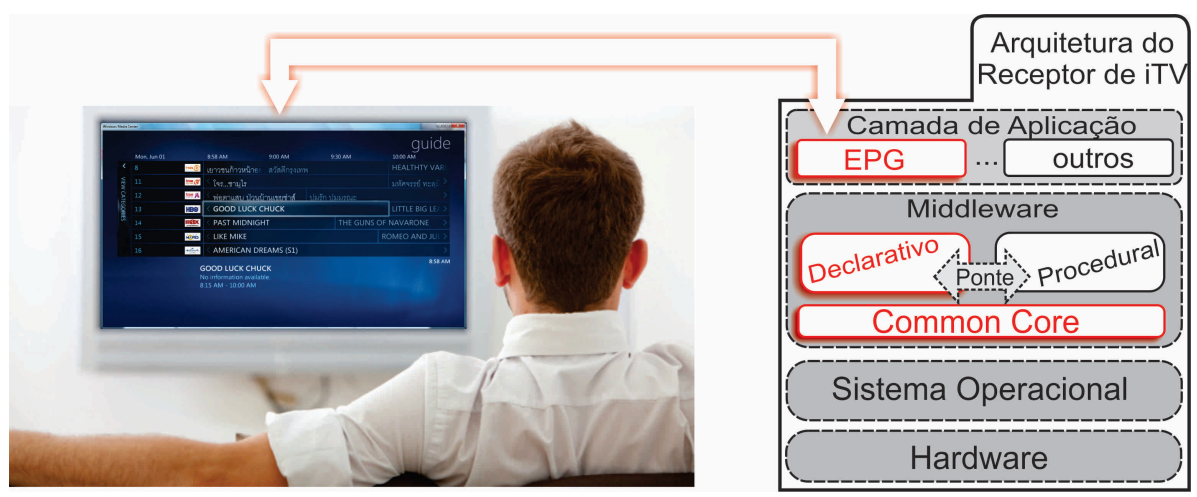

Figura 4.1: Cenário de Aplicações Desenvolvidas para o Ambiente Declarativo.

Sob outra perspectiva, o ambiente procedural está direcionado para o uso de tecnologias em Java. Esse ambiente de desenvolvimento permitiu que as soluções algoritmas fossem desenvolvidas com os recursos da tecnologia Java, com o auxilio de uma JVM como subcamada de software. Em decorrência desse cenário de software para TV Digital, a camada de Common Core do middleware é preservada com mínimas alterações, possibilitando futuras pesquisas com uso de tecnologias existentes em Java para outras plataformas, tais como, Spring, Hibernate, Ajax, JSF, conforme apresentado na Figura 4.2, e as vantagens consolidadas com o desenvolvimento em Java, como reúso, separação de interesses, coesão, acoplamento, dentre outras.

\footnotetext{
${ }^{1}$ Exemplo: Ginga-NCL, XHTML, DVB-HTML

${ }^{2}$ É o processo pelo qual pode-se obter o produto final de um processamento digital qualquer, como gráficos em $2 \mathrm{D}$ e $3 \mathrm{D}$.

${ }^{3}$ É um sistema de software projetado para encontrar informações armazenadas em um sistema computacional a partir de palavras-chave indicadas pelo utilizador, ou informações do usuário reduzindo o tempo necessário para encontrar informações
} 


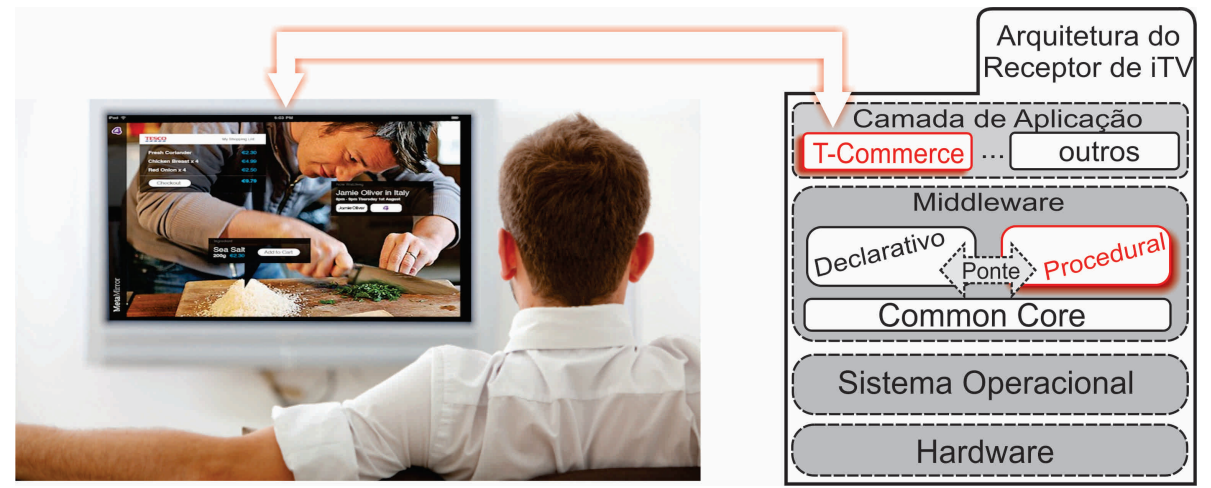

Figura 4.2: Cenário de Aplicações Desenvolvidas para o Ambiente Procedural.

O ambiente procedural baseado em Java tem apresentado inumeras características para diferentes nichos de mercado, e essas características têm sido distribuídas conforme as áreas de atuação dos grupos de pesquisas existentes nesse cenário, tais como: (i)TV Digital interativa e automação residencial; (ii) Aplicações interaticas de recomendação de conteúdo para o usuário; e (iii) Aplicações interativas de comércio eletrônico;

Considerando as vantagens presentes no ambiente procedural, tais como a portabilidade, reúso e processo de desenvolvimento eficiente, a ArciTV foi desenvolvida para o desenvolvimento de aplicações para o ambiente procedural para TV Digital, de acordo com a Figura 4.2.

\subsection{Passo RA-1: Investigação das Fontes de Informações}

No primeiro passo do ProSA-RA, denominado de "Investigação de Fontes de Informação", foram identificadas diferentes fontes para obtenção de informações sobre o domínio de aplicações para TV Digital interativa. Nesse contexto, foram considerados os seguintes grupos de informações; (i) Arquiteturas e ferramentas para iTV, (ii) Diretrizes de desenvolvimento de aplicações para iTV e (iii) Arquiteturas de referência de outros domínios. Conforme a singularidade da pesquisa, foram levantadas arquiteturas de referência de outros domínios para o auxílio no desenvolvimento da ArciTV, dentre essas foi dada atenção à RefTEST (Nakagawa, 2006), (Nakagawa et al., 2007), que forneceu bases e conceitos de qualidade e já se encontra previamente avaliada.

\subsubsection{Arquiteturas e Ferramentas para iTV}

Como fonte de informações iniciais, foram pesquisadas as arquiteturas concretas de aplicações e sistemas previamente desenvolvidas para iTV, considerando diferentes nichos de atuação da tecnologia, modelos de negócios distintos conforme interesse das indústrias e ferramentas existentes na literatura. Os trabalhos referentes a essas fontes de informações são apresentados na Tabela 4.1.

Finke e Balfanz (2004) propõem uma arquitetura de referência para o domínio de hipervídeo ${ }^{4}$, com aplicações para TV Digital interativa. Essa arquitetura de referência foi apresentado no modelo MVC ( Model View Controller), com funcionalidades para o Engine de Hipervídeo (apresentação, anotação e informação). Essa iniciativa foi dada como precursora para arquiteturas de referência no domínio multimída, posteriormente sendo aplicada no domínio web, conforme apresentado na Figura 4.3.

\footnotetext{
${ }^{4}$ Vídeo com inserção de metadados para manipulação de dados pelo usuário.
} 
CAPÍTULO 4. ARCITV: ARQUITETURA DE REFERÊNCIA PARA ITV

Tabela 4.1: Plataformas de Software

\begin{tabular}{|l|c|}
\hline Descrição & Referência \\
\hline \hline Arquitetura de referência em hipervídeo & Finke e Balfanz (2004) \\
\hline Framework de metadados & Vrba et al. (2006) \\
\hline Framework para múltiplos dispositivos & Wang et al. (2009) \\
\hline Framework para dados de diferentes plataformas & Pequeno et al. (2010) \\
& Ló andrez Nores et al. (2010) \\
\hline & Chang et al. (2008) \\
& De Lucena et al. (2009) \\
Arquiteturas concretas de aplicações para iTV & Oliveira et al. (2009) \\
e automação residencial & Maia e de Lucena (2009) \\
& Maia et al. (2009) \\
& Salviato et al. (2011) \\
& Carvalho et al. (2008) \\
& Moreno et al. (2011) \\
& Viana et al. (2009) \\
\hline
\end{tabular}

Ainda nessa perspectiva, nos trabalhos de Vrba et al. (2006), Wang et al. (2009), Pequeno et al. (2010) e Ló andrez Nores et al. (2010) foram desenvolvidos frameworks ${ }^{5}$ para tratamento de aplicações no ambiente procedural para TV Digital interativa, com representação da arquitetura em camadas do receptor digital, conforme a Figura 4.2.

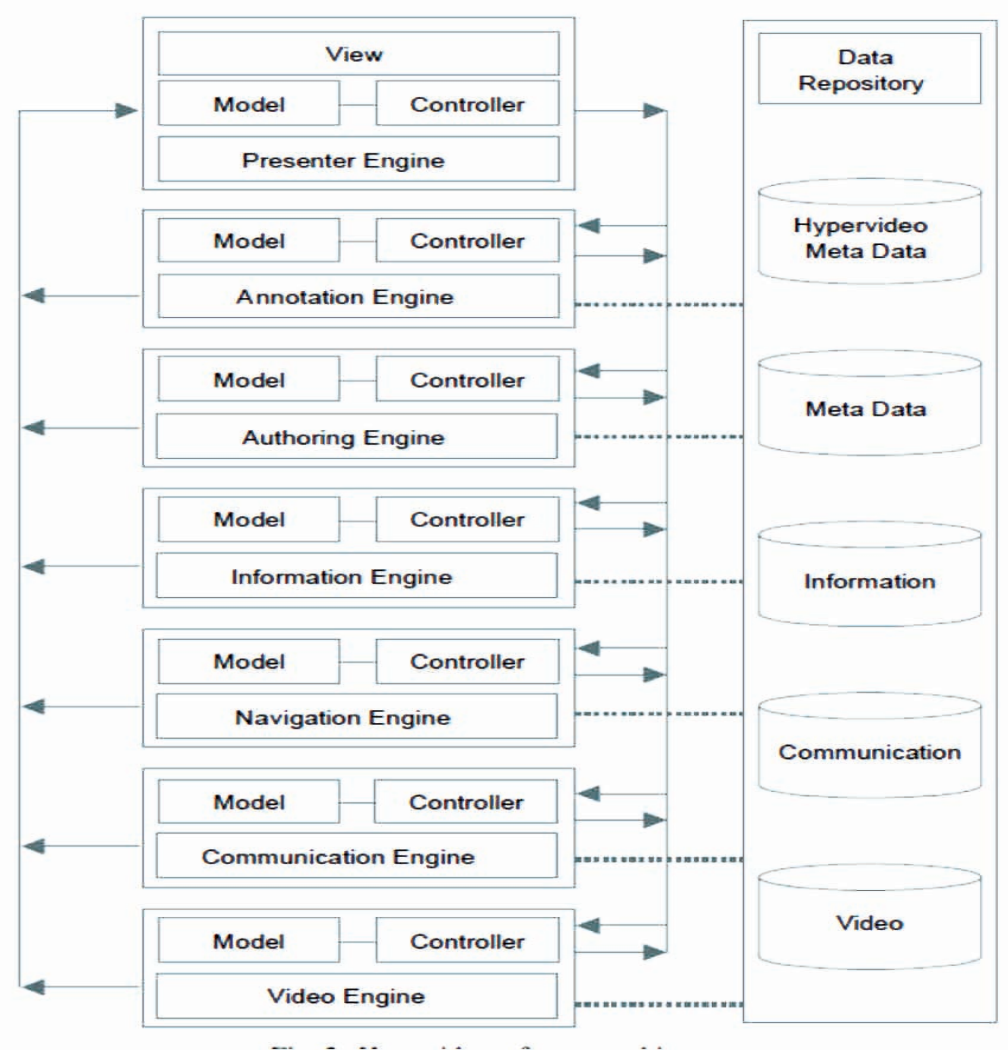

Figura 4.3: Arquitetura de Referência (Finke e Balfanz, 2004)

\footnotetext{
${ }^{5} \mathrm{E}$ uma abstração que une códigos comuns entre vários projetos de software provendo uma funcionalidade genérica.
} 
Em Vrba et al. (2006), foi explorado o uso de metadados direcionado para reúso e construção de novos componentes na plataforma. Esse framework tornou-se útil para o desenvolvimento de aplicações baseadas em compartilhamento de objetos, uso de templates para importação de linguagem do usuário e geração de metadados. A pesquisa de Vrba et al. (2006) foi um primeiro marco no uso de arquiteturas para abstração de funcionalidades e seu projeto arquitetural é apresentado na Figura 4.4.

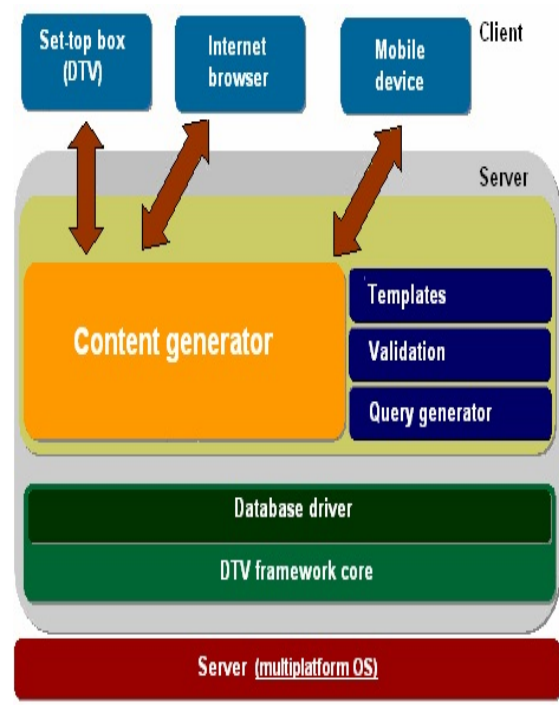

Figura 4.4: Arquitetura de Referência extraída de Vrba et al. (2006)

Em uma perspectiva similar, no trabalho de Wang et al. (2009) foi desenvolvida uma arquitetura no modelo MVC para usuários IPTV(Internet Protocol Television.) para atender o uso de múltiplos dispositivos (Figura 4.5), que foram mapeados como interfaces de interação com o usuário final. Essa pesquisa apresentou claramente uma extensão da arquitetura de Vrba et al. (2006), com respeito aos itens arquiteturais como servidor de aplicações e múltiplos dispositivos, e foram apresentadas na arquitetura componentes para controle de execução e protocolos de segurança.

Em Pequeno et al. (2010), foi proposta uma arquitetura com foco no desenvolvimento de aplicações com uso do canal de retorno, gerando a primeira implementação de recursos de redes, como gerenciamento de recursos embarcados e tratamento de segurança para troca de informações com o usuário. Esse framework foi desenvolvido para o ambiente $\mathrm{GEM}^{6}$, com foco em aplicações de T-Voting ${ }^{7}$, T-Mail ${ }^{8}$, $E P G^{9}$ e Portal $^{10}$. Essa padronização permitiu uma orquestração entre o uso de API's e recursos em rede.

Ainda na perspectiva de Pequeno et al. (2010), de acordo com a Figura 4.6, a arquitetura para TV Digital no ambiente procedural apresenta cinco pacotes fundamentais, divididos segundo o modelo MVC, com um grupo de funcionalidades suscintas, porém, importantes apresentadas abaixo:

\footnotetext{
${ }^{6}$ Globally Executable MHP.

${ }^{7}$ Aplicação de voto eletrônico, por meio do ambiente de TV Digital interativa.

${ }^{8}$ Aplicação de email, por meio do ambiente de TV Digital interativa.

${ }^{9}$ Aplicação de guia eletrônico programável do ambiente de TV Digital interativa.

${ }^{10}$ Aplicação de mosaico de informações, no ambiente de TV Digital interativa.
} 


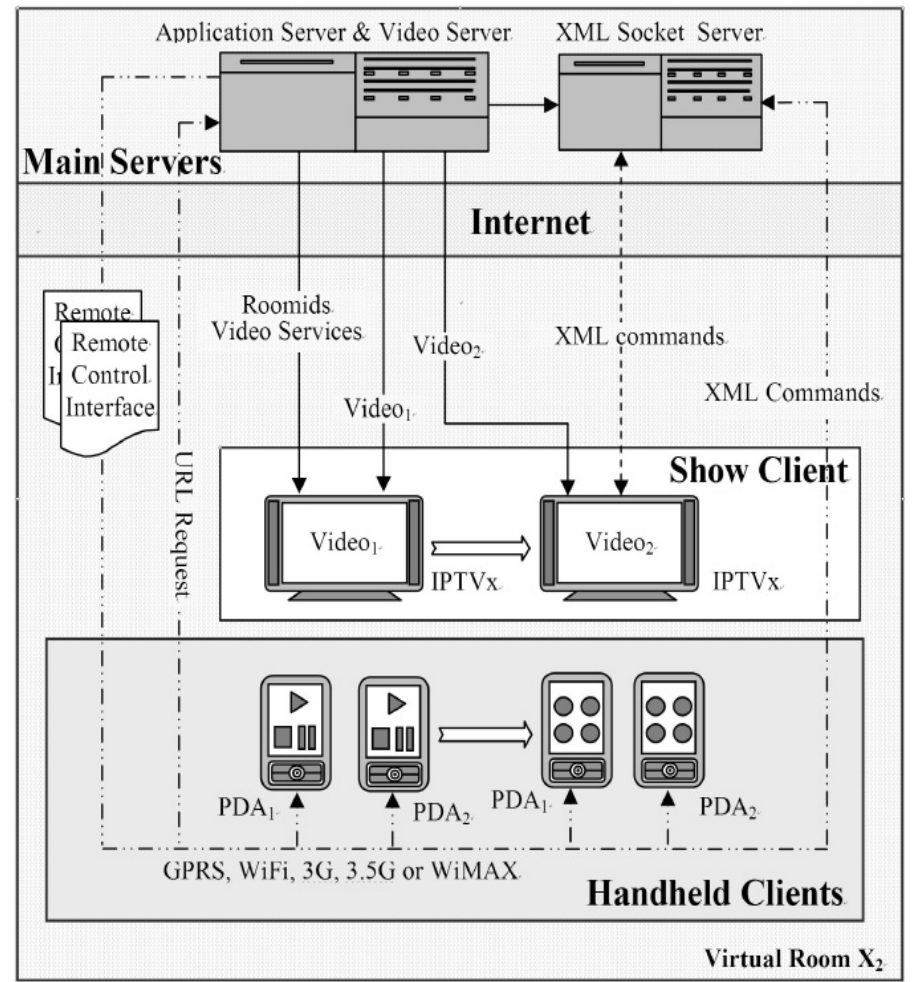

Figura 4.5: Arquitetura de Referência extraída de Wang et al. (2009)

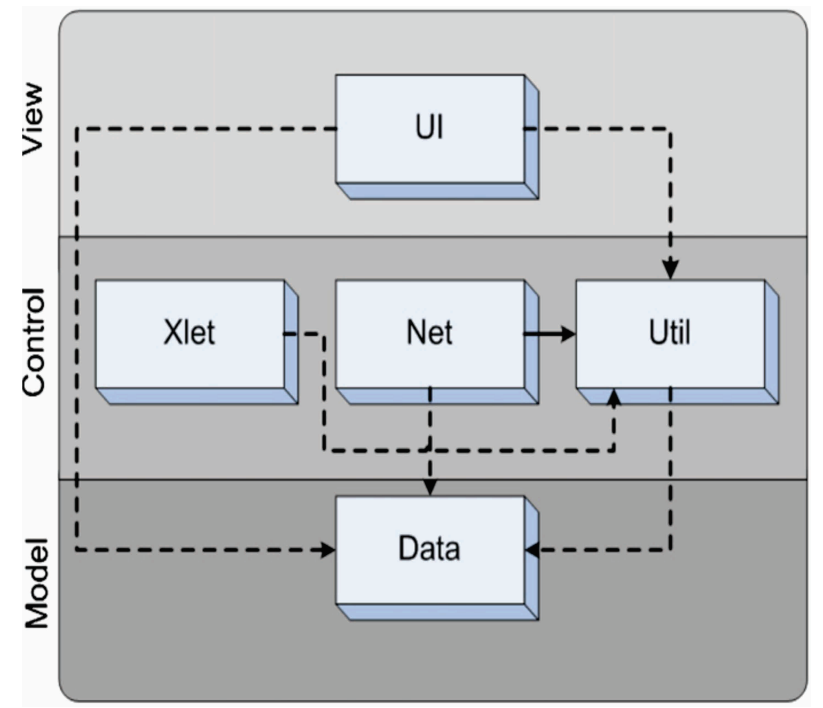

Figura 4.6: Arquitetura de Referência extraída de Pequeno et al. (2010)

UI User Interface, pacote responsável pela interface visual com o usuário, contendo classes e elementos gráficos para construção de interfaces de aplicações como, IconBox ${ }^{11}$, TextBox ${ }^{12}$, IconListBox ${ }^{13}$, dentre outros, todos com desenvolvimento prévio nas API's Java AWT ${ }^{14}$.

\footnotetext{
${ }^{11}$ Termo em inglês para Ícones.

${ }^{12}$ Termo em inglês para caixas de textos.

${ }^{13}$ Termo em inglês para listagens de ícones.

${ }^{14}$ Abstract Windows Toolkit.
} 
Xlet Pacote responsável pela interface de aplicação Xlet, o qual é a interface em Java equiparada com Applet, originalmente introduzido como controlador de aplicações para o ambiente procedural em TV Digital interativa. Esse pacote é responsável diretamente pelo ciclo de vida das apliações em TV Digital;

Net Esse pacote é responsável por orquestrar a comunicações entre cliente e servidor para as aplicações em iTV, com gerencimento de comunicação TCP/IP por meio do canal de interatividade. Esse cenário fez desse pacote um gerenciador de recursos de metadados, possibilitanto futuras pesquisas em Web Services;

Util Esse pacote é responsável pelo auxílio às aplicações por meio de recursos embarcados, além de promover legibilidade de código para os desenvolvedores. Recursos embarcados como casting ${ }^{15}$, gerenciamento de imagens, conteiners de controle de elementos e controle de exceções; e

Data Esse pacote responde pela infraestrutura de armazenamento, consulta e gerência de informações. Assimilando com uso funcionalidades intrísecas de persistência de dados.

Ainda sob o mesmo prisma, Ló andrez Nores et al. (2010) propuseram uma arquitetura para TV Digital interativa que promove o ambiente de aprendizado proporcionado pela plataforma televisiva (T-Learning). Essa arquitetura é desenvolvida no ambiente procedural (Java) do middleware e é direcionado ao T-Learning por meio de funcionalidades distribuídas, proporcionando às comunidades estudantis ambientes compartilhados e eficientes para troca de informações, utilizando a tecnologia $\mathrm{P} 2 \mathrm{P}^{16}$, conforme apresentado na Figura 4.7.
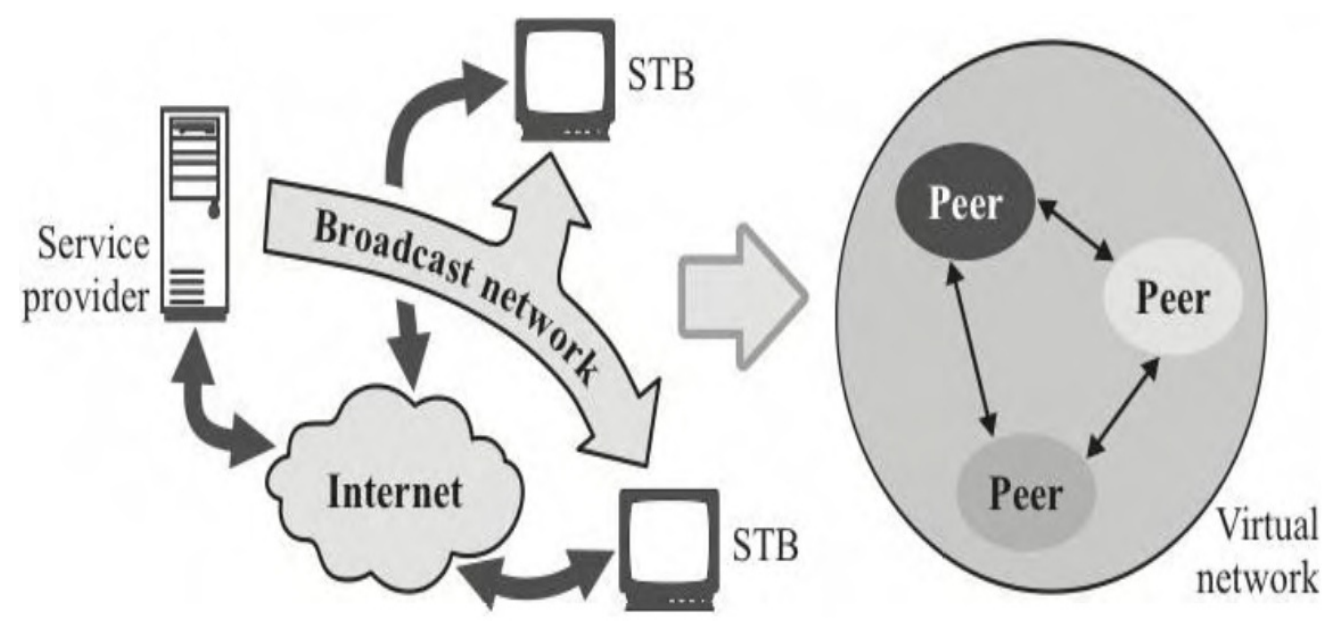

Figura 4.7: Infraestrutura P2P para a Arquitetura em TV Digital (Ló andrez Nores et al., 2010).

Em uma perspectiva paralela, como a TV Digital interativa compõe uma série de itens arquiteturais(Morris e Smith-Chaigneau, 2005) e o receptor digital é um item da eletrônica de consumo (Miller, 1999), essa plataforma não possui unicamente pesquisas exclusivas para o receptor digital, mas um conjunto de pesquisas que envolvam o receptopr digital como sistema de automação residencial, conforme apresentado na Figura 4.8.

\footnotetext{
${ }^{15}$ Termo em inglês para, a capacidade de um programa observar ou até mesmo modificar sua estrutura ou comportamento.

${ }^{16}$ Abreviação em inglês para, peer-to-peer.
} 


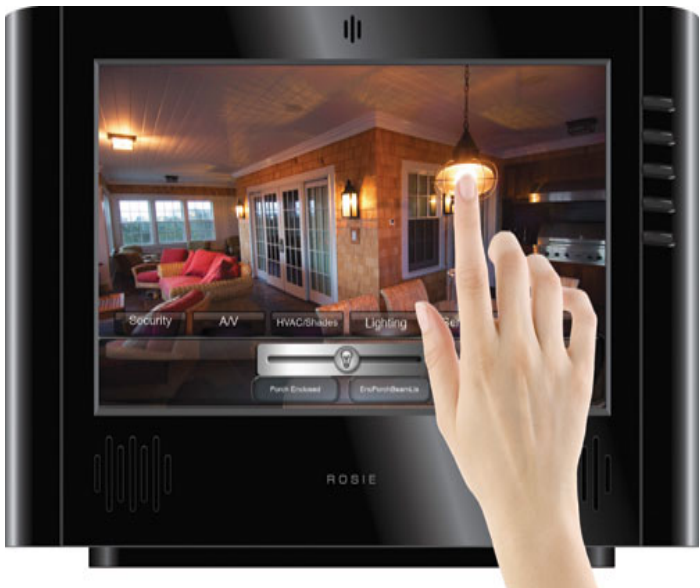

Figura 4.8: Exemplo de uso da iTV como Veículo de Automação Residencial. (Figura extraída de Montgomery, L. (2012))

As pesquisas de arquiteturas concretas para integração entre TV Digital e automação residencial são apresentadas por Chang et al. (2008), Viana et al. (2009), De Lucena et al. (2009), Oliveira et al. (2009), Maia e de Lucena (2009), Salviato et al. (2011), Carvalho et al. (2008), Moreno et al. (2011), Viana et al. (2009) e Maia e de Lucena (2009).

As pesquisas em Viana et al. (2009), De Lucena et al. (2009), Oliveira et al. (2009) e Maia e de Lucena (2009) apresentam a construção de componentes arquiteturais que permitem a comunicação de tecnologias de automação residencial como OSGi (Open Services Gateway Initiative)(Engel e Spinczyk, 2009a), a qual é uma plataforma de serviços para o desenvolvimento de aplicativos em linguagem Java modulares e orientados a serviço para automação residencial, e o Xlet. Essa arquitetura provê o uso de serviços e modelos de negócios de aplicações, com contribuições práticas e aplicadas na indústria para o ambiente procedural desenvolvido em GEM, conforme apresentado na Figura 4.9.

Ainda na perspectiva de Viana et al. (2009), as principais funcionalidades da arquitetura com interações entre OSGi e Xlet envolvem; (i) Autorização e descoberta de serviços OSGi, (ii)Interoperabilidade entre serviços OSGi e o middleware Ginga e (iii) Comunicação entre elementos básicos das duas plataformas como, registros, armazenamentos de dados e tráfego de informações mutuas.

Em resumo, vale destacar que as fontes de informações utilizadas para a construção da ArciTV são amplas, inclusive foram também considerados outros trabalhos já apresentados na revisão bibliográfica deste trabalho.

\subsection{Passo RA-2: Estabelecimento de Requisitos arquite- turais para TV Digital Interativa.}

No passo 2 do ProSA-RA ocorre o "Estabelecimento de Requisitos Arquiteturais", as informações e conceito adquiridos no decorrer da fase de investigação de fontes de informações são aglutinadas, e o levantamento de requisitos da arquitetura de referência é realizado.

Foram então identificados 10 principais requisitos arquiteturais com a abreviação RA-(número), com o seu detalhamento apresentado a seguir; 


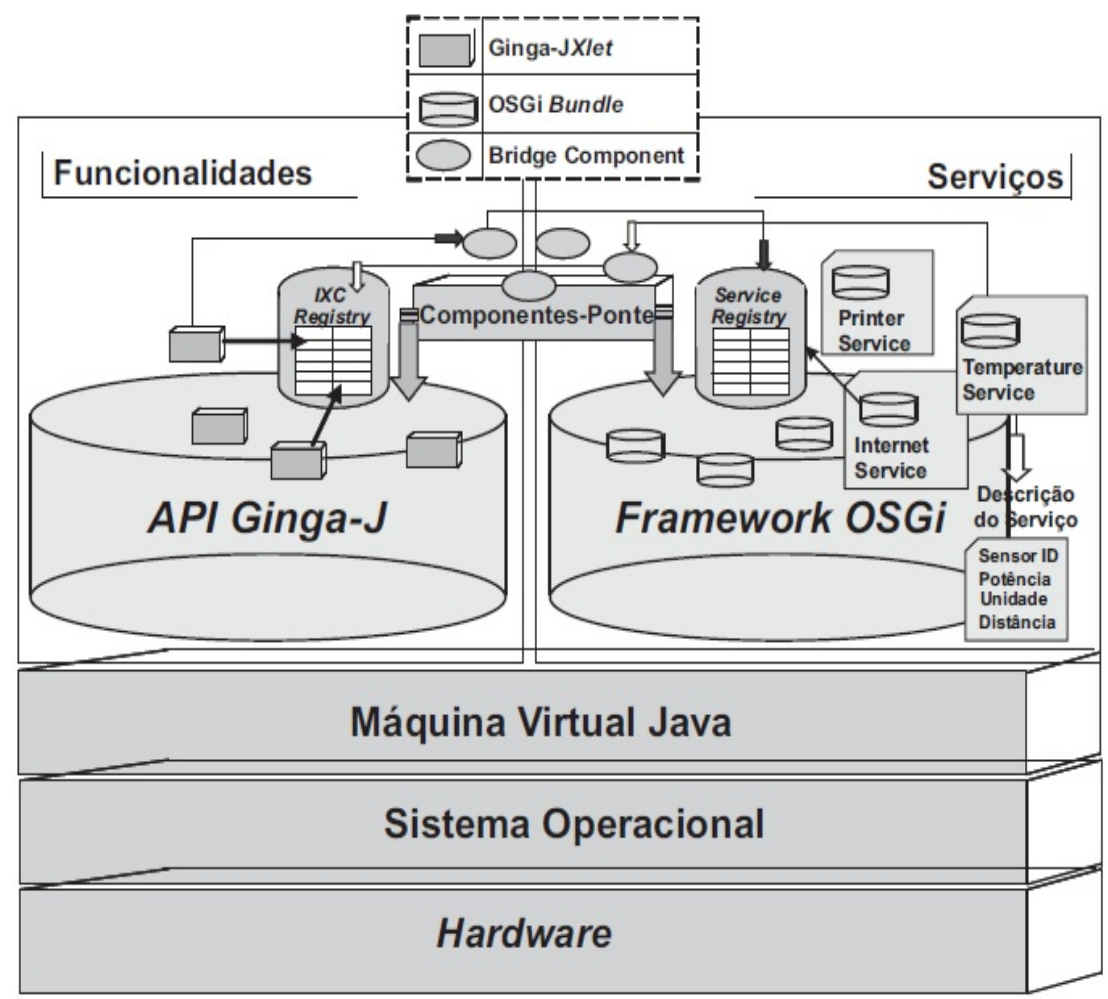

Figura 4.9: Arquitetura com Interação entre Automação Residencial e TV Digital. (Viana et al., 2009)

RA-1: A arquitetura de referência deve viabilizar o desenvolvimento de aplicações para todos os modelos de transmissão de dados via TV Digital, como, IPTV, Broadcasting, TV a Cabo, TV Terrestre e TV via satélite.

RA-2: A arquitetura de referência deve permitir a utilização dos recursos para o ambiente procedural do middleware para TV Digital, com as devidas estruturas de ponte para o ambiente declarativo e de Common Core.

RA-3: A arquitetura de referência deve viabilizar a geração de estruturas ortogonais que permitam o desenvolvimento de aspectos arquiteturais, para o entrecorte de funcionalidades espalhadas na plataforma de iTV.

RA-4: A arquitetura de referência deve viabilizar o desenvolvimento de aplicações que utilizem recursos multimídia, como envio de vídeo paralelos à programação televisiva, estruturas de arquivos estáticos, conversões de documentos, dentre outras.

RA-5: A arquitetura de referência deve permitir o tratamento particular para casos especiais de uso de metadados, como recursos para iTV que envolvam Web Services e aplicações orientadas a serviços.

RA-6: A arquitetura de referência deve vislumbrar o desenvolvimento de aplicações resilientes, ou seja, aplicações que sejam desenvolvidas no padrão normatizado pela GEM e sejam executáveis em quaisquer plataformas de hardware e software equiparadas.

RA-7: A arquitetura de referência deve viabilizar o desenvolvimento de aplicações no hardware do receptor digital para TV Digital e possíveis ferramentas de emulação, vislumbrando com isso todas as fases do desenvolvimento e teste de aplicações. 
RA-8: A arquitetura de referência deve permitir que aplicações residentes sejam desenvolvidas como aplicações que tenham interações com o hardware diretamente, como exemplo, aplicações para USB(Universal Serial Bus), Ethernet ${ }^{17}$ e desenvolvimento de drivers.

RA-9: A arquitetura de referência deve viabilizar o desenvolvimento de aplicações para iTV com existência de tecnologias portáveis, como, protocolos de automação residencial, protocolos de aplicações na área de saúde, aplicações na área de ensino, dentre outras.

RA-10: A arquitetura deve possibilitar o desenvolvimento de aplicações que apresentem âmbito de interface com o usuário com usabilidade acessível e de fácil penetração para todos níveis sociais e econômicos.

Deve-se destacar que os requisitos arquiteturais apresentados foram baseados na primeira fase do ProSA-RA, que é a investigação de fontes de informações.

\subsection{Passo RA-3: Projeto Arquitetural}

Nessa fase do ProSA-RA, o projeto arquitetural é realizado, ou seja, a fase de documentação da arquitetura de referência, que irá constituir as visões arquiteturais da ArciTV. As visões arquiteturais utilizadas foram: a visão estrutural ou de módulos (do inglês, module view) e a visão física ou de implantação (do inglês, deployment view). E as técnicas utilizadas para a representação dessas visões arquiteturais são da UML 2.0 .

\subsubsection{Visão Geral}

Nesta seção, é apresentada a visão geral da ArciTV, mostrada na Figura 4.10. O objetivo dessa visão é apresentar a arquitetura de referência em uma representação de mais alto nível, apresentando os principais elementos e relação entre esses elementos. De um modo geral, a ArciTV é baseada no estilo arquitetural em três camadas. Observa-se então que nessa visão apresentam-se as seguintes camadas: (i) camada de persistência para armazenamento de informações; (ii) camada de aplicação que contém o modelo lógico para as diferentes aplicações a serem desenvolvidas com base na ArciTV; e (iii) camada de apresentação que se refere à interface do usuário e que possibilita a interação do usuário com as aplicações desenvolvidas a partir da ArciTV. Além disso, na camada de aplicação, pode-se observar cinco pacotes, sendo eles: (i) serviços ortogonais; (ii) elementos residentes; (iii) configurações para o meio físico; (iv) tecnologias portáveis; e (v) resiliência. Cada um desses pacotes é explicado em mais detalhes na seção seguinte. Observa-se também que a arquitetura de referência considerou o uso do padrão arquitetural MVC, possibilitando desenvolver aplicações que são organizadas em três partes principais: (i) Modelo que contém as funcionalidades principais das aplicações resultantes da ArciTV; (ii) Visão que contém a interface do usuário; e (iii) Controle que recebe requisições dos usuários e encaminha para o Modelo, sendo que essas requisições são atendidas pelos Xlets.

\footnotetext{
${ }^{17}$ Tecnologia de interconexão para redes locais.
} 


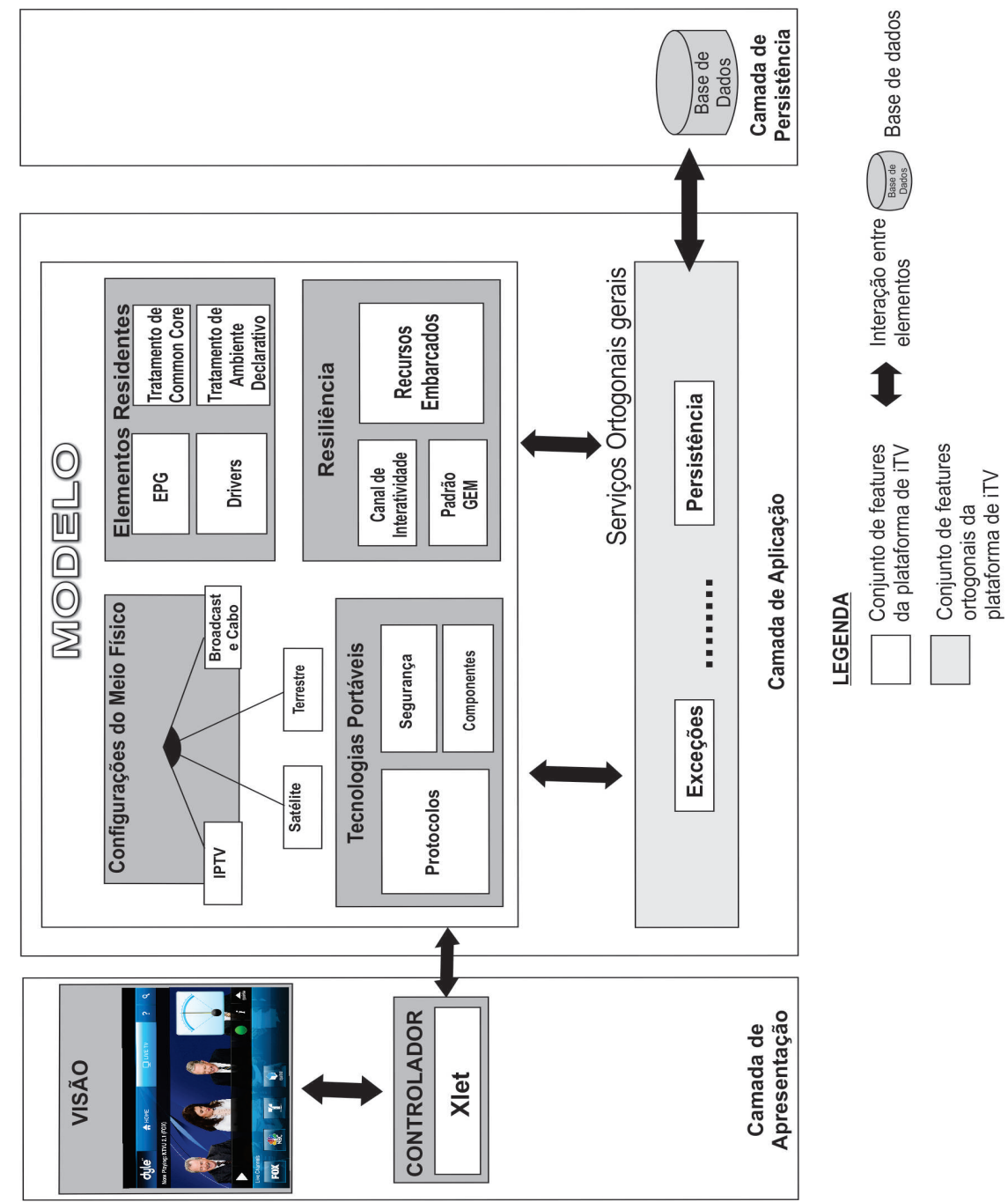

Figura 4.10: Visão Geral do ArciTV

\subsubsection{Visão em Módulo}

A visão arquitetural em módulos apresenta a estrutura do sistema de forma modular, contendo módulos com funcionalidades especificas, sejam como pacotes, interfaces, aspectos, classes, dentre outros, conforme a Figura 4.11. Ainda nessa perspectiva, essa visão é a "planta fundamental"para o desenvolvimento dos sistemas baseados na arquitetura de referência. Essa visão apresenta os módulos principais (pacotes) que compõem a arquitetura ArciTV, sendo elas: Resiliência, Aplicações Residentes, Serviços Ortogonais Gerais e Tecnologias Portáveis.

As funcionalidades espalhadas na plataforma de TV Digital ocorrem com frequência, devido principalmente ao contato direto do usuário com o sistema.

Foi criado o pacote Serviços Ortogonais Gerais, que representa as funcionalidades espalhadas na aplicação e que podem ser encapsuladas como elementos transversais (ou seja, aspecto). Foram identificados aspectos básicos que claramente apresentam funcionalidades espalhadas, tais como o aspecto "Exceções"e "Persistência". Dentre as tecnologias envolvidas no desenvolvimento desse pacote, pode-se utilizar o AspectJ e o Spring.

Com relação ao aspecto "Persistência", esse tem o objetivo de armazenar informãções. Em vista das diferentes tecnologias de envio e armazenamento de informações para TV Digital, esse aspecto deve tratar 


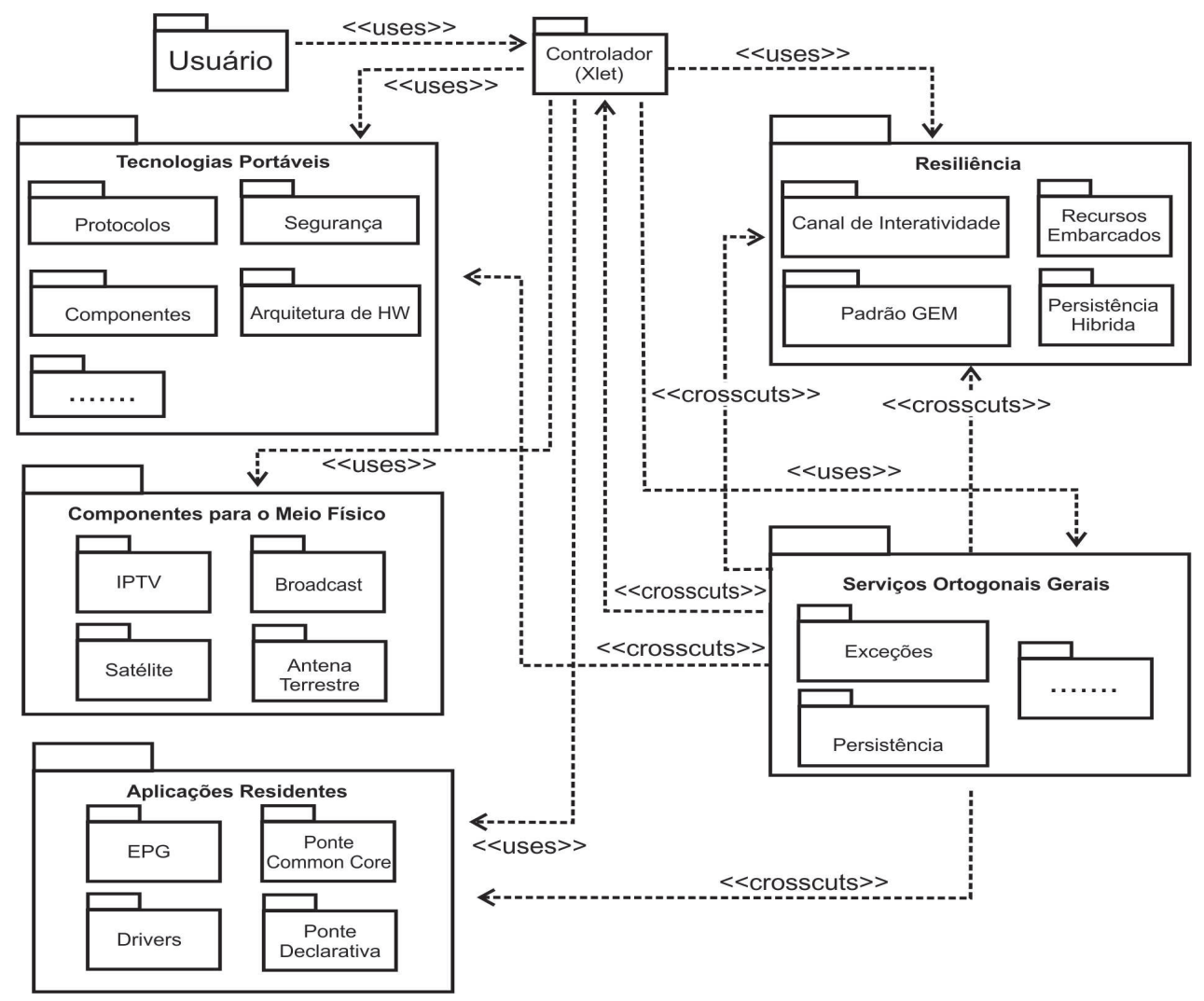

Figura 4.11: Visão em Módulo da ArciTV.

funcionalidades, tais como, tratamento de buffer de dados, serialização de informações, tratamento de erros, checksum de dados, dentre outros.

Conforme a Figura 4.12, em uma aplicação de comércio eletrônico televisivo ocorrem constantes funcionalidade espalhadas de exceções, tais como, exceções pertinentes ao ambiente multimídia, exceções de I/O, exceções devido ao envio de dados no modelo de carrossel de objetos e exceções de armazenamento.

O pacote Elementos Residentes, estrutura as interações das aplicações com os elementos residentes de diferentes receptores de TV Digital. Ou seja, esse pacote contempla um grupo de aplicações comuns em todos os receptores digitais, onde o programador pode optar no uso, e sua existência é em conjunto com as demais. Por exemplo, o subpacote de EPG (Electronic Programmable Guide) é um exemplo clássico do conceito de aplicações residentes, o EPG é a aplicação interativa presente em todos os receptores de iTV de acordo com Fagerqvist e Marcussen (2000), e a função do EPG é de disponibilizar ao usuário a programação televisiva e funcionalidade de pay-per-view ${ }^{18}$.

Ainda no pacote Elementos Residentes estão presentes os subpacotes de "Tratamento de Common Core", que é o interador com o ambiente de desenvolvimento para o Common Core do middleware, e o subpacote de "Tratamento de Ambiente Declarativo", que regula as aplicações de metadados em comunicação com o ambiente declarativo. Dentre os casos existentes para esse uso, está a adaptação de aplicações desenvolvidas a partir da ArciTV para diferentes padrões de middleware, ou seja, na reconstrução de aplicações interativas, alguns artefatos tecnológicos são passíveis de estarem omissos em camadas

\footnotetext{
${ }^{18}$ É o nome dado a um sistema no qual os que assistem a televisão podem adquirir uma programação específica, a qual desejem assistir, comprando por exemplo o direito a assistir a determinados eventos, filmes ou outros programas.
} 
de baixo nível, conforme apresentado por de Ávila e Zorzo (2009), Moreno e Soares (2010) e Alic et al. (2008).

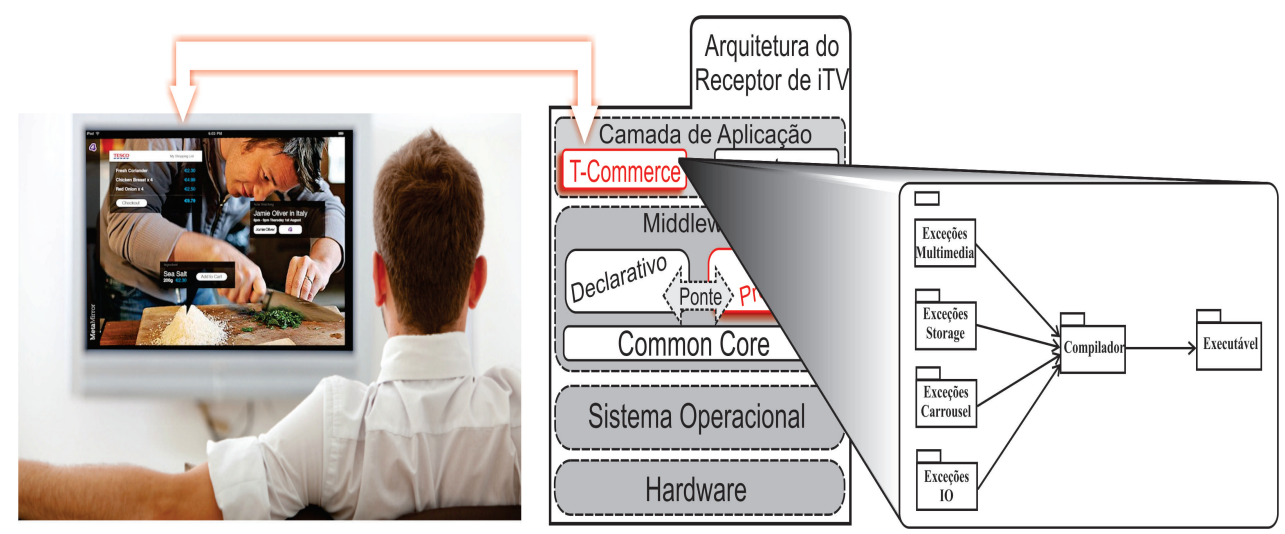

Figura 4.12: Funcionalidades Espalhadas em Ambiente de iTV.

Outro subpacote para Elementos Residentes é apresentado como "Drivers", o qual representa a possível interação de novos dispositivos com o receptor de TV Digital, que irá gerar a necessidade de desenvolvimento de drivers. Esse cenário ocorre devido ao constante uso de tecnologias paralelas a esse ambiente, como interações com uso de múltiplos dispositivos ${ }^{19}$ (Costa et al., 2009), interações multimodais $^{20}$ (Ibrahim e Johansson, 2002), conforme apresentado na Figura 4.13.

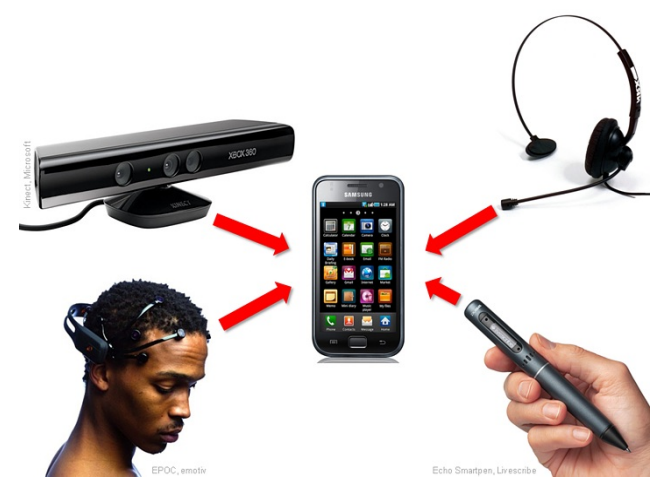

Figura 4.13: Interações Multimodais, extraído de Universidade Vrije em Bruxelas (2012)

O pacote Resiliência, organiza na arquitetura de referência os subpacotes que serão utilizados em funcionalidade básicas e padronizadas do sistema. Por exemplo, o "Padrão GEM", que é o subpacote responsável pelas aplicações padronizadas segundo a normatização MHP para o ambiente procedural de todos os middlewares, o que não exclui a possibilidade de implementações diferentes devido ao padrão (Ex: Aplicações no Ginga e MHP); porém, o desenvolvedor em conhecimento desse pacote tem como organizar as possíveis classes e interfaces distintas.

Ainda no pacote Resiliência, os "Recursos Embarcados"são organizados em um subpacote com o intuito de ordenar as requisições de recursos desse nível, tais como o casting, uso de recursos multimidia (Ex.: Execução de vídeos secundários), tratamento de extensões distintas, como gerencimentos de imagens estáticas de diferentes extensões, dentre outros. No decorrer do desenvolvimento de aplicações para iTV, o uso de recursos embarcados torna-se mais presente, devido às características de convergência digital

\footnotetext{
${ }^{19}$ Interações realizadas por meio de dispositivos com interfaces diferentes.

${ }^{20}$ Interações realizadas por meio da mesma interface, para dispositivos diferentes.
} 
encontradas na plataforma, tendo como exemplo, um componente para TV interativa que possibilita o uso de smartphones e tablets baseados na plataforma Android ${ }^{21}$ como controle remoto Lin et al. (2012).

O subpacote "Canal de interatividade"tambem é implementado com o intuito de organizar as aplicações que necessitem de comunicação direta com o provedor de contéudo. Dentro dessa necessidade de comunicação com o broadcaster, o canal de retorno torna-se presente em todos os modelos de negócios para TV Digital, onde mesmo em ambientes com estruturas físicas alteradas como IPTV, a importância do canal de retorno é presente.

No pacote Tecnologias Portáveis, são organizados os subpacotes que irão ter interação direta com outras tecnologias, sejam em ambientes convergentes com a TV Digital interativa (Ex.: iTV e automação residencial), ou em ambiente de execução secundária (Ex: Rede de Sensores e Protocolo Bluetooth). Os subpacotes desse pacote são "Protocolos", "Segurança"e "Componentes".

O subpacote Protocolos é presente na ArciTV por conta das diferentes interações entre tecnologias e plataformas para TV Digital, como apresentado em (Viana et al., 2009), conforme a Figura 4.14. Dentro dessa pesquisa pode ser encaixado o subpacote componentes, devido a utilização de técnicas de componentização para utilização do Xbundle.

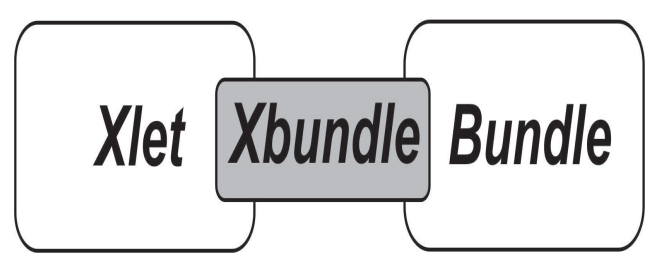

Figura 4.14: Integração entre protocolos Xlet e Bundle.

O subpacote Segurança, descreve o uso de recursos de seguranaça da informação para as aplicações de TV Digital, essas medidas de segurança são presentes em aplicações interativas avançadas, em especial em aplicações de T-Commerce((Comércio Eletrônico Televisivo), onde os dados do usuário trafegam no protolo de comunicação televisivo. Temos como exemplos de pesquisas em segurança, Herget et al. (2011) e Meei-Ling et al. (2011).

Em outra perspectiva, o subpacote Componentes, descreve o desenvolvimento de componentes de software como aplicações para TV Digital, esses componente podem ser executados como aplicações principais em execução Trojahn et al. (2012), ou como componentes que auxiliem o desenvolvimento Okada e Takano (2011). Em ambos os casos, o uso de componentes é necessários para a integração dessas funcionalidades.

O pacote Configurações para o Meio Físico, organiza na arquitetura de referência os subpacotes que serão utilizados conforme a necessidade das tecnologias físicas. Esse cenário, ocorre para a plataforma de TV Digital interativa no casos de transmissão de sinal pelos Subpacotes; (i) IPTV, para sinal televisivo enviado por meio de protocolos de internet, (ii) Broadcast e cabo, para o sinal enviado no modelo convencional, por meio de uma antena de difusão existente no provedor de conteúdo, ou em tecnologias de cabo, (iii) Satélite, para aplicações enviados por meio de recursos de satélite, e (iv) Antenas Terrestres, para provedores que utilizem essa tecnologia para TV Digital. Cada meio físico é importante, porque representa um modelo de negócios diferente para tecnologia, consequentemente com usuários diferentes.

\footnotetext{
${ }^{21}$ É um sistema operacional baseado no núcleo Linux para dispositivos móveis.
} 


\subsubsection{Visão de Implantação}

Diante das características da plataforma de TV Digital, com as diferentes interações físicas, tais como IPTV, as estruturas de envio a cabo, broadcast de dados, a representação dos elementos físicos que dão suporte à execução de aplicações para TV Digital e, em particular, o ambiente procedural é particularmente útil. Por meio dessa visão de implantação, é apresentada a estrutura física (hardware) onde as aplicações resultantes da ArciTV são executadas. Para a representação da visão de implantação, foi utilizado o diagrama de implantação da UML conforme a Figura 4.15.

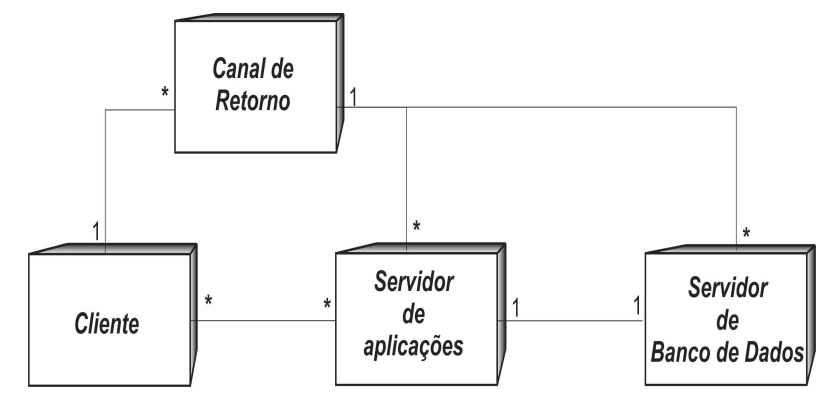

Figura 4.15: Visão de Implantação da ArciTV

De acordo com essa visão arquitetural, os seguintes itens são considerados:

- Servidor de Aplicações, que é responsável pelas interações de conteúdo com anunciantes ${ }^{22}$ para TV Digital. Nesse item da arquitetura são inseridas as lógicas de publicidade para TV Digital, Recomendação de Conteúdo, vendas de pay-per-view, dentre outros. A importância do servidor de aplicações, se destaca devido a descentralização de processamento do receptor, ou seja, as limitações de processamento do receptor seriam preservadas no servidor de aplicações.

- Servidor de Banco de Dados é responsável por armazenar e enviar dados dos provedores de conteúdo, esse item arquitetural engloba as possíveis tecnologias físicas para TV Digital.

- Canal de Retorno, representa a estrutura física de comunicação direta com o usuário, a qual permite que informações sejam coletadas do usuário e enviadas para a emissora televisiva, e em alguns caso o processo inverso é realizado, onde o canal de retorno é usado para envio de informações.

\subsection{Passo RA-4: Avaliação da Arquitetura de Referência}

No passo RA-4 do ProSA-RA, é realizada a Avaliação da Arquitetura de Referência, ou seja, esse passo tem o objetivo de organizar estudos de caso com o objetivo de avaliar a viabilidade da arquitetura de referência. No contexto desta pesquisa, as avaliações arquiteturais foram realizadas por meio de um estudo de caso, para a construção de uma aplicação baseada na arquitetura proposta, além de consultas ao especilista.

\footnotetext{
${ }^{22}$ Ex: Publicitários e Recomendadores de Conteúdo de Vendas
} 


\subsection{Considerações Finais}

Frente ao crescente desenvolvimento de aplicações para o receptor de TV digital interativa, em especial no ambiente procedural, bem como a necessidade de uma visão arquitetural que atenda aos diversos nichos mercado industrial e à área acadêmica, neste capítulo foi apresentada a ArciTV, uma arquitetura de referência que visa prover diretrizes para o desenvolvimento de aplicações para TV interativa. O desenvolvimento da ArciTV pretende contribuir para o desenvolvimento de aplicações com possibilidade de reúso, manutenabilidade, além da facilidade de integração com outras plataformas para eletrônica de consumo e plataformas correlatas.

O estabelecimento de uma arquitetura de referência é uma tarefa desafiadora, em especial para casos nos quais objetiva-se nortear o desenvolvimento de sistemas para domínios recentes, os quais, ainda não dispõem de arquiteturas concretas e maduras. Nessa perspectiva, é importante ressaltar que um processo para o desenvoolvimento de arquitetura de referência é muito importante, desde a fase inicial com o levantamento de trabalhos relacionados, normas técnicas da área, sistemas previamente desenvolvidos, até a fase de avaliação arquitetural. Nesse contexto, o ProSA-RA foi de grande importânica para o estabelecimento da arquitetura proposta. Em virtude da necessidade de avaliar a arquitetura proposta, no próximo capítulo, é apresentado um estudo de caso, no qual uma aplicação é desenvolvimento com base na ArciTV. 


한

\section{Estudo de Caso: Utilização da ArciTV}

\subsection{Considerações Iniciais}

Para a avaliação da arquitetura de referência proposta no contexto deste trabalho, neste capítulo é apresentado um estudo de caso em que, a partir da ArciTV, é constituída uma aplicação para TV Digital interativa.

A aplicação desenvolvida têm o objetivo de possibilitar aos usuários a abstração de hardware para armazenamento multimidia em dispositivos USB. Junto com esse objetivo, o mesmo possui alguns serviços definidos em tempo de execução, um deles é a execução da transferência dos bytes, responsável em localizar o arquivo, carrega-lo na memória do receptor, e em seguida descarrega-lo na memória de destino.

Esse cenário é desenvolvimento por meio da arquitetura ArciTV, a qual, apresenta os elementos necessárias para a implementação do projeto e ferramentas capazes de auxiliar o processo de desenvolvimento do sistema.

Esse estudo de caso concentra-se no middleware europeu, o MHP, pelo fato de seu ambiente procedural ser estável e definido, e residente no receptor, componente importante do sistema de televisão digital. O receptor gerencia as aplicações implementadas por meio da interface procedural para televisão digital, o Xlet. O componente GEM possui o seu equivalente no middleware brasileiro o que facilita uma possível integração da aplicação desenvolvida no decorrer do projeto.

\subsection{Motivação para o Estudo de Caso}

Recentemente, o crescimento da eletrônica de consumo é acompanhamento do crescimento da convergência entre aplicações multimida e sistemas computacionais. Esse cenário foi reproduzido na TV Digital 
interativa, especialmente com os novos nichos de mercado explorados pela indústria televisiva (Jo et al., 2009).

O legado das aplicações de armazenamento é proveniente da TV analógica, devido aos VCRs(Video Cassete Recording) (Tan et al., 2003), sequencialmente substituídos por dispositivos portáteis de armazenamento para computadores (Billinghurst e Starner, 1999). Devido há esse grupo de funcionalidades oferecidas pela plataforma analógica, o usuário de iDTV possui expectativas de armazenamento crescentes, em especial devido ao crescente poder computacional do ambiente. Conforme apresentado na Figura 5.1 .

Em concordância com esse cenário, existem os crescentes desafios tecnológicos, os quais foram inicialmente desenvolvidas técnicas de transmissão, manipulação da largura de banda do sinal elétrico para TV Digital (Milenkovic, 1998).

Em paralelo a esse cenário, houve o crescimento das soluções de hardware para eletrônica de consumo, em particular para o sistema de iDTV. Foram inicialmente desenvolvidas, soluções para captura de imagens estáticas (Kim et al., 2004), em sequência houve a popularização de dispositivos USB para receptores televisivos(Li e Guo, 2009). Posteriomente, houve o desenvolvimento de soluções que envolviam tecnologias de Blue-ray ${ }^{1}$ (Mai et al., 2007), frameworks para reúso de solução de produção em massa (Miljkovic et al., 2010) e o uso de dispositivos de armazenamento para funcionalidades básicas, como inicilização de receptores e recuperação de memória (Jo et al., 2009).
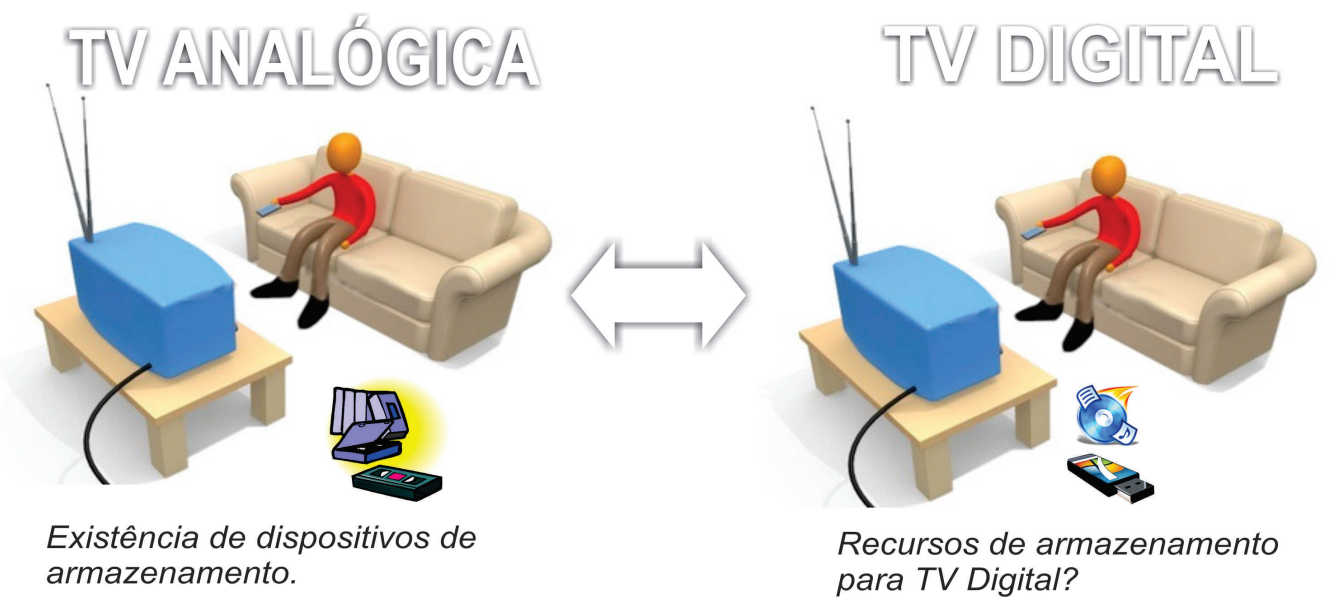

Figura 5.1: Cenário de Armazenamento para Sistemas TV.

Ainda nessa mesma perspectiva, em paralelo ao desenvolvimento do hardware, as soluções na camada de software emergiram para a paltaforma de TV Digital devido ao recursos presentes no middleware (Issarny et al., 2007). Todos os padrões abertos de TV Digital possuem suporte para execução de aplicações no ambiente procedural e declarativo do middleware, de acordo com a ITU (International telecommunication union)(Morris e Smith-Chaigneau, 2005). Contudo, para cada ambiente, as especificações de middleware utilizam as tecnologias padronizadas (HAVi, DAVIC, JavaTV, XHTML, XML)(Union, 2003), direcionadas para necessidades especificas de cada middleware. Devido essas características, as contribuições na área de armazenamento de informações para iDTV cresceram com as seguintes evidências;

- O armazenamento de informações para iDTV é apresentado como um requisito funcional, contudo o uso da funcionalidade pelo usuário é secundário.

${ }^{1}$ É um formato de disco óptico da nova geração com $12 \mathrm{~cm}$ de diâmetro (igual ao CD e ao DVD) para vídeo e áudio de alta definição e armazenamento de dados de alta densidade. 
- As pesquisas em armazenamento de dados estão divididas de acordo com a especialidade dos grupos de pesquisa, onde alguns desenvolvem aplicações no common core do middleware com uma apresentação declarativa(Cattelan et al., 2008), (Oliveira et al., 2009), (Miljkovic et al., 2010), e outros utilizam o ambiente procedural do middleware (Hsu et al., 2006), (Piccolo e Baranauskas, 2006), (dos Santos et al., 2008), (Viana et al., 2009), (Dong et al., 2011).

Ainda na mesma perspectiva, aplicações em execução no middleware procedural decompõe o desenvolvimento por meio de uma implementação algoritimica. E mesmo com o uso de um ambiente de desenvolvimento que requer maior abstração do que o ambiente declarativo, o middleware procedural possui vantagens como o reúso de componentes, possibilidade de criação de componentes para funcionlidades especificas, como apresentado em Union (2003) e Jo et al. (2009).

A contribuição principal desse estudo caso é a apresentação de uma solução de software para armazenamento de dados no middleware procedural para iDTV. Para o desenvolvimento dessa solução foi realizado um levantamento de soluções existentes, e a implementação irá realizar o armazenamento de dados em um dispositivo USB. Essa aplicação foi realizada unicamente no ambiente de software, o que permitiu o desacoplamento do middleware não comprometendo as outras camadas do receptor televisivo, gerando com isso independência de hardware. Esse cenário permitiu que possíveis evoluções desse sistema, como uso de recursos de banco de dados e computação em nuvem, as quais são tendências futuras dessa área de pesquisa, conforme a Figura 5.2.

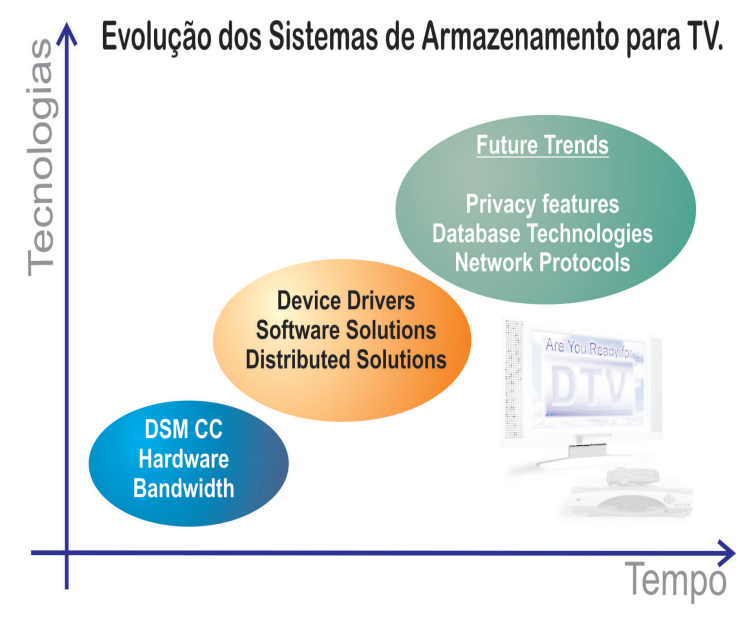

Figura 5.2: Evolução dos Sistemas de Armazenamento para TV Digital.

\subsection{Sistemas de Armazenamento de Dados para iDTV}

As pesquisas em armazenamento de informações para TV Digital apresenta características pulverizadas no condizente a evolução temporal e resultados. Essas contribuições foram desenvolvidas no decorrer da última década, e dentre as diferentes soluções encontradas foram constatadas diferentes motivações;

- Diferentes nichos de mercado para cada middleware;

- A funcionalidade de armazenamento tinha uma importância secundária;

- Existem contribuições em todas as camadas na estrutura do receptor digital; 
- Com o crescimento de recursos computacionais para eletrônica de consumo, recursos avançados foram habilitados;

De acordo com essas evidências, foram consideradas duas categorias para o desenvolvimento de aplicações de armazenamento para iDTV; (1) Pesquisas que utilizam a funcionalidade de armazenamento de forma secundária e (2) Pesquisas que utilizam o armazenamento como foco principal de uso do sistema.

Na categoria (1), encontra-se a pesquisa de Mai et al. (2007), a qual realiza uma contribuição na area de hardware com o desenvolvimento da tecnologia de de Blue Ray para o ambiente televisivo, suportando com isso interatividade no ambiente em Java, permitindo com isso que recursos multimidia e conteúdo interativo seja armazenado em Blue Ray.

Ainda na perspectiva da categoria (1), Jo et al. (2009) e Miljkovic et al. (2010) apresentou pesquisas na pilha de software do receptor digital direcionadas para o uso de Device Drivers. Em Jo et al. (2009) foi desenvolvido o uso de dispositivos de memória flash para redução de tempo de inicialização de receptores digitais, resultando com isso em uma melhoria de velocidade de 35\%. Na pesquisa de Miljkovic et al. (2010) são desenvolvidas técnicas de frameworls em nível de camada de middleware common core, onde são utilizadas técnicas de reuso para rotinas de armazenamento do kernel.

Em uma visão paralela, ainda na categoria (1) Cattelan et al. (2008) utiliza as tecnologias de XML para armazenamento de informações do usuário no middleware common core, sendo essa iniciativa aproveitada para aplicações na área de saúde com Oliveira et al. (2009).

A Tabela apresenta o comparativo entre categorias evidenciadas, tecnologias utilizadas e ambientes do experimento para pesquisa de armazenamento em iDTV.

Para a categoria (2), a primeira pesquisa documentada encontra-se em Hayasaka et al. (1999), sendo essa a primeira pesquisa especificamente em armazenamento de conteúdo televisivo como objetivo principal, o qual implementa recursos de armazenamento para iDTV em intervalos do sinal elétrico. Em sequência, Milenkovic (1998) implementou um serviço de envio de dados aglutinados ao aúdio e vídeo, por meio da interface aéres de broadcast para o protocolo MPEG2, sendo essa tecnologia nomeada de DSMCC, a qual, reproduz uma estrutura de pastas do provedor de conteúdo no receptor digital.

Ainda na categoria (2), é apresentado em Kim et al. (2004) uma pesquisa na camada de hardware para captura de imagens estáticas no ambiente de TV Digital, nessa pesquisa foi proposto um dispositivo físico, que decodifica as imagens estáticas em formatos conhecidos (JPEG, BMP, TIFF). E foi desenvolvida tambem a pesquisa de Li e Guo (2009), apresentando um método de gravação digital integrado há iDTV, por meio do formato H.264 em dispositivos USB, com desenvolvimento em kernel e no ambiente common core do middleware.

\subsection{Requisitos Arquiteturais Instanciados da ArciTV}

Conforme a utilização do ProSA-RA, a arquitetura de referência ArciTV foi especializadaDe acordo com a especilização da ArciTV apresentada na Figura 5.3. Os componentes e os artefatos foram instanciados visando um uso especifico para a aplicaçãode armazenamento de dados.

Ainda nessa mesma perspectiva, a aplicação deve manter uma comunicação com o usuário informando suas atividades e resultados, ou seja, ser informativo. O sistema de garantir a integridade do arquivo recém copiado para outro sistema de arquivos configurado. Da mesma forma, criar condições para que o desempenho seja maior utilizando o mínimo possível de recursos de hardware e software do receptor digital e desenvolver um código-fonte otimizado e refinado. Os requisitos foram listados a seguir, conforme os casos de uso na Figura 5.5. 
Tabela 5.1: Comparação entre pesquisas existentes para armazenamento televisivo.

\begin{tabular}{|c|c|c|c|c|}
\hline Categoria & Referência & Tecnologias & Camada & Experimento \\
\hline (1) & (Mai et al., 2007) & $\begin{array}{l}D V B-M H P \quad \text { e } \\
\text { Blu-Ray }\end{array}$ & Hardware & Real \\
\hline (1) & $\begin{array}{l}\text { (Jo et al., 2009) } \\
\text { (Miljkovic et al., } \\
2010)\end{array}$ & $\begin{array}{l}\text { Kernel e User } \\
\text { Space }\end{array}$ & $\begin{array}{l}\text { Common Core } \\
\text { do Middleware }\end{array}$ & Real \\
\hline (1) & $\begin{array}{l}\text { (Oliveira et al., } \\
2009)\end{array}$ & $\begin{array}{l}I P T V, \\
\text { Ginga-J, USB } \\
\text { e Sun Spot }\end{array}$ & $\begin{array}{l}\text { Middleware } \\
\text { Procedural }\end{array}$ & Simulação \\
\hline (1) & $\begin{array}{l}\text { (Piccolo e Bara- } \\
\text { nauskas, 2006) }\end{array}$ & TV Terrestre & $\begin{array}{ll}\text { Camada } & \text { de } \\
\text { aplicação } & \text { do } \\
\text { Middleware } & \\
\text { (Interface) } & \end{array}$ & Simulação \\
\hline (1) & $\begin{array}{l}\text { (Cattelan et al., } \\
\text { 2008) }\end{array}$ & $\begin{array}{l}X M L, \quad \text { User } \\
\text { Space, } \quad \text { Ginga } \\
N C L \text { e } P 2 P\end{array}$ & $\begin{array}{l}\text { Middleware } \\
\text { common core } \\
\text { e apresentador } \\
\text { declarativo }\end{array}$ & Simulação \\
\hline (1) & $\begin{array}{l}\text { (Hsu et al., 2006) } \\
\text { (dos Santos et al., } \\
2008)\end{array}$ & $\begin{array}{l}X M L \quad \text { Schema, } \\
\text { GEM-J, } \\
\text { Ginga-J } \\
\text { IPTV }\end{array}$ & $\begin{array}{l}\text { Middleware } \\
\text { Procedural }\end{array}$ & Simulação \\
\hline$(2)$ & $\begin{array}{l}\text { (Hayasaka et al., } \\
1999)\end{array}$ & $\begin{array}{l}\text { Broadcast } \\
\text { MPEG-2 } \\
D C S\end{array}$ & $\begin{array}{l}\text { Interface aérea } \\
\text { de broadcast }\end{array}$ & Real \\
\hline (2) & $\begin{array}{l}\text { (Dong-Hwan et } \\
\text { al., 2006) } \\
\text { (Milenkovic, 1998) } \\
\text { (Tan et al., 2003) } \\
\text { (Sun et al., 2003) }\end{array}$ & $D S M-C C$ & $\begin{array}{l}\text { Interface aérea } \\
\text { de broadcast }\end{array}$ & Real \\
\hline$(2)$ & $\begin{array}{l}\text { (Kim et al., 2004) } \\
\text { (Li e Guo, 2009) }\end{array}$ & $\begin{array}{l}\text { Cartão de me- } \\
\text { mória, } W X G A \text {, } \\
U S B \text { e } H .264\end{array}$ & Hardware & Real \\
\hline$(2)$ & (Dong et al., 2011) & $\begin{array}{l}\text { Base de dados } \\
\text { em } S Q L\end{array}$ & $\begin{array}{ll}\text { Camada } & \text { de } \\
\text { Middleware } & \end{array}$ & Simulação \\
\hline
\end{tabular}

Selecionar o arquivo a ser copiado; O sistema deverá armazenar uma referencia da localização do arquivo no momento em que for selecionado pelo usuário.

Localizar arquivo no sistema de arquivos original; O sistema deverá localizar o arquivo a partir da referencia informada na seleção, com ela o sistema rastreará o bloco de dados (caso seja um sistema de arquivos local) inicial do arquivo para que o carregamento na memória seja iniciado. 


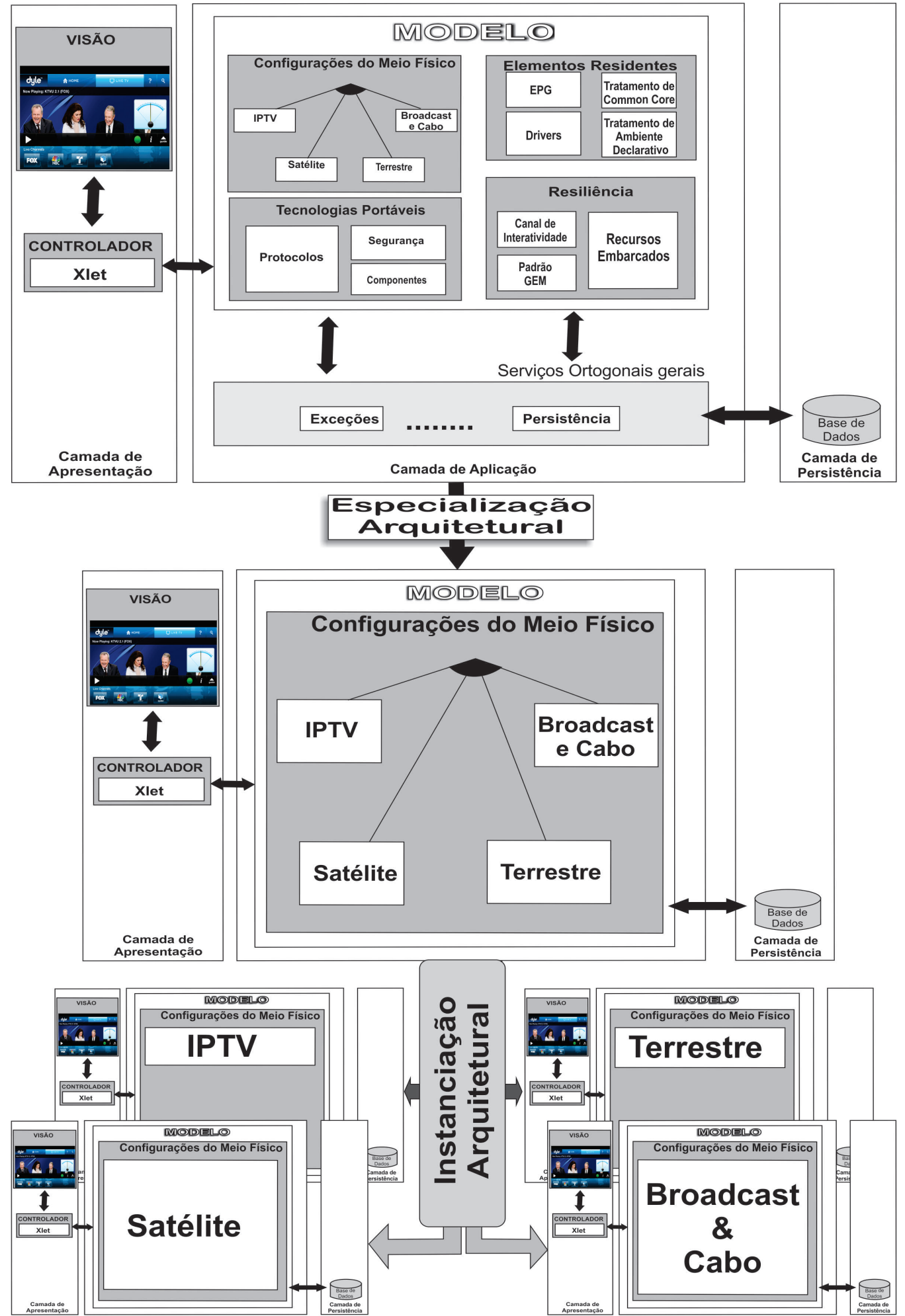

Figura 5.3: Instanciação da Arquitetura de Referência

No caso do sistema de arquivos ser o broadcaster o funcionamento da busca é diferente, pois será realizada pela JavaTV. 


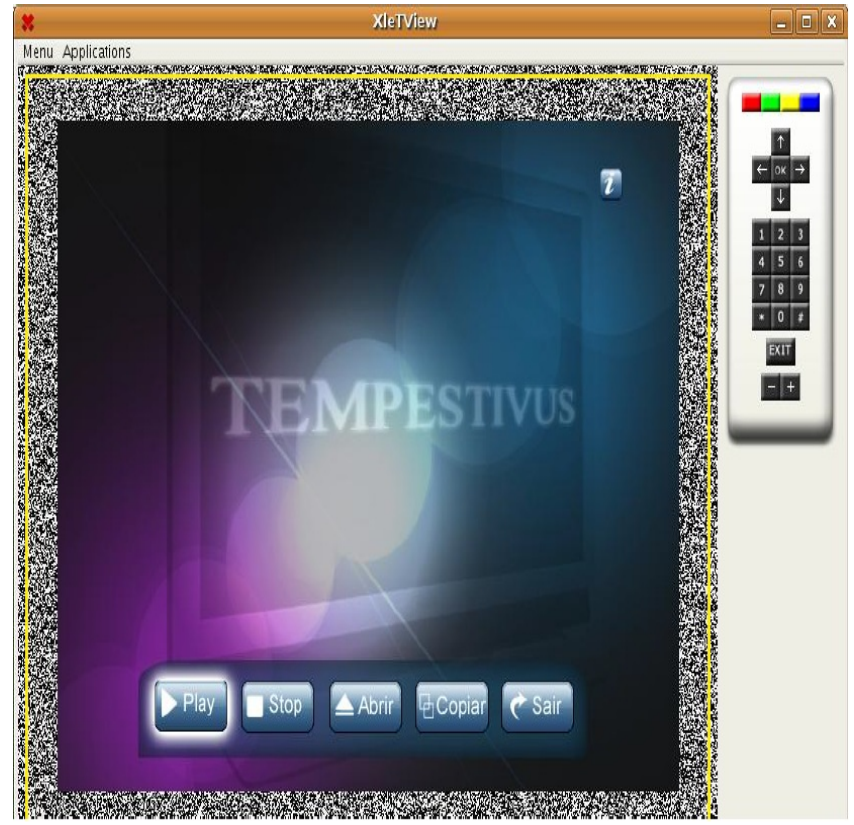

Figura 5.4: Aplicação executada no Emulador Xletview.

Localizar o sistema de arquivos de destino; O sistema deverá localizar a posição do bloco para onde o arquivo começará a ser copiado dentro de algum diretório definido e contido no sistema de arquivos de destino para que assim a transferência dos bytes inicie.

Copiar arquivo; Responsável em transferir os dados para o sistema de arquivos de destino.

Ler arquivo; A partir da localização do arquivo, o sistema inicia o carregamento para a memória do set-top box. A leitura aponta para o bloco de dados inicial do arquivo.

Transformar estruturas de dados em bytes; O sistema por meio da JVM converterá os dados residentes em memória em um fluxo de bytes num processo chamado de serialização.

Realizar tratamento dos erros; O sistema deverá tratar os erros de forma amigável para exibir aos usuários, caso exista algum problema no processamento.

Transformar bytes em estruturas de dados; O sistema por meio da JVM converterá os bytes residentes em dispositivo de armazenamento secundário em uma estrutura de dados num processo chamado de deserialização.

A aplicação foi estruturada segundo a arquitetura MVC, conforme a Figura 5.6 a classe TempestivusXlet é o controlador da arquitetura, por meio dela as outras classes são instanciadas para que o processamento da interface de tela seja iniciada, o gerenciamento da transferência de dados seja iniciado e a reprodução do arquivo de mídia seja executado. A classe Display gera os componentes gráficos de modo a criar um ambiente intuitivo para o usuário utilizar o aplicativo de teste da transferência de dados, por meio dessa GUI ( Graphic User Interface) é possível solicitar as operações implementadas no sistema. A classe GerenteArquivo, é o modelo da arquitetura responsável em criar as condições para o carregamento do bytes na memória do receptor digital por meio do método da classe FileInputStream.read(), é então iniciado a leitura dos dados e realizada a gravação no sistema de arquivos determinado.

O diagrama de estados da Figura 5.7 a seguir mostra os possíveis estados assumidos pela classe de GerenteArquivo, ou seja, o comportamento em função das operações executadas. 


\section{CAPÍTULO 5. ESTUDO DE CASO: UTILIZAÇÃO DA ARCITV}

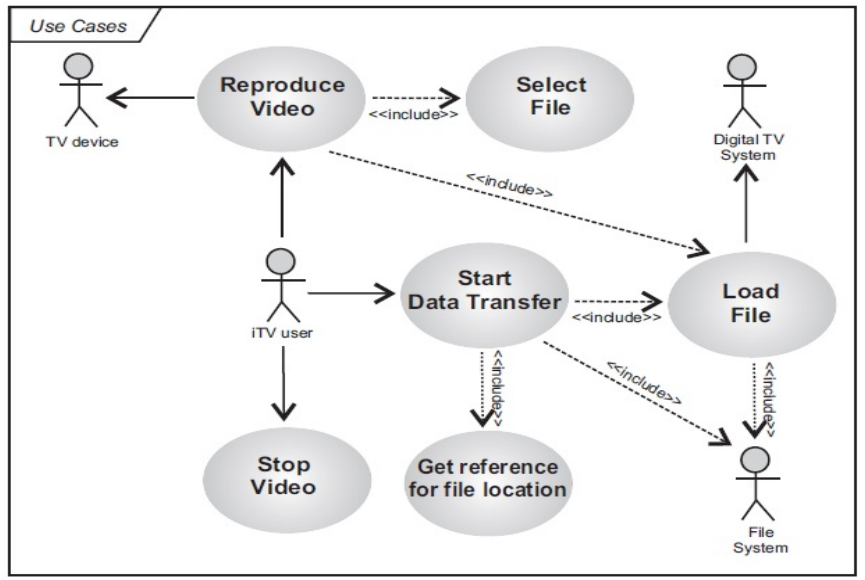

Figura 5.5: Casos de Uso para Aplicação de Armazenamento USB na iTV

\begin{tabular}{|c|c|}
\hline View Display & \multirow{2}{*}{\begin{tabular}{|c|} 
Model/CileManager \\
\end{tabular}} \\
\hline \multirow[b]{2}{*}{$\begin{array}{l}\text { - background: HGraphicButton } \\
\text { - openButton: HStaticText } \\
\text { - copyButton: HStaticText } \\
\text { - playButton: HStaticText } \\
\text { - aboutButton: HStaticText } \\
\text { - stopButton: HStaticText } \\
\text { - image: Image } \\
\text { - message: String } \\
\text { - userMessage: HStaticText } \\
\text { - labelCopy } \text { HStatic Text } \\
\text { - labelCopySequence: HStaticText } \\
\text { - scene: HScene } \\
\text { - title: HStaticText } \\
\text { - videoUrl: String } \\
\end{array}$} & \\
\hline & $\begin{array}{l}\text { - file: File } \\
\text { - fileCopy: File } \\
\text { - fileInputStream: FileInputStream } \\
\text { - fileOutputStream: FileOutputStream } \\
\text { - dataOutputStream: DataOutputStream }\end{array}$ \\
\hline $\begin{array}{l}\text { + setComponents( ): void } \\
\text { + buildScenario( ): HScene } \\
\text { + Display( ) } \\
\text { + displayMessage( ): void } \\
\text { + getMessage( ): String } \\
\text { + getVideoUrl( ): String } \\
\text { + setMessage(String): void } \\
\text { + setVideoUrl(String): void } \\
\text { + setComponentVisibility(boolean): void }\end{array}$ & \multirow{6}{*}{$\begin{array}{l}\text { - linkDataOutputStream( ): void } \\
\text { - linkInputStream( ): void } \\
\text { - linkOutputStream( ): void } \\
\text { + FileManager(File, File) } \\
\text { + dataTransfer( ): boolean }\end{array}$} \\
\hline & \\
\hline Controller & \\
\hline Tempestivus Xlet & \\
\hline $\begin{array}{l}\text { - context: XletContext } \\
\text { display: Display } \\
\text { - FILE NAME: String\{readOnly\} } \\
\text { - player: Player } \\
\text { - scene: HScene } \\
\text { - VIDEO URL: String \{readOnly\} } \\
\end{array}$ & \\
\hline $\begin{array}{l}\text { + controllerUpdate(ControllerEvent): void } \\
+ \text { destroyXlet(boolean): void } \\
+ \text { initXlet(XletContext): void } \\
+ \text { pauseXlet }(): \text { void } \\
+ \text { startXlet( }) \text { : void }\end{array}$ & \\
\hline
\end{tabular}

Figura 5.6: Arquitetura MVC

No momento em que a classe GerenteArquivo é inicializada, uma instancia da classe é criada e os parâmetros de localização da origem do arquivo e do destino da gravação já foram atribuídos à classe. 
Posteriormente, a leitura do arquivo é inicializada e a classe entra no estado de leitura Read, na seqüência o sistema verifica a ocorrência de exceções, em caso positivo o sistema entra no estado Abort e em sequencia no estado Finish.

Com a inexistência de exceções, o estado Record, após a inicialização desse estado, ocorre um ciclo de repetições de estado até que o final do arquivo seja atingido, passando ao estado Finish.

O digrama de atividades na Figura 5.8 apresenta a sequencia de passos obedecida pelo sistema. Quando a cópia do arquivo é inicializada o sistema solicita do usuário a localização do arquivo para que a busca inicie, após o inicio da busca pelo arquivo, o sistema armazena na memória o conjunto de arquivos para em sequência iniciar a transferência dos bytes para o destino conFigurado, neste caso um dispositivo de armazenamento USB.

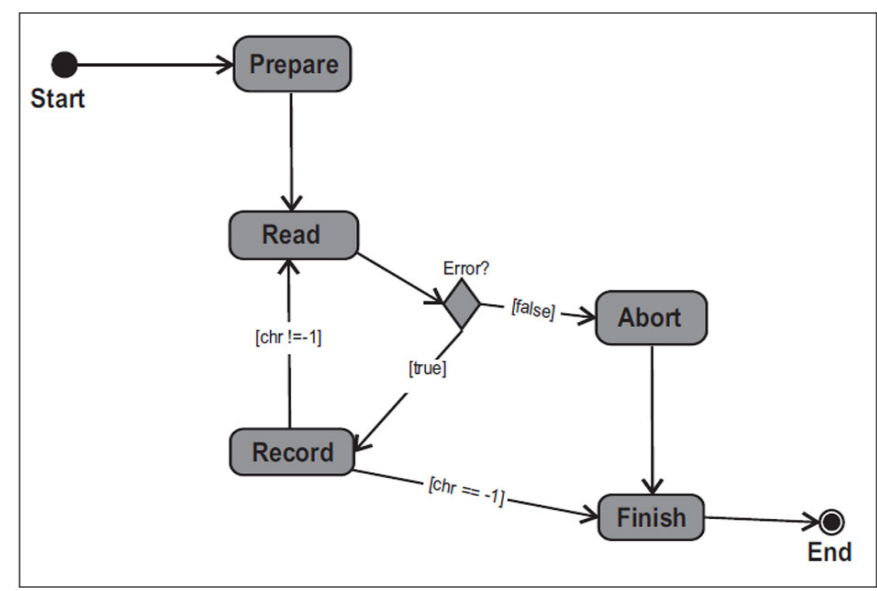

Figura 5.7: Diagrama de Estados

A descrição e a relação dos pacotes e classes utilizados pelos processos do aplicativo, são apresentadas a seguir e na Figura 5.5:

Selecionar opção para copiar; Nesta fase o aplicativo seleciona qual arquivo será copiado. No caso do projeto foi fixado o arquivo de origem.

Informar URL do arquivo A partir da URL, o sistema busca o arquivo no sistema de arquivos local. As bibliotecas utilizadas nessa busca java.io.File, java.io.FileInputStream, java.io.FileNotFoundException e java.io.IOException;

Buscar arquivo no carrossel de objetos; Buscar arquivo no sistema de arquivos do broadcast. As bibliotecas utilizadas javax.tv.carousel.CarouselFileListener, java.io.File, java.io.FileInputStream, são, javax.tv.locator.Locator, javax.tv.carousel.CarouselFileChangeEvent, java.io.FileNotFoundException java.io.IOException.

Carregar arquivo na memória do Set-Top Box Após a busca do arquivo, o sistema carrega na memória os bytes organizados em estruturas de dados.

Transferir bytes para o dispositivo USB Inicia o processo de transferência dos bytes para o dispositivo USB. As bibliotecas utilizadas foram java.io.DataOutputStream, java.io.FileNotFoundException, java.io.FileOutputStream e java.io.IOException.

Informar o termino da transferencia; Quando a transferência dos bytes termina o sistema informa por meio de uma mensagem. 


\section{CAPÍTULO 5. ESTUDO DE CASO: UTILIZAÇÃO DA ARCITV}

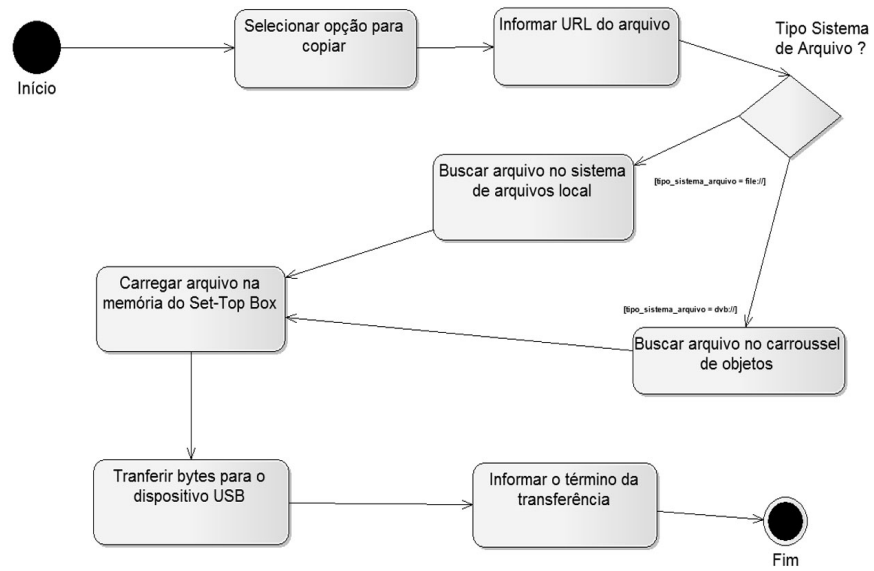

Figura 5.8: Diagrama de Atividades

\subsection{Considerações Finais}

A utilização das funcionalidades de armazenamento de dados é de grande frequência para o ambiente de TV digital interativa. Nesse capítulo foram discutidos os detalhes relacionados ao desenvolvimento de uma aplicação de armazenamento de dados para dispositivo USB, uma aplicação que tem como base a arquitetura de referência ArciTV. O desenvolvimento dessa aplicação apresentou evidências da facilidade de uso da arquitetura proposta e, em uma análise prévia, indicou que sua utilização pode trazer benefícios quanto a capacidade de manutenabilidade, integração e reúso. Vale ressaltar que esse mesmo estudo de caso poderia se estendido para o ambiente procedural, aumento posteriormente os componentes arquiteturais da ArciTV. Dentre as limitações encontradas, está uma análise qualitativa do uso da arquitetura trazendo uma visão mais geral do uso da arquitetura. No próximo capítulo, são discutidas em mais detalhes as conclusões desse trabalho. 


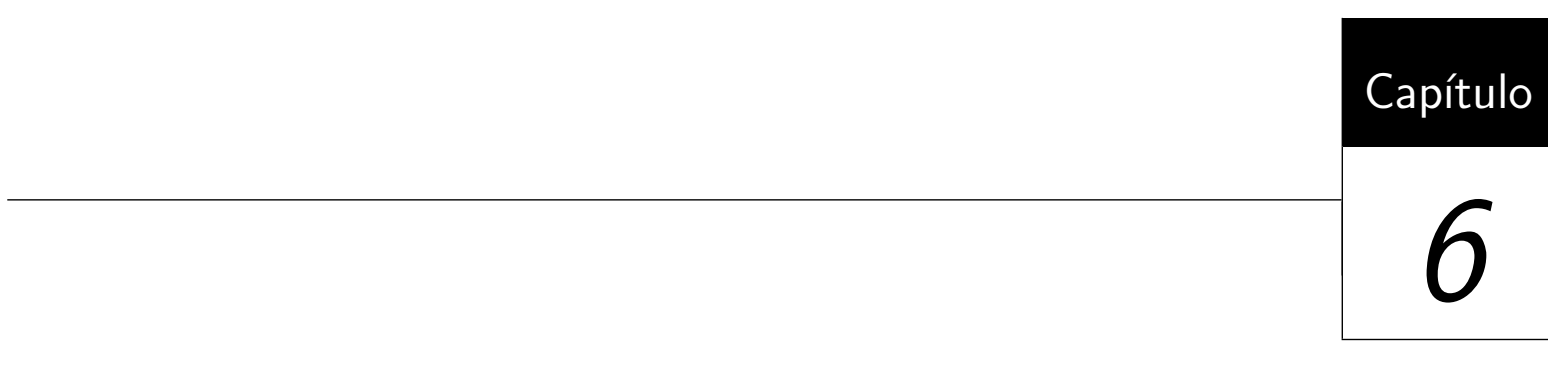

Conclusão

Neste capítulo é apresentado suscintamente o contexto que o trabalho foi inserido e suas contribuições para a area de Arquitetura de Software e TV Digital interativa. São elucidadas também, os desafios e dificuldades encontrados, as delimitações referentes a pesquisa e quais vertentes existem para trabalhos futuros.

\subsection{Caracterização da Pesquisa Realizada}

O desenvolvimento de software na área de TV Digital interativa tem tecnologias emergentes recentes, e envolve um nicho de mercado crescente na indústria de eletrônica de consumo. Nesse contexto, o desenvolvimento de diversas aplicações no cenários de TV Digital envolvem contato direto com o usuário final, em situações adversas, como envio de email, votação, comércio eletrônico, guias eletrônicos de programação, dentre outros. Contudo, esse desenvolvimento ainda requer pesquisas que deêm iniciativa ao amadurecimento da tecnologia, como técnicas de documentação, reúso, frameworks, e organização arquitetural. Dessa forma, esforços no intuito de estabelecer arquiteturas de software direcionadas para essas aplicaçoes, trarão um legado de auxilio no desenvolvimento, integração entre ferramentas e otimização de tempo e recursos humanos.

Recentemente, a área de sistemas embarcados para eletrônica de consumo tem adotado técnicas de engenharia de software para o desenvolvimento de aplicações, visando com isso metas de coesão e acoplamento. Dentre essas técnicas, as visões arquiteturais tem se destacado, devido a viabilidade de implantação em diferentes domínios, reutilização de recursos e orquestação de tecnologias novas. Esse cenário, tem fomentado a utilização de técnicas de arquiteturais de outras plataformas como a arquitetura de referência, legada de sistemas web.Dessa forma, uma arquitetura de referência que auxilie no desenvolvimento de aplicações para TV Digital, constitui uma importante ferramenta para aumento da integração, reúso e métricas de qualidade. 


\subsection{Contribuições}

Como contribuição principal deste trabalho, foi apresentada uma arquitetura de referência para aplicações procedurais em TV Digital interativa, com o objetivo de organizar o desenvolvimento de todos os tipos de aplicações desse domínio. É fundamental ressaltar que, dentro do referencial teórico levantado, a arquitetura de referência proposta é a única a dar base para o desenvolvimento de aplicações para middleware em TV Digital. Ainda nessa perspectiva, os componentes arquiteturais desenvolvidos dão suporte para os quatros tipos principais de aplicações, residente, tecnologias portáveis, resilientes e aplicações de meio físico.

Ainda nessa perspectiva, os requisitos arquiteturais apresentandos na Seção 4.3 servem como base de desenvolvimento em outras camadas arquiteturais, no ambiente de TV Digital, como no ambiente Common Core. O panorama para o desenvolvimento para a arquitetura de referência foi desenvolvido por meio de duas revisões sistemáticas, a primeira foi direcionada para pesquisa em sistemas embarcados e o uso de programação orientada a aspectos, e a segunda foi direcionada para aplicações em TV Digital interativa. Com base na aglutinação desses conhecimentos, foram desenvolvidos os requisitos arquiteturais.

De maneira geral, o objetivo deste trabalho foi alcançado que a normatização de uma arquitetura para o ambiente de TV Digital, contribuindo como uma documentação pertinente ao cenário de desenvolvimento de software, para middlewares em TVDs interativas e consequentemente um visão ampla e sistémica de aplicações da área.

\subsection{Dificuldades e Limitações}

Dentre as dificuldades encontradas no desenvolvimento deste trabalho, uma delas foi a necessidade de consulta de diferentes subáreas de pesquisa, isso se fez necessário para adquirir uma visão holística das aplicações desenvolvidas em middleware para TV Digital. Dentre essas subáres de pesquisa é válido destacar: (i) Tv Digital e Automação Residencial, (ii) Aplicações Embarcadas, (ii) Desenvolvimento em middleware para TV Digital, (iv) Camadas distintas de desenvolvimento de aplicações para iTV.

As limitações enfrentadas no desenvolvimento deste trabalho destacam-se na validação da arquitetura de referência, onde foi instaciado por meio da arquitetura de referência ArciTV um estudo de caso com o desenvolvimento de uma aplicação USB para armazenamento de dados multimidia. No condizente há atualizações da arquitetura a prática já está instriseca ao desenvolvimento arquitetural desse projeto, conforme Angelov et al. (2008).

\subsection{Trabalhos Futuros}

Como futuras contribuições em continuidade deste trabalho, podem ser citados os seguintes tópicos abaixo;

Extensão da Arquitetura para o ambiente Common Core do middleware; A presente arquitetura de referência contempla o desenvolvimento de aplicações no ambiente procedural, para camadas de mais alto nível, no momento o pacote de Aplicações Residente contempla o uso de

Inserção Métodos de Processos de Desenvolvimento de Software; A Arquitetura de Referência contempla o desenvolvimento de aplicações para iTV, porem, futuras contribuições podem con- 


\section{CAPÍTULO 6. CONCLUSÃO}

templar melhorias no processo de desenvolvimento, visando com isso melhorias de qualidade arquiteturais.

Desenvolvimento de Diretrizes para Aplicações no Ambiente Televisivo; Durante o levantamento de fontes de informações, não foram constatadas diretrizes maduras de desenvolvimento, como o direcionamento em métricas de coesão e acoplamento. 



\section{Referências}

Akkawi, F.; Bader, A.; Elrad, T. Aspect-oriented technology for business applications: a case study in stock trading. In: Proceedings of the 12th International Workshop on Database and Expert Systems Applications(DEXA'01), Munich, Germany: IEEE, 2001, p. 906 - 914.

Alic, K.; Zajc, M.; Tkalcic, M.; Burnik, U.; Tasic, J. Development of interactive television t-learning course. In: Proceedings of the 14th IEEE Mediterranean Electrotechnical Conference(MELECON'08)., 2008, p. $139-144$.

Alwis, B. Aspects of incremental programming. Dissertação de mestrado, University of British Columbia., Vancouver, Canada, 2002.

Angelov, S.; Grefen, P.; Greefhorst, D. A classification of software reference architectures: Analysing their sucess and effectiveness. In: Proceedings of 8th Working IEEE/IFIP Conference on Software Architecture(WICSA'09), Cambrigde, UK, 2009, p. 141-150.

Angelov, S.; Trienekens, J.; Grefen, P. Towards a method for the evaluation of reference architectures: Experiences from a case. In: Proceedings of the $2^{\text {nd }}$ European Conference on Software Architecture (WICSA/ECSA 2008), Paphos, Cyprus: Springer-Verlag, 2008, p. 225-240 (LNCS v.5292).

Arsanjani, A.; Zhang, L.; Ellis, M.; Allam, A.; Channabasavaiah, K. S3: A service-oriented reference architecture. IT Professional, p. 10-17, 2007.

AUTOSAR AUTOSAR (AUTomotive Open System ARchitecture). [On-line], World Wide Web, available in: http://www. autosar.org/ (Acessado em 26/04/2012), 2012.

de Ávila, P. M.; Zorzo, S. D. A personalized tv guide system compliant with ginga. In: Proceedings of the XV Brazilian Symposium on Multimedia and the Web(WebMedia'09), Fortaleza, Ceará, Brasil: ACM, 2009, p. 5:1-5:8.

Barbosa, S.; Soares, L. Tv digital interativa no brasil se faz com ginga: Fundamentos, padrões, autoria declarativa e usabilidade. In: Jornada de Atualização em Informática (JAI'08), Belém, PA, Brasil: ACM, 2008, p. 105-174.

Barr, M. Programming embedded systems in C and C++. New York, NY, USA: O'Reilly, 1999. 
Bass, L.; Clements, P.; Kazman, R. Software architecture in pratice. Addison-Wesley, 2003.

Bayer, J.; Forster, T.; Ganesan, D.; Girard, J. F.; John, I.; Knodel, J.; Kolb, R.; Muthig, D. Definition of reference architectures based on existing systems. Relatório Técnico 034.04/E, Fraunhofer IESE, 2004.

Beuche, D.; Guerrouat, A.; Papajewski, H.; Schroder-Preikschat, W.; Spinczyk, O.; Spinczyk, U. The PURE family of object-oriented operating systems for deeply embedded systems. In: Proceedings of 2nd International Symposium on Object-Oriented Real-Time Distributed Computing(ISORC'g9), Saint-Marlo, France: IEEE, 1999, p. 45-53.

Billinghurst, M.; Starner, T. Wearable devices: new ways to manage information. IEEE Transactions on Consumer Electronics, v. 32, n. 1, p. 57-64, 1999.

Boehm, B. A view of 20th and 21st century software engineering. In: ICSE'06, New York, NY, USA, 2006, p. 12-29.

Bonér, J.; Vasseur, A. Aspectwerkz - plain java aop. [On-line], World Wide Web, disponível em: http://aspectwerkz.codehaus.org/ (Acessado em 12 de janeiro de 2011), 2004.

Borg, Z. A reference architecture for marine systems. Dissertação de Mestrado, University of Kaiserslautern and Fraunhofer Institute for Experimental Software Engineering (IESE), Kaiserslautern, Germany, 2011.

Burke, B.; Brock, A. Aspect-oriented programming and jboss. [On-line], World Wide Web, disponível em: http://www.onjava.com/pub/a/onjava/2003/05/28/aop_jboss.html (Acessado em 12 de janeiro de 2011), 2003.

Calder, B.; Courtney, J.; Foote, B.; Kyrnitszke, L.; Rivas, D.; Saito, C.; Vanloo, J.; Ye, T. The javatv api whitepaper. Relatório Técnico 1.0, Sun Microsystems, 2004.

Camargo, V.; Ramos, R.; Penteado, R.; Masiero, P. Projeto baseado em aspectos do padrão camada de persistência. In: Proceedings of Simpósio Brasileiro de Engenharia de Software(SBES'03), Manaus, AM, Brasil: IEEE, 2003, p. 5-14.

Carvalho, L. A. M. C.; Guimarães, A. P.; Macêdo, H. T. Architectures for interactive vocal environment to brazilian digital tv middleware. In: Proceedings of the Euro American Conference on Telematics and Information Systems(EATIS'08), Aracaju, SE, Brasil: ACM, 2008, p. 22:1-22:8.

Cattelan, R. G.; Teixeira, C.; Goularte, R.; Pimentel, M. D. G. C. Watch-and-comment as a paradigm toward ubiquitous interactive video editing. ACM Transactions on Multimedia Computing, Communications and Applications, v. 4, n. 24, p. 1-24, 2008.

Chang, H.-B.; Liu, P.-L.; Shih, T.; Chen, Y.-L. Developing qti compliant assessment platform on digital tv. In: Proceedings of IEEE International Symposium on IT in Medicine and Education(ITME'08)., Xiamen, China, 2008, p. $786-789$.

Chavez, C. A model-driven approach to aspect-oriented design. Tese de Doutoramento, Departamento de Informática, Pontifícia Universidade Católica do Rio de Janeiro, Rio de Janeiro, RJ, Brasil, 2004. 
Chen, D.; Törngren, M. A metrics system for quantifying operational coupling in embedded computer control systems. In: Proceedings of the 4th International Conference on Embedded Software(EMSOFT'04), Pisa, Italy: ACM, 2004, p. 184-192.

Cheok, A. D.; Fong, S. W.; Goh, K. H.; Yang, X.; Liu, W.; Farzbiz, F. Human pacman: a sensing-based mobile entertainment system with ubiquitous computing and tangible interaction. In: Proceedings of $2^{\text {nd }}$ Workshop on Network and System Support for Games(NetGames'03), Redwood City, California, USA: ACM, 2003, p. 106-117.

Chidamber, S.; Kemerer, C. A metrics suite for object oriented design. IEEE Transactions on Software Engineering, v. 20, n. 6, p. 476-493, 1994.

Choi, H.; Lim, C.; Kim, J. Architecture for iptv content delivery. In: Proceedings of the 11th International Conference on Advanced Communication Technology(ICACT'09), Phoenix Park, Korea: Springer Verlag, 2009, p. 284-287.

Clarke, S.; Baniassad, E. Aspect-oriented analysis and design: The theme approach. Addison-Wesley Professional, 2005.

Clarke, S.; Walker, R. J. Composition patterns: an approach to designing reusable aspects. In: Proceedings of the 23rd International Conference on Software Engineering (ICSE'01), Toronto, Ontario, Canada: IEEE, 2001, p. 5-14.

Clarke, S.; Walker, R. J. Towards a standard design language for AOSD. In: Proceedings of 1st International Conference on Aspect-oriented Software Development(AOSD'02), Enschede, The Netherlands: ACM, 2002, p. 113-119.

Clements, P.; Kazman, R.; Klein, M. Evaluating software architectures: Methods and case studies. 2 ed. Addison-Wesley, 2002.

Coady, Y.; Kiczales, G.; Feeley, M.; Smolyn, G. Using aspectC to improve the modularity of path-specific customization in operating system code. In: Proceedings of the 8th European software engineering conference held jointly with 9th International Symposium on Foundations of Software Engineering, Vienna, Austria: ACM, 2001, p. 88-98.

Conejero, J.; Hernandez, J.; Jurado, E.; Clemente, P.J.; Rodriguez, R. Early analysis of modularity in software product lines. In: Proceedings of the 21th International Conference on Software Engineering and Knowledge Engineering(SEKE'09), Boston, USA: ACM, 2009, p. 102-105.

Costa, R. M. d. R.; Moreno, M. F.; Soares, L. F. G. Ginga-ncl: supporting multiple devices. In: Proceedings of the 15th Brazilian Symposium on Multimedia and the Web(WebMedia'09), Fortaleza, Ceará, Brasil: ACM, 2009, p. 6:1-6:8.

DAVIC Digital Audio Visual Council. Online, http://www.davic.org - Acessado em 12/11/2011, 2011.

De Lucena, V.; Filho, J.; Viana, N.; Maia, O. A home automation proposal built on the ginga digital tv middleware and the osgi framework. Consumer Electronics, IEEE Transactions on, v. 55, n. 3, p. $1254-1262,2009$. 
Dijkstra, E. W. A discipline of programming. Upper Saddle River, NJ, USA: Prentice-Hall, 1976.

Dong, Q.; Wen, Y.; Zhang, P.; Jiang, J. Design and realizing of the lightweight cable digital television data analysis system. In: Proceedings of the International Conference on Electronic and Mechanical Engineering and Information Technology(EMEIT'11), ACM, 2011, p. 813-815.

Dong-Hwan, P, .; Tai-Yeon, K.; Kyeong-Deok, M. Real-time carousel caching and monitoring in data broadcasting. In: Proceedings of the International Conference on Consumer Electronics(ICCE'06), Las Vegas, USA, 2006, p. $273-274$.

Duarte, L.; Nakagawa, E. Aspect-orientation in the development of embedded systems: A systematic review. In: Proceedings of 24th International Conference on Software Engineering and Knowlegde Engineering(SEKE'12), Redwood City, San Francisco Bay, USA: DBLP, 2012, p. 1-4.

Eickelmann, N.; Richardson, D. An evaluation of software test environment architectures. In: Proceedings of the 18th International Conference on Software Engineering(ICSE'96), Berlin, Germany, 1996, p. $353-364$.

Eklund, U.; Askerdal, O.; Granholm, J.; Alminger, A.; Axelsson, J. Experience of introducing reference architectures in the development of automotive electronic systems. SIGSOFT Software Engineering Notes, v. 30, n. 4, p. 1-6, 2005.

Electronics AND You Consumer electronics. [On-line], World Wide Web, disponível em: http://www . electronicsandyou.com/consumer-electronics/consumer_electronics.html (Acessado em 12 de janeiro de 2011), 2009.

Elrad, T.; Aksit, M.; Kiczales, G.; Lieberherr, K.; Ossher, H. Discussing aspects of AOP. Communications of the $A C M$, v. 44, n. 10, p. 33-38, 2001a.

Elrad, T.; Filman, R.; Bader, A. Aspect-oriented programming. Communications of the ACM, v. 44, n. 10, p. 29-32, 2001b.

Engel, M.; Spinczyk, O. A radical approach to network-on-chip operating systems. Hawaii International Conference on System Sciences, v. 0, n. 4, p. 1-10, 2009a.

Engel, M.; Spinczyk, O. A radical approach to network-on-chip operating systems. Hawaii International Conference on System Sciences, v. 0, n. 4, p. 1-10, 2009b.

ETSI European telecommunications standards institute. [On-line], World Wide Web, disponível em: http://www.etsi.org (Acessado em 12 de novembro de 2011), 2011.

Fagerqvist, M.; Marcussen, A. Application and system migration from opentv to dvb-mhp. Master thesis, Institutionen för Systemteknik - Avdelningen för Programvaruteknik - Lulea Tekniska Universitet, Lulea, Suécia, 2000.

Fanjiang, Y.; Kuo, J.; Ma, S.; Huang, W. An aspect-oriented approach for mobile embedded software modeling. In: Proceedings of 11th International on Computational Science and Its Applications(ICCSA'10), Fukuoka, Japan: Lecture Notes in Computer Science(LNCS), 2010, p. 257-272. 
Fernandes, J. $\quad T v$ digital interativa. Pós graduação lato sensu em engenharia de sistemas, Escola Superior Aberta do Brasil de Vitória, Vitória, Brasil, 2006.

Filman, R.; Friedman, D. Aspect-oriented programming is quantification and obliviousness. In: Proceedings of Conference on Object-Oriented Programming, Systems, Languages, and Applications(OOPLA'00), Minneapolis, Minnesota, USA: ACM, 2000, p. 21-35.

Filman, R. E.; Elrad, T.; Clarke, S.; Aksit, M. Aspect-oriented software programming. Princeton, NJ, USA: Addison-Wesley, 2004.

Finke, M.; Balfanz, D. A reference architecture supporting hypervideo content for itv and the internet domain. Computers and Graphics, v. 28, n. 2, p. 179 - 191, 2004.

Fioravanti, M. L.; Nakagawa, E. Y.; Barbosa, E. F. EducAR: Uma arquitetura de referência para ambientes educacionais. In: XXI Simpósio Brasileiro de Informática na Educação (SBIE'2010), João Pessoa, PB, 2010, p. 1-10.

Flintham, M.; Benford, S.; Anastasi, R.; Hemmings, T.; Crabtree, A.; Greenhalgh, C.; Tandavanitj, N.; Adams, M.; Row-Farr, J. Where on-line meets on the streets: experiences with mobile mixed reality games. In: Proceedings of the Conference on Human Factors in Computing Systems(CHI'03), Ft. Lauderdale, Florida, USA: ACM, 2003, p. 569-576.

Freitas, E.; Wehrmeister, M.; Pereira, C.; Wagner, F.; Silva, E.; Carvalho, F. Using aspect-oriented concepts in the requirements analysis of distributed real-time embedded systems. In: Proceedings of International Federation for Information Processing(IFIP'07), Cracow, Poland: Springer Boston, 2007, p. 221-230.

Gal, A.; Schröder-Preikschat, W.; Spinczyk, O. Aspectc++: Language proposal and prototype implementation. Book Chapter, 2001.

Genuchten, M. The impact of software growth on the electronics industry. Computer, v. 40, n. 3, p. $106-108,2007 \mathrm{a}$.

Genuchten, M. The impact of software growth on the electronics industry. IEEE Society, v. 40, n. 3, p. 106-108, 2007b.

Grosskurth, A.; Godfrey, M. W. A reference architecture for web browsers. Proceedings of the 21th IEEE International Conference on Software Maintenance(ICSM'05), p. 661-664, 2005.

Gustafsson, T.; TeŠAnović, A.; Du, Y.; Hansson, J. Engineering active behavior of embedded software to improve performance and evolution: an aspect-oriented approach. In: Proceedings of the Symposium of Applied Computing (SAC'07), Chicago, USA: ACM, 2007, p. 673-679.

Haupt, M. Virtual machine support for aspect-oriented programming languages. Tese de Doutoramento, Fachbereich Informatik der Technischen Universitat Darmstadt, TU Darmstadt, 2006.

HAVi HAVi: The Home Audio and Video Interoperability. Online, http://www .havi.org - Acessado em 12/11/2011, 2011. 
Hayasaka, R.; Matoba, H.; Maeno, K. New digital broadcasting services for use with tv sets containing digital storage devices. In: Proceedings of the 7th ACM international conference on Multimedia(MM'99), ACM, 1999, p. 127-130.

Herget, M.; Obradovic, N.; Marasanov, Z.; Savic, M. Connecting linux based connected tv: Application implementation guidelines. In: Proceedings of 19th Telecommunications Forum (TELFOR'11), 2011, p. $1406-1409$.

Herrmann, S.; Hundt, C.; Mosconi, M. Objectteams/java language definition — version 1.0. Tech. Report Fak. IV, Technical University Berlin, Berlin, Germany, 2007.

Herrmann, S.; Hundt, C.; Mosconi, M. Objectteams and java language definition version 1.2 built on. Relatório Técnico, Technical University of Berlin, Berlin, Germany, 2009.

Hirschfeld, R. AspectS - Aspect-oriented programming with Squeak. In: Revised Papers from the International Conference NetObjectDays on Objects, Components, Architectures, Services, and Applications for a Networked World, (NODe '02), London, United Kingdom: Springer-Verlag, 2003, p. $216-232$.

Hsu, K.-S.; Yang, C.; Chao, T.-H. An authoring tool and extendable production architecture for interactive television services. In: Proceedings of the 10th International Symposium on Consumer Electronics(ISCE`06), St Petersburg, Russia: ACM, 2006, p. 1-6.

Hundt, C.; Glesner, S. Optimizing aspectual execution mechanisms for embedded. In: Electron. Notes Theor. Comput. Sci., n. 2, Berlin, Germany: Elsevier, 2009, p. 35-45.

Hundt, C.; Glesner, S. Optimizing aspectual execution mechanisms for embedded. In: Electron. Notes Theor. Comput. Sci., n. 2, Berlin, Germany: Elsevier, 2009, p. 35-45.

Ibrahim, A.; Johansson, P. Multimodal dialogue systems for interactive tv applications. In: Proceedings of 4 th IEEE International Conference on Multimodal Interfaces(ICMI'02), Pittsburgh, PA, USA, 2002, p. $117-122$.

International Telecommunications Union Worldwide common core - application environment for digital interactive television services. Tech. Report J.200, ITU, Los Angeles, California, USA, 2001.

ISO (International Organization for Standardization) ISO/IEC 13818-6:1998/Cor2:2002. Generic Coding of Moving Pictures and Associated Audio Information: Extensions for DSMCC. Online, http: //www.iso.org - Acessado em 09/11/2011, 1998.

ISO (International Organization for Standardization) ISO/IEC 13818-2000. Generic Coding of Moving Pictures and Associated Audio Information. Online, http: //www . iso .org - Acessado em 09/11/2011, 2000 .

Issarny, V.; Caporuscio, M.; Georgantas, N. A perspective on the future of middleware-based software engineering. In: Proceedings of the International Conference on Future of Software Engineering(FoSE'07), Minneapolis, Minnesota, USA, 2007, p. $244-258$.

ITU International Telecommunication Union. Online, http://www .itu.int - Acessado em 11/11/2011, 2011. 
Jacobson, I.; Pan-Wei, N. Aspect-oriented software development with use cases. Princeton, NJ, USA: Addison-Wesley, 2004.

Jerraya, A.; Wolf, W. Hardware/software interface codesign for embedded systems. IEEE Computer, v. 38, n. 2 , p. $63-69,1998$.

Jo, H.; Kim, H.; Jeong, J.; Lee, J.; Maeng, S. Optimizing the startup time of embedded systems: a case study of digital tv. IEEE Transactions on Consumer Electronics, v. 55, n. 4, p. 2242 -2247, 2009.

Johnson, R.; Hoeller, J.; Arendsen, A.; Sampaleanu, C.; Davison, D.; Kopylenko, D.; Risberg, T.; Pollack, M.; Harrop, R. Spring - java/j2ee application framework. reference documentation version 1.1.4. [On-line], World Wide Web, disponível em: http://static.springsource.org/spring/docs/1.1. 3/reference/ (Acessado em 12 de janeiro de 2011), 2004.

Jonker, W.; Linnartz, J. Digital rights management in consumer electronics products. IEEE Signal Processing Magazine, v. 21, n. 2, p. 82-91, 2004.

Kairer, R. Smartphones showed strong growth in 2007. [On-line], World Wide Web, disponível em: http://www.palminfocenter.com/news/9617/smartphones-showed-strong-growth-in-2007 (Acessado em 12 de janeiro de 2011), 2008.

Kairer, R. Worldwide mobile phone sales grew $17 \%$ in q1 $2010 . \quad$ [On-line], World Wide Web, disponível em: http://www.palminfocenter.com/news/6435/ worldwide-mobile-phone-sales-grew-17-in-q1-2010/ (Acessado em 12 de janeiro de 2011), 2010 .

Karlof, C.; Sastry, N.; Wagner, D. Tinysec: a link layer security architecture for wireless sensor networks. In: Proceedings of the $2^{\text {nd }}$ International Conference on Embedded Networked Sensor Systems(SenSys'02), New York, NY, USA, 2002, p. 162-175.

Kartal, Y.; Schmidt, E. An evaluation of aspect oriented programming for embedded real-time systems. In: Proceedings of the the 220 International Symposium on Computer and Information Sciences (ISCIS'07), Ankara, Turkey: IEEE, 2007, p. 1-6.

Kiczales, G.; Hilsdale, E.; Hugunin, J.; Kersten, M.; Palm, J.; Griswold, W. Getting started with ASPECTJ. Communications of the ACM, v. 44, n. 7, p. 59-65, 2001a.

Kiczales, G.; Hilsdale, E.; Hugunin, J.; Kersten, M.; Palm, J.; Griswold, W. An overview of Aspectj. In: Proceedings of the 15th European Conference on Object-Oriented Programming (ECOOP'01), London, UK: Springer-Verlag, 2001b, p. 327-353.

Kiczales, G.; Irwin, J.; Lamping, J.; Loingtier, J.; Lopes, C.; Maeda, C.; Menhdhekar, A. Aspect-oriented programming. In: Proceedings of 11th European Conference on Object-Oriented Programming(ECOOP'97), Jyväskylä, Finland: Springer-Verlag, 1997, p. 220-242.

Kim, H. AspectC\#: An AOsD implementation for C\#. Tese de Doutoramento, Department of Computer Science on Trinity College Dublin, Dublin, Germany, 2002.

Kim, I. H.; Choi, J. S.; Lee, Y. J.; Nam, J. Y.; Ha, Y. H. Delivering interactive services via a digital tv infrastructure. IEEE Transactions on Consumer Electronics, v. 50, n. 3, p. 962-967, 2004. 
Kitchenham, B. Procedures for performing systematic reviews. Relatório Técnico TR/SE-0401, Keele University, 2004.

Koong, C.-S.; Lai, H.-J.; Lai, K.-C. An embedded software architecture for robot with variable structures. In: Proceedings of 4 th International Conference on Frontier of Computer Science and Technology (FCST '09), Shanghai, China: IEEE, 2009, p. 478-484.

Kruchten, P.; Obbink, H.; Stafford, J. The past, present, and future for software architecture. IEEE Software, v. 23, n. 2, p. 22-30, 2006.

Leite, L. E. C.; De Souza Filho, G. L.; De Lemos Meira, S. R.; Araujo, P. C. T.; Lima, J. F.; Filho, S. M. A component model proposal for embedded systems and its use to add reconfiguration capabilities to the flextv middleware. In: Proceedings of the 12th Brazilian Symposium on Multimedia and the web(WEBMEDIA'06), Natal, Rio Grande do Norte, Brasil: ACM, 2006, p. 203-212.

Li, Q.; Guo, M. Digital recordable integrated television based on embedded linux operating system. In: Proceedings of the World Congress on Computer Science and Information Engineering(CSIE'09), Los Angeles, California, USA, 2009, p. 81-84.

Lin, C.-L.; Hung, Y.-H.; Chen, H.-Y.; Chu, S.-L. Content-aware smart remote control for android-based tv. In: Proceedings IEEE International Conference on Consumer Electronics(ICCE'12), Santander, Spain, 2012, p. $678-679$.

Ling, C.; Hwang, W.; Salvendy, G. A survey of what customers want in a cell phone design. Behaviour Information Technology, v. 26, p. 149-163, 2007.

Liu, F.; Tong, J.; Mao, J.; Bohn, R. B.; Messina, J. V.; Badger, M. L.; Leaf, D. M. NIST Cloud Computing Reference Architecture, p. 1-26. 2011.

Mai, Z.; Nasiopoulos, P.; Ward, R. Efficient dvb-mhp to blu-ray system information transcoding. In: Proceedings of the Canadian Conference on Electrical and Computer Engineering(CCECE'07), Vancouver, BC, Canada, 2007, p. 20-23.

Maia, O.; Viana, N.; de Lucena, V. Using the idtv for managing services in the ubiquitous computing environment. In: Symposia and Workshops on Ubiquitous, Autonomic and Trusted Computing(UIC-ATC'09)., Brisbane, Australia, 2009, p. $143-148$.

Maia, O. B.; de Lucena, Júnior, V. F. A communication infrastructure between the brazilian interactive digital tv and residential devices. In: Proceedings of the 7th european conference on European interactive television conference(EuroiTV'09), Leuven, Belgium, 2009, p. 115-118.

Marwedel, P. Embedded system design - embedded systems foundations of cyber-physical systems. Dortmund, Germany: Springer, 2011.

Medvidovic, N.; Roseblum, D.; Redmiles, D.; Robbins, J. Modeling software architectures in the unified modeling language. ACM Transactions onf Software Engineering and Methodology, v. 11, n. 1, p. $52-57,2002$.

Medvidovic, N.; Taylor, R. A classification and comparation framework for software architecture description language. IEEE Transactions on Software Engineering, v. 26, n. 2, p. 70-93, 2000. 
Meei-Ling, H.; Cheng-Fang, H.; Jui-Sheng, L.; Jun-Juh, Y.; Teh-Lu, L.; Yuan-Tai, H. Design of random digital sequence generators and its application of secure communication. In: Proceedings of the International Conference on Fluid Power and Mechatronics(FPM'11), Beijing, China, 2011, p. 889 -892 .

Mendes, A. Arquitetura de software: Desenvolvimento orientado para arquitetura. São Paulo, Brasil: Ed. Campus, 2002.

Mikkonen, T. On the dominance of decompositions in models and their aspect-oriented implementations. In: Proceedings of the $2^{\text {nd }}$ International Workshop on Aspect-Based and Model-Based Separation of Concerns in Software Systems(ABMB'06), Amsterdam, The Netherlands: Elsevier Science Publishers B. V., 2007, p. 19-28.

Milenkovic, M. Delivering interactive services via a digital tv infrastructure. IEEE Multimedia, v. 5, n. 4 , p. $34-43,1998$.

Miljkovic, G.; Mihic, V.; Ristic, M.; Kovacevic, V. DTV linux device abstraction for embeded systems. In: Proceedings of the 14th International Symposium on Consumer Electronics, IEEE, 2010, p. 1-6.

Miller, P. Consumer electronics. IEEE Spectrum, v. 36, n. 1, p. 41-45, 1999.

Mobile Network Smartphones. [On-line], World Wide Web, disponível em: http://redemobi. wordpress.com/ (Acessado em 12 de janeiro de 2011), 2009.

Montez, C.; Becker, V. Tv digital interativa: Conceitos, desafios e perspectivas para o brasil. 2 ed. UFSC, 2005.

Montgomery, L. Home control interfaces get personal. [On-line], World Wide Web, disponível em: http://www.electronichouse.com/article/print/home_control_interfaces_get_ personal/ (Acessado em 12 de julho de 2012), 2012.

Moreno, M.; Soares, L. Resilient hypermedia presentations. In: Software Aging and Rejuvenation (WoSAR), 2010 IEEE Second International Workshop on, 2010, p. 1 -6.

Moreno, M. F.; Marinho, R. S.; Gomes Soares, L. F. Ginga-ncl: architecture for plug-ins. In: Proceedings of the 1st Workshop on Developing Tools as Plug-ins(TOPI'11), Waikiki, Honolulu, HI, USA, 2011, p. $12-15$.

Morris, S.; Smith-Chaigneau, A. Interactive TV standards: A guide to MHP, OCAP and javaTV. Princeton, NJ, USA: Focal Press, 2005.

Mottola, L.; Murphy, A. L.; Picco, G. P. Pervasive games in a mote-enabled virtual world using tuple space middleware. In: Proceedings of 5th Workshop on Network and System Support for Games (NetGames'06), Singapore, Malasya: ACM, 2006, p. 161-168.

Muller, G. A reference architecture primer. Relatório Técnico whitepaper, Eindhoven University of Technology, 2008a.

Muller, G. A reference architecture Primer. [On-line], World Wide Web, disponível em http://www . gaudisite.nl/ (Acesso em 24/07/2012), 2008b. 
Nakagawa, E. Uma contribuição ao projeto arquitetural de ambientes de engenharia de software. Tese de doutorado, Instituto de Ciências Matemáticas e de Computação - ICMC/USP, São Carlos, SP, 2006.

Nakagawa, E.; Simão, A.; Ferrari, F. C.; Maldonado, J. Towards a reference architecture for software testing tools. In: Proceedings of 4 th International Conference on Software Engineering and Knowlegde Engineering(SEKE'07), Massachussets, Boston, USA: DBLP, 2007, p. 157-162.

Nakagawa, E. Y.; Barbosa, E. F.; Fioravanti, M. L.; Maldonado, J. C. ProSA-RA: A process for the design, representation, and evaluation of aspect-oriented reference architectures. Journal of Systems and Software, p. 1-40, 2011.

Nakagawa, E. Y.; Barbosa, E. F.; Maldonado, J. C. Exploring ontologies to support the establishment of reference architecture: An example on software testing. In: Proceedings of the 10th IEEE/IFIP Conference on Software Architecture, 6th European Conference on Software Architecture(WICSA/ECSA'9), Helsinki, Finland, 2009a, p. 249-252.

Nakagawa, E. Y.; Maldonado, J. C. Reference architecture knowledge representation: An experience. In: 3rd Workshop on SHAring and Reusing architectural Knowledge (SHARK'2008), 30th International Conference on Software Engineering (ICSE'2008), Leipzig, Germany, 2008, p. 51-54.

Nakagawa, E. Y.; Martins, R.; Felizardo, K.; Maldonado, J. C. Towards a process to design aspect-oriented reference architectures. In: Proceedings of the 35th Latin American Informatics Conference(CLEI'09), Pelotas, Brazil, 2009b, p. 1-10.

National Instruments Reference architecture for mobile robotics. [On-line], World Wide Web, available in http://zone.ni.com/devzone/cda/tut/p/id/10820 (Acessado em 26/04/2012), 2010.

Noergaard, T. Embedded system architecture - a compreensive guide for engineers and programmers. Burlington, USA: Elsevier, 2005.

Ló andrez Nores, M.; Blanco-Fernandez, Y.; Pazos-Arias, J. Architecting multimedia-rich collaborative learning services over interactive digital tv. In: Proceedings of 5th Iberian Conference on Information Systems and Technologies(CISTI'10), Santiago de Compostela, Galiza, 2010, p. 1 -6.

OASIS Reference model for service oriented architecture 1.0. Relatório Técnico, Open Standards for Information Society, 2006.

Okada, Y.; Takano, S. Application framework for data broadcast contents integrated with web services on digital tv. In: Proceedings of the 15th International Conference on Knowledge-Based and Intelligent Information and Engineering Systems, v. 6884, Kaiserslautern, Germany, p. 63-72, 2011.

Oliveira, M.; Cunha, P.; da Silva Santos, M.; Bezerra, J. Implementing home care application in brazilian digital tv. In: Proceedings of the Global Information Infrastructure Symposium(GIIS'09), CRP Henri Tudor, Luxembourg City, Luxembourg, 2009, p. 1 -7.

Oliveira, M. R.; Filho, C. B.; Fer, A. F. itv project: an authoring tool for mhp and ginga-j based on a web environment. In: Proceedings of the 1st international conference on Designing interactive user experiences for TV and video(UXTV'08), Silicon Valley, California, USA, 2008, p. 179-182. 
Oliver, E. A survey of platforms for mobile networks research. SIGMOBILE Mob. Comput. Commun. Rev., v. 12, n. 4, p. 56-63, 2009a.

Oliver, E. A survey of platforms for mobile networks research. SIGMOBILE Mob. Comput. Commun. Rev., v. 12 , n. 4, p. 56-63, 2009b.

Park, J.; Hong, S. Building a customizable embedded operating system with fine-grained joinpoints using the aox programming environment. In: Proceedings of the Symposium on Applied Computing (SAC'09), New York, NY, USA: ACM, 2009, p. 1952-1956.

Pequeno, H. S. L.; Gomes, G. A. M.; Andrade, R. M. C.; de Souza, J. N.; de Castro, M. F. Frameidtv: A framework for developing interactive applications on digital television environments. Journal of Network Computers Applications, v. 33, n. 4, p. 503-511, 2010.

Piccolo, L. S. G.; Baranauskas, M. C. C. Desafios de design para a tv digital interativa. In: Proceedings of the "7th Brazilian symposium on Human factors in computing systems, ACM, 2006, p. 1-10.

Rashid, A.; Moreira, A.; Araújo, J. Modularisation and composition of aspectual requirements. In: Proceedings of the $2^{\text {nd }}$ International Conference on Aspect-oriented Software Development (AOSD'03), Boston, Massachusetts, USA: ACM, 2003, p. 11-20.

Rocha, A. Uma ferramenta baseada em aspectos para apoio ao teste funcional de programas java. Dissertação de mestrado, Instituto de Ciências Matemáticas e de Computação, USP, São Carlos, SP, 2005 .

Salviato, T.; Costa, P.; Filho, J.; Vale, I. Framework for context-aware applications on the brazilian digital tv. In: Proceedings of 4th International Conference on Ubi-Media Computing(U-Media'11), Sao Paulo, Brazil, 2011, p. $112-117$.

dos Santos, J. a. B.; Abrão, I. C.; Barrére, E.; de Ávila, P. M.; Prado, G. M.; dos Santos, M. A platform for difusion interactive multimedia content: an approach focused on IPTV system and broadcasting digital television system. In: Proceedings of the Euro American Conference on Telematics and Information Systems(EATIS'08), Aracaju, SE, Brazil, 2008, p. $1-5$.

Saraiva, D.; Pereira, L.; Batista, T.; Delicato, F.C, .; Pires, P. F. Architecting a model-driven aspect-oriented product line for a digital tv middleware: a refactoring experience. In: Proceedings of the the 4th European Conference on Software Architecture(ECSA'10), Kopenhagen, Dinamark, 2010, p. $166-181$.

SEI Software Engineering Institute, Community Software Architecture Definitions. Online, http: //www.sei.cmu.edu/architecture/start/community.cfm - Acessado em 11/11/2011, 2011.

Silva, E.; Wehrmeister, M.; Becker, L.; Wagner, F.; Pereira, C. Design exploration in HW/SW co-design of real-time object-oriented embedded systems: the scheduler object. In: Proceedings of 10th IEEE International Workshop on Object-Oriented Real-Time Dependable Systems (WORDS'05), Sedona, Arizona, USA: IEEE, 2005, p. 1530-1443.

Soares, L. MAESTRO: the declarative middleware proposal for the sbtvd. In: Proceedings of 4 th European Interactive TV Conference(EUROiTV'06), Leuven, Belgium: ACM, 2006, p. 16-21. 
Soares, L.; Moreno, M.; De Salles Soares Neto, C. Ginga-ncl: Declarative middleware for multimedia iptv services. Communications Magazine, IEEE, v. 48, n. 6, p. $74-81,2010$.

Soares, L. F. G.; Barbosa, S. D. J.; Neto, C. S. Desenvolvimento de aplicações declarativas para tv digital interativa. In: Anais do XII Simpósio Brasileiro de Sistemas Multimídia e Web (Webmedia'06), Natal, RN, Brasil: ACM Press, 2006, p. 43-48.

Stamey, J. Aspect-oriented PHP. [On-line], World Wide Web, disponível em: http://www.aophp.net/ (Acessado em 12 de janeiro de 2011), 2007.

Steffen P., W.; Ballagas, R.; Borchers, J.; Mendonza, J.; Kratz, S.; Christoph, W.; Fuhr, C.; Tann, M.; Shin, D. Y.; Hameed, B.; Bardos, L.; Hovestadt, L. Cell spell-casting: Designing a locative and gesture recognition multiplayer smartphone game for tourists. In: Proc. of the Third International Workshop on Pervasive Gaming Applications at Pervasive 2006 (PERGAMES'06), Dublin, Ireland, 2006, p. 1-8.

Stein, D.; Hanenberg, S.; Unland, R. A UML-based aspect-oriented design notation for AspectJ. In: Proceedings of the 1st International Conference on Aspect-oriented Software Development (AOSD'02), New York, NY, USA: ACM, 2002, p. 106-112.

Sun, L.; Zhang, W.; Yu, S. Storage scheme of system information for digital television receiver. IEEE Transactions on Consumer Electronics, v. 49, n. 1, p. 147-151, 2003.

Suzuki, J.; Yamamoto, Y. Extending uml with aspects: Aspect support in the design phase. In: Proceedings of the Workshop on Object-Oriented Technology(ECOOP'99), London, UK: Springer-Verlag, 1999, p. 299-300.

Tan, J.; Newton, P.; Kelly, D.; Shi, J.; Gan, L. Recording interactive tv. In: Proceedings of the International Conference on Consumer Electronics(ICCE'03), Shangai, China, 2003, p. 22-23.

The AspectJ Team The aspectj programming guide. [On-line], World Wide Web, disponível em: http://eclipse.org/aspectj/ (Acessado em 12 de janeiro de 2011), 2006.

Thomas, B.; Close, B.; Donoghue, J.; Squires, J.; Bondi, P. D.; Piekarski, W. First person indoor/outdoor augmented reality application: Arquake. Personal Ubiquitous Comput., v. 6, n. 1, p. 75-86, 2002.

Trojahn, T.; ANDd Gonçalves, J.; Mattos, J.; Agostini, L.; Da Rosa, L. Evaluating two implementations of the component responsible for decoding video and audio in the brazilian digital tv middleware. Multimedia Tools and Applications, v. 57, p. 373-392, 10.1007/s11042-011-0753-x, 2012.

Union, E. B. Digital video broadcasting (DVB) - Multimedia Home Platform (MHP). Technical Report 101201 V1.0.3, European Broadcasting Union, Munich, Germany, 2003.

Union, E. B. The MHP knowledge project (MHP-KDB). Relatório Técnico, Institut für Rundfunktechnik, Munich, Germany, 2006.

Union, I. T. A guide to digital terrestrial television broadcasting in the VHF and UHF bands. Relatório Técnico, ITU - Digital Terrestrial TV, Geneve, Switzerland, 1996. 
Universidade Vrije em Bruxelas Multimodal and multi-touch interaction. [On-line], World Wide Web, disponível em: http://wise.vub.ac.be/content/multimodal-and-multi-touch-interaction (Acessado em 12 de novembro de 2011), 2012.

Vardaman, E. MCMs: niche market or mainstream product? In: Proceedings of 6th International Conference on Multichip Modules(ICMCM'97), Denver, USA, 1997, p. 11-13.

Viana, N. S.; Maia, O. B.; Lucena, Jr., V. F. Convergence model between the idtv brazilian middleware and home networking software platforms. In: Proceedings of the XV Brazilian Symposium on Multimedia and the Web(WebMedia'09), Fortaleza, CE, Brazil, 2009, p. 7:1-7:8.

Vrba, V.; Cvrk, L.; Sykora, M. Framework for digital tv applications. In: Proceedings of the International Conference on Networking, International Conference on Systems and International Conference on Mobile Communications and Learning Technologies(ICNICONSMCL'06), Washington, DC, USA, 2006, p. 184-. $^{-}$

Wagelaar, D. Towards a context-driven development framework for ambient intelligence. In: Proceedings of the $4^{\text {th }}$ International Workshop on Distributed Auto-adaptive and Reconfigurable Systems(ICDCS'04), Tokyo, Japan, 2004, p. 12-18.

Wang, S. C.; Chih, C. T.; Yan, K. Q. A smart mvc-itv framework for interactive tv. In: Proceedings of the 2009 International Joint Conference on Computational Sciences and Optimization(CSO'09), Washington, DC, USA, 2009, p. 82-84.

Wasserman, A. I. Toward a discipline of software engineering. IEEE Softw., v. 13, n. 6, p. 23-31, 1996.

Wehrmeister, M.; Freitas, E.; Orfanus, D.; Pereira, C.; Rammig, F. Evaluating aspect and object-oriented concepts to model distributed embedded real-time systems using rt-uml. In: Proceedings of 17th IFAC World Congress,(IFAC'08), Seoul, Korea, 2008, p. 44-54.

Wehrmeister, M.; Freitas, E.; Pereira, C.; Wagner, F. An aspect-oriented approach for dealing with non-functional requirements in a model-driven development of distributed embedded real-time systems. In: Proceedings of 11th International Conference on International Embedded and Real-Time Computing Systems and Applications(ISORC'07), Washington, DC, USA: IEEE, 2007, p. 428-432.

Yennun, Y.; Kintala, C. Software implemented fault tolerance: Technologies and experience. In: Proceedings of 23rd International Symposium on Fault Tolerant Computing(FTCS'93), Toulouse, France, 1993, p. 2-9.

Zhang, L.; Liu, R. A generic architecture for on-chip packet-switched interconnections. In: Proceedings of 11th International Conference on Embedded and Real-Time Computing Systems and Applications(RTCSA'05), Campinas, SP, Brazil, 2005, p. 373-376. 